OPEN ACCESS

Edited by:

Luigia Cristino,

Istituto di Chimica Biomolecolare

(CNR), Italy

Reviewed by:

Heather Bradshaw,

Indiana University Bloomington,

United States

Brady Atwood,

Indiana University, United States

*Correspondence:

Erik B. Oleson

erik.oleson@ucdenver.edu

†These authors have contributed equally to this work

Received: 29 January 2021 Accepted: 05 May 2021

Published: 10 June 2021

Citation:

Oleson EB, Hamilton LR and Gomez DM (2021) Cannabinoid Modulation of Dopamine Release

During Motivation, Periodic Reinforcement, Exploratory Behavior,

Habit Formation, and Attention.

Front. Synaptic Neurosci. 13:660218. doi: 10.3389/fnsyn.2021.660218

\section{Cannabinoid Modulation of Dopamine Release During Motivation, Periodic Reinforcement, Exploratory Behavior, Habit Formation, and Attention}

\author{
Erik B. Oleson ${ }^{1 *}$, Lindsey R. Hamilton ${ }^{1}$ and Devan M. Gomez ${ }^{2 \dagger}$
}

'Department of Psychology, University of Colorado Denver, Denver, CO, United States, ${ }^{2}$ Department of Biomedical

Sciences, Marquette University, Milwaukee, WI, United States

Motivational and attentional processes energize action sequences to facilitate evolutionary competition and promote behavioral fitness. Decades of neuropharmacology, electrophysiology and electrochemistry research indicate that the mesocorticolimbic DA pathway modulates both motivation and attention. More recently, it was realized that mesocorticolimbic DA function is tightly regulated by the brain's endocannabinoid system and greatly influenced by exogenous cannabinoidswhich have been harnessed by humanity for medicinal, ritualistic, and recreational uses for 12,000 years. Exogenous cannabinoids, like the primary psychoactive component of cannabis, delta-9-tetrahydrocannabinol, produce their effects by acting at binding sites for naturally occurring endocannabinoids. The brain's endocannabinoid system consists of two G-protein coupled receptors, endogenous lipid ligands for these receptor targets, and several synthetic and metabolic enzymes involved in their production and degradation. Emerging evidence indicates that the endocannabinoid 2-arachidonoylglycerol is necessary to observe concurrent increases in DA release and motivated behavior. And the historical pharmacology literature indicates a role for cannabinoid signaling in both motivational and attentional processes. While both types of behaviors have been scrutinized under manipulation by either DA or cannabinoid agents, there is considerably less insight into prospective interactions between these two important signaling systems. This review attempts to summate the relevance of cannabinoid modulation of DA release during operant tasks designed to investigate either motivational or attentional control of behavior. We first describe how cannabinoids influence DA release and goal-directed action under a variety of reinforcement contingencies. Then we consider the role that endocannabinoids might play in switching an animal's motivation from a goal-directed action to the search for an alternative outcome, in addition to the formation of long-term habits. Finally, dissociable features of attentional behavior using both the 5-choice serial reaction time task and the attentional set-shifting task are discussed along with their distinct influences by DA and cannabinoids. We end with discussing potential targets for further research regarding DA-cannabinoid interactions within key substrates involved in motivation and attention.

Keywords: cannabinoids, dopamine, motivation, reinforcement, attention, habit, timing, adjunctive 


\section{INTRODUCTION}

\section{Statement of Purpose}

Because many reviews already exist that describe endocannabinoid $(\mathrm{eCB})$ signaling (Toczek and Malinowska, 2018; Zou and Kumar, 2018; Cristino et al., 2020; Kaczocha and Haj-Dahmane, 2021), the risks of cannabis abuse (Ferland and Hurd, 2020; Hindley et al., 2020), and the potential cannabinoids may offer in psychiatric medicine (Amar, 2006; Black et al., 2019; Navarrete et al., 2020), our goal in the present manuscript is to describe how exogenous cannabinoids and eCBs influence dopamine (DA) signaling and behavior. While we will emphasize our own observations, we will also consider how they fit into the context of the general literature on reinforcement, appetitive behavior, adjunctive behavior, habit formation, and attentional processes. We conclude by considering how cannabinoidinduced changes in one neurobehavior might influence another if they share overlapping neural circuitry.

\section{Phytocannabinoids, Synthetic Cannabinoids, Endocannabinoids}

Approximately 535 chemicals and 90 different $\mathrm{C}_{21}$ terpenophenolic phytocannabinoids exist in the cannabis plant (Radwan et al., 2009; Andre et al., 2016). While these chemicals act synergistically to produce an entourage effect with delta-9-tetrahydrocannabinol (THC), the latter is principally responsible for cannabis's psychoactive effects by activating G protein-coupled receptors (GPCR) in the brain (e.g., cannabinoid receptor type 1; CB1) (Casajuana Kögel et al., 2018; Russo, 2019). The first synthetic cannabinoids (e.g., CP-55,940) were developed by Pfizer and found to be more potent and effective at activating the CB1 than THC (Matsuda et al., 1990; Marzo and Petrocellis, 2006). The Sterling research group then discovered that uniquely structured aminoalkylindole agonists also activate the CB1 with high potency and efficacy (D'Ambra et al., 1992). The aminoalkylindole synthetic cannabinoid WIN 55,212-2 (WIN) is particularly noteworthy because it has been employed extensively in psychopharmacology research (D'Ambra et al., 1992) -including several studies that will be described herein. However, it should be noted that WIN is about $80 \%$ more effective at activating the $\mathrm{CB} 1$ than the phytocannabinoid THC (Sim et al., 1996). The discovery of a brain cannabinoid receptor led to an exploration for its endogenous ligands, or eCBs (Marzo and Petrocellis, 2006). The best characterized eCBs are 2-arachidonoylglycerol (2AG) (Mechoulam et al., 1995; Sugiura et al., 1995) and $\mathrm{N}$-arachidonoylethanolamine (anandamide; AEA) (Devane et al., 1992). It is now recognized that $2 \mathrm{AG}$ and AEA have different synthetic and metabolic pathways ( $\mathrm{Lu}$ and Mackie, 2016). 2AG is predominantly synthesized from 2-arachidonoyl-containing phospholipids (e.g., diacylglycerol; DAG) by DAG lipase (DAGL) and metabolized by monoacylglycerol lipase (MAGL); AEA is predominantly synthesized from $N$-acyl-phosphatidylethanolamine (NAPE) by NAPE-specific phospholipase D (NAPE-PLD) and metabolized by fatty acid amidohydrolase (FAAH) (Lu and Mackie, 2016;
Toczek and Malinowska, 2018; Zou and Kumar, 2018). In this review, we will describe several studies that manipulate $2 \mathrm{AG}$ levels by inhibiting either DAGL or MAGL. We attempt to specify when we are describing the specific effects of phytocannabinoids, synthetic cannabinoids, or eCBs on neurobiology and behavior. When making broader conclusions we use the term cannabinoid, which we define as any ligand that interacts with the cannabinoid receptors or their associated machinery.

\section{Cannabinoid Receptors}

In addition to the aforementioned $\mathrm{CB} 1$ it is necessary to acknowledge several other cannabinoid receptor targets, most notably the cannabinoid receptor type 2 (CB2). While once thought to be relegated to the immune system and spleen, recent evidence suggest that $\mathrm{CB} 2$ is expressed in both neurons and glial cells of the brain as a unique isoform (Jordan and $\mathrm{Xi}, 2019)$. Specifically, mRNA for the $\mathrm{CB}_{2 A}$ variant was found to be expressed in the brain and the testis, whereas mRNA for the $\mathrm{CB}_{2 B}$ variant was found in the spleen and immune cells (Liu et al., 2009). The exact role that the $\mathrm{CB}_{2 A}$ variant plays in modulating operant behavior remains to be fully elucidated, but it appears to be involved in multiple cellular and behavioral functions (Jordan and $\mathrm{Xi}, 2019$ ). There is also evidence that AEA activates TRPV1 ion channels (van der Stelt et al., 2005), which have been shown to modulate habitual behavior (Shan et al., 2015). But also see (Gianessi et al., 2019), who recently reported that antagonism of TRPV1 does not influence habit formation. The GPR55 orphan receptor, which is thought to be activated by both eCBs and synthetic cannabinoids (Marichal-Cancino et al., 2017), was also reported to influence learning in a T-maze (Marichal-Cancino et al., 2016). Peroxisome proliferator-activated receptors (PPAR) are yet another target worth considering. PPARs are activated by various lipids, including eCBs (Iannotti and Vitale, 2021), and are thought to influence DA release (Melis et al., 2013a). In all, at least 12 different receptors are known to be activated by eCBs (Maccarrone, 2020), suggesting that the scope of mechanisms through which phytocannabinoids, synthetic cannabinoids, and eCBs regulate behavior are considerably more complex than our current conception.

\section{eCBs, DSI, and a Model of DA Release}

A unique feature of eCB signaling is that these molecules are not stored in vesicles like classical neurotransmitters but are instead synthesized de novo and released from postsynaptic neurons in times of sustained neuronal activity (Freund et al., 2003; Castillo et al., 2012; Ohno-Shosaku and Kano, 2014). Heightened neural activity results in increased intracellular $\mathrm{Ca}^{2+}$ that leads to the activation of synthetic enzymes (DAGL, NAPE-PLD) responsible for the rapid synthesis of eCBs (Marsicano et al., 2003; Lu and Mackie, 2016). Following their release from the postsynaptic neuron into the synaptic cleft, eCBs retrogradely activate CB1s located on presynaptic terminals of both GABA and glutamate neurons (Wilson and Nicoll, 2002; Melis et al., 2004; Alger and Kim, 2011). Retrograde eCB modulation of GABA terminals can produce depolarization-induced suppression of inhibition (DSI), 
whereas retrograde eCB modulation of glutamate terminals can produce depolarization-induced suppression of excitation (DSE) (Fortin and Levine, 2007; Lange et al., 2017). In DSI, eCB activation of $\mathrm{CB} 1 \mathrm{~s}$ on GABA terminals is thought to produce a transient suppression of GABA release onto the postsynaptic neuron, thereby disinhibiting it. By contrast, during DSE, eCB activation of CB1s on glutamate terminals is thought to produce a transient suppression of glutamate release onto the postsynaptic neuron, thereby inhibiting it. While CB1 activation mediates both DSI and DSE, DSI is believed to be much more prominent than DSE due to differences in CB1 sensitivity between inhibitory and excitatory synapses (Ohno-Shosaku et al., 2002).

Cannabinoid receptor type 1-mediated DSI provides a model that might explain how phytocannabinoids, synthetic cannabinoids, and eCBs increase DA release from the midbrain. For a thorough description of how DSI is thought to modulate DA release, we refer the reader to a previously published review clarifying the mechanisms involved (Covey et al., 2017). In the midbrain, CB1s are thought to occur on GABAergic and glutamatergic terminals rather than on DA neurons (Julian et al., 2003; Mátyás et al., 2008). In the awake and behaving animal, midbrain DA neurons fire in one of two distinct patterns: tonic and phasic (Grace and Bunney, 1984; Grace, 1991; Grace et al., 2007). At rest, DA neurons are tonically active and exhibit steady pacemaker activity, firing at an average rate of $5 \mathrm{~Hz}$. By contrast, DA neurons fire in phasic bursts of 10$20 \mathrm{~Hz}$ when an animal is presented with a motivationally salient stimulus (Grace et al., 2007). These phasic bursts are thought to give rise to high-concentration transient DA release events in the NAc that encode the value of motivationally salient stimuli and actuate goal seeking (Wise, 2004; Grace et al., 2007; Schultz et al., 2015; Stauffer et al., 2016). Burst firing of DA neurons also leads to eCB synthesis, retrograde signaling, and activation of $\mathrm{CB} 1 \mathrm{~s}$ on GABA and glutamate terminals (Szabo et al., 2002; Riegel and Lupica, 2004; Melis et al., 2013b; Wang et al., 2015). If DSI is more prevalent than DSE in the midbrain, the result would be disinhibition of DA neurons and the subsequent release of DA at terminal sites of the mesocorticolimbic and nigrostriatal DA pathways. In support of this model, a growing body of evidence using a multitude of techniques report that eCBs (Solinas et al., 2006; Oleson et al., 2012), THC (Chen et al., 1990, 1993; Diana et al., 1998; Gessa et al., 1998; Voruganti et al., 2001; Pistis et al., 2002; Bossong et al., 2009), and synthetic cannabinoids (Tanda et al., 1997; Diana et al., 1998; Gessa et al., 1998; Fadda et al., 2006; Oleson et al., 2014) increase striatal brain DA levels in both rodents (Gessa et al., 1998; Pistis et al., 2002; Fadda et al., 2006) and humans (Voruganti et al., 2001; Bossong et al., 2009, 2015). Using in vitro electrophysiology, Melis et al. (2013b) demonstrated that this DSI-induced disinhibition of DA release is principally mediated by $2 \mathrm{AG}$ activating CB1s. Indeed, several studies will be presented herein demonstrating that the eCB 2AG effectively modulates DA-associated behavior in a $\mathrm{CB} 1$ dependent manner. However, while this model may explain the effects of synthetic cannabinoids and eCBs on DA release presented within this review, we acknowledge that it is incomplete because it does not account for the role of CB2 or other receptor targets (e.g., PPARs) that likely modulate DA release as well.

\section{eCB Modulation of the Mesocorticolimbic System}

The mesocorticolimbic DA system originates from DA neurons in the ventral tegmental area (VTA) that project to a variety of brain regions. Its most prominent target is the ventral portion of the striatum, or nucleus accumbens (NAc) (Morales and Margolis, 2017). While the VTA is primarily composed of DA neurons $(\sim 60 \%)$, GABA $(\sim 25 \%)$ and glutamate $(\sim 15 \%)$ neurons also exist and are capable of modulating DA neural activity, mesocorticolimbic output, and behavior (Swanson, 1982; Morales and Root, 2014; Yoo et al., 2016). It is theorized that these neurons form subpopulations that then receive disproportionate afferent input from distinct brain structures (e.g., periaqueductal gray, lateral hypothalamus, raphe nuclei, rostromedial tegmental nucleus) to form dissociable microcircuits that may subserve unique behavioral functions (Lammel et al., 2014; Breton et al., 2019). Thus, in addition to disinhibiting DA release in the VTA, it is likely that eCBs also modulate DA-associated behavior by acting on distinct afferents that then synapse onto DA neurons. It is also worth considering eCB modulation of neural activity at terminal fields of the mesocorticolimbic system. Like other monoamines, DA functions as a relatively slow neuromodulator of fast glutamateand GABA-mediated neurotransmission and, in the awake and behaving rat, the effect that DA exerts on postsynaptic potentials is greatly influenced by these converging inputs into a given terminal field (O’Donnell et al., 1999; Brady and O'Donnell, 2004). As a prominent mesocorticolimbic hub, the effect DA exerts in the NAc can therefore be influenced by eCB modulation of amygdalar, hippocampal, and cortical input into it. The neuromodulatory effects of DA in the NAc can also be influenced by co-release of GABA and glutamate from VTA DA neurons. Emerging evidence suggests that VTA DA neurons are capable of co-releasing GABA and glutamate in a manner that regulates motivational drive along with DA (Tritsch et al., 2012; Zhang et al., 2015; Yoo et al., 2016).

Dopamine signaling in the NAc is primarily mediated through D1- and D2-like receptors. D1 receptors generally exhibit low binding affinity for DA and preferentially couple to $G_{s}$ protein subunits. D2 receptors generally exhibit high binding affinity for DA and preferential coupling to $G_{i}$ or $\mathrm{G}_{o}$ protein subunits (Beaulieu and Gainetdinov, 2011). Both D1 and D2 DA receptors are expressed as heteroreceptors on dendritic spines of medium spiny GABA neurons (MSNs) within the NAc (Levey et al., 1993; Monory et al., 2007), though D2s are also expressed on presynaptic DA terminals where they function as autoreceptors to attenuate DA release (Bello et al., 2011; Budygin et al., 2017). Notably, CB1s form heterodimeric complex with D2s where colocalization exists, suggesting CB1 may interact with D2 autoreceptors to modulate DA release (Khan and Lee, 2014). It is also 
noteworthy that CB1s are expressed in a subpopulation of fast-spiking interneurons (FSI) within the NAc (Winters et al., 2012). Despite only composing 2-3\% of striatal neurons, FSI are thought to powerfully orchestrate the activity of the more predominate MSNs and, possibly, control gamma frequency oscillations originating from this region (Tepper et al., 2010). Individual FSIs innervate hundreds of MSNs and, when excited, inhibit their collective output (Tepper et al., 2008). Within the NAc, eCBs are synthesized and released from MSNs following activation of either D1 (Shonesy et al., 2020) or D2 (Lerner and Kreitzer, 2012) receptors. Also noteworthy is recent evidence suggesting that tyrosine receptor kinase $\mathrm{B}$ activation augments intracellular calcium transients to promote eCB synthesis and spike-timing dependent plasticity in the striatum (Gangarossa et al., 2020). Upon release from MSNs, the eCBs then travel retrogradely before acting upon $\mathrm{CB} 1$ s located on FSIs within the NAc (Mateo et al., 2017; Wright et al., 2017). Wright et al. (2017) recently used electrophysiology to demonstrate that the inhibitory control that CB1-expressing FSIs exert over MSNs is suppressed by eCB signaling. In addition, these authors (Wright et al., 2017) found that the CB1 expressing FSIs that synapse onto MSNs facilitate a long-term form of eCB-mediated synaptic plasticity (i.e., long-term depression, LTD) that might be important for learning and memory. While previous immunohistochemical studies suggested CB1s are also expressed on cholinergic interneurons within the striatum (Fusco et al., 2004), a more recent study using $\mathrm{CB} 1$ radioactive antisense riboprobes found no evidence of CB1 mRNA expression within cholinergic interneurons of the NAc (Mateo et al., 2017). This latter finding is particularly relevant for the current review because we primarily focus on transient DA release events in the NAc. And, it is now recognized that these transient release events can be promoted by either local cholinergic interneurons that activate acetylcholine receptors on adjacent DA terminals (Cachope et al., 2012) or by VTA DA cell activation, both of which are modulated by eCB signaling (Mateo et al., 2017). However, the lack of $\mathrm{CB} 1 \mathrm{~s}$ on cholinergic interneurons in the NAc suggests that eCBs modulate the influence local cholinergic interneurons exert over terminal dopamine release indirectly. In support of this notion, Mateo et al. (2017) recently reported that eCB modulation of cholinergic-induced terminal dopamine release results from $\mathrm{CB} 1$ activation on cortical glutamate afferents into the NAc. In addition to the aforementioned findings by (Wright et al., 2017), this latter observation is highly relevant for eCB- and DA-modulation of learning and memory. D2-dependent eCB-LTD has been verified in glutamatergic corticostriatal projections within the indirect pathway of the basal ganglia-a group of subcortical nuclei including the striatum that modulate behavioral action, procedural learning, and working memory (Lerner and Kreitzer, 2012; Simonyan, 2019). Thus, eCBs likely influence skill learning and memory by indirectly modulating terminal DA release and by gating FSI-control of MSN feedforward inhibition. These separate mechanisms-comprising eCB-mediated DSI/DSE within the VTA, eCB modulation of neural signaling with the NAc, and eCB modulation of afferent input into the NAc and VTA-may all converge to influence mesolimbic DA neurotransmission (Covey et al., 2017).

\section{A Synthetic Cannabinoid Dose-Dependently Increases DA Release and Tolerance Develops to This Effect Following Chronic Exposure}

Abused drugs are theorized to exert their reinforcing effects by mimicking these endogenous patterns of DA release in the NAc that normally strengthen goal-directed behavior (Volkow and Morales, 2015; Volkow et al., 2017), and cannabinoids are no exception. We recently confirmed that the synthetic cannabinoid WIN increases accumbal transient DA release events in a dosedependent manner and further investigated whether tolerance develops to this effect. We used fast-scan cyclic voltammetry (FSCV) to measure sub-second DA transients using NAcimplanted electrodes while treating awake and behaving rats with increasing, cumulative doses of intravenous (IV) WIN. As illustrated in Figures 1A-C, WIN dose-dependently increased both the frequency and amplitude of transient DA release events in the NAc shell (Gomez et al., 2020). We next wanted to assess whether chronic WIN exposure produces tolerance to the DA releasing effects of WIN. Although chronic treatment with synthetic or phytocannabinoids is known to produce tolerance to a tetrad of behavioral/physiological effects that is used to screen whether a drug functions as a cannabinoid (i.e., antinociception, catalepsy, hyopthermia, and hypomotility) (Little et al., 1988; Wiley and Martin, 2003; Hama and Sagen, 2009; Nealon et al., 2019) - it remains unclear whether tolerance develops to the rewarding/reinforcing and the DA releasing effects of cannabinoids. Because the degree of tolerance that develops to specific cannabimimetic effects varies as a result of CB1 desensitization occurring in a brain region-dependent manner (Breivogel et al., 1997; Whitlow et al., 2003), it is possible that midbrain CB1s show resistance to tolerance. Supporting this notion, Frau et al. (2019) found that prenatal exposure to THC produces a hyperDAergic rather than a hypoDAergic phenotype, Mavrikaki et al. (2010) found that chronic WIN exposure does not alter brain-reward thresholds, Hirvonen et al. (2012) found that $\mathrm{CB} 1 \mathrm{~s}$ are downregulated in cortical but not subcortical regions of cannabis smokers, and Wu and French (2000) found that chronic THC treatment does not influence its ability to induce burst firing in putative DA neurons.

To test whether tolerance develops to the DA-releasing effects of WIN, we treated rats with either vehicle or intravenous (IV) WIN using an escalating dosing regimen. To determine if this dosing regimen produced tolerance to standard cannabimimetic effects, we first tested the consequences of it using the tetrad test. As expected, we found that WIN-treated rats displayed a rightward shift in the dose-response relationship (0.002$0.8 \mathrm{mg} / \mathrm{kg} \mathrm{IV}$ ) across all behavioral/physiological measures when compared to vehicle-treated controls. We then used FSCV to investigate whether the same pharmacological history produced tolerance to the DA releasing effects of WIN and cross-tolerance to the DA releasing effects of heroin. We additionally characterized whether this dosing regimen produces 
A

A $15 \mathrm{~min}$ recording after VEH (IV) infusion

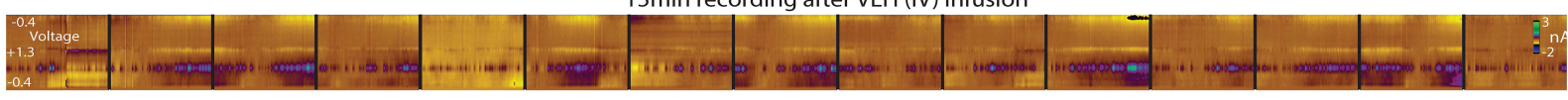

I50nM

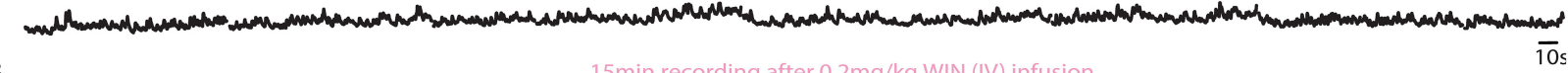

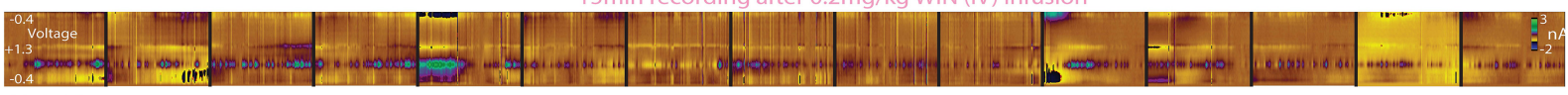

I50nM

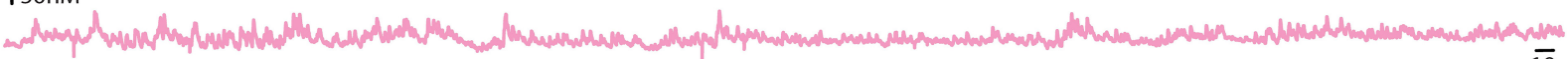

C

$15 \mathrm{~min}$ recording after $0.8 \mathrm{mg} / \mathrm{kg}$ WIN (IV, cumulative) infusion

$\overline{10 s}$

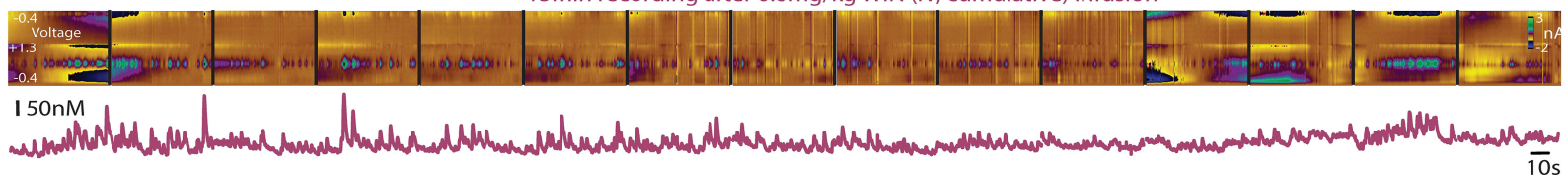

D

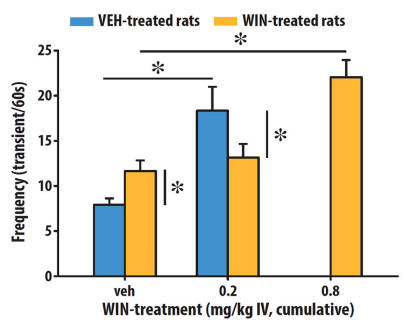

E

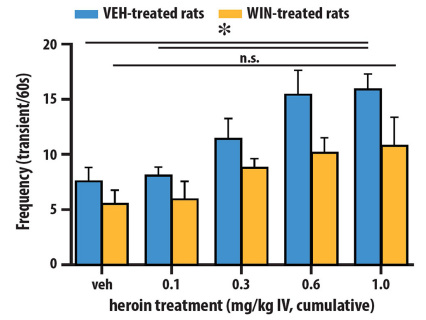

$\mathbf{F}$

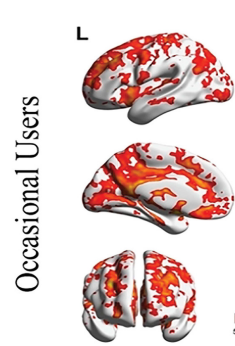

Placebo
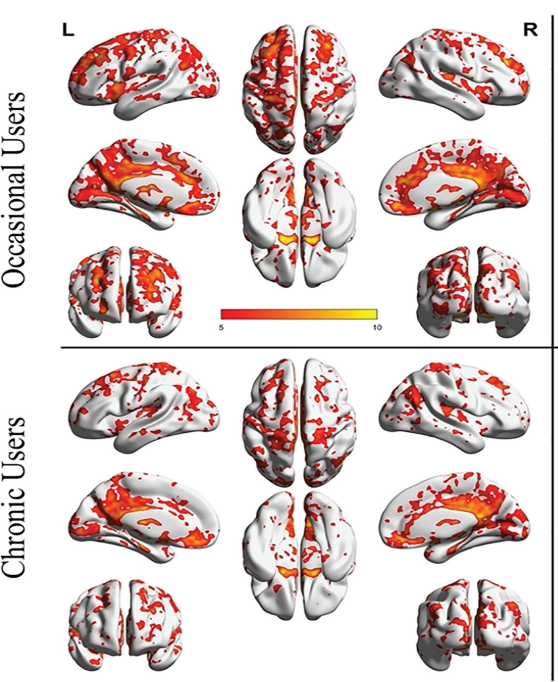

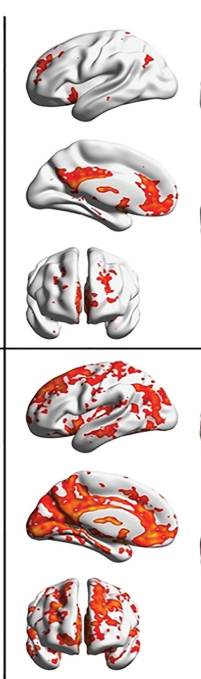

THC
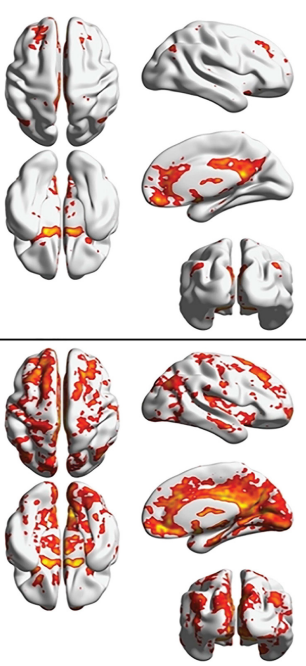

FIGURE 1 | Cannabinoids increase the frequency and amplitude of DA transients. Illustrative recording session in which the synthetic cannabinoid WIN was administered to an awake and freely moving rat. Stitched color plots [voltammetric current ( $z$-axis) $\times$ applied scan potential $(y$-axis $) \times$ time $(x$-axis)] are shown above corresponding DA concentration traces. Vehicle (A), $0.2 \mathrm{mg} / \mathrm{kg}$ (B), and $0.8 \mathrm{mg} / \mathrm{kg}$ WIN (C) were administered in cumulative, ascending IV doses while FSCV measurements of DA release events occurred in the NAc shell in near real-time. Dose dependent increases in the frequency and amplitude of DA release events can be observed by the larger and more frequent green dots at a potential of $+0.6 \mathrm{~V}$ in the color plots and the more frequent and pronounced transient peaks in the corresponding DA concentration traces. (D) WIN increased the frequency of DA release events but was less potent in chronically WIN-treated rats. A higher dose of WIN (0.8 vs. $0.2 \mathrm{mg} / \mathrm{kg} \mathrm{IV}$ ) was required to produce a significant increase in DA release vs. vehicle treated rats. (E) Heroin dose-dependently increased the frequency of DA release events but was less effective in chronically WIN-treated rats. In WIN-treated rats, heroin did not significantly increase the frequency of DA transients vs. vehicle at any dose tested. Republished from Gomez et al. (2020). (F) NAc-related functional connectivity in the left hemispheres. Shown are thresholded Z-score maps of functional connectivity for each group and each condition. Smoked THC reduced functional connectivity between the NAc and broad areas of the frontal, temporal, parietal and occipital lobes in occasional, but not chronic cannabis users. Republished from Gomez et al. (2020). * $p<0.05$.

cross-tolerance to the DA releasing effects of heroin because Cadoni et al. (2008) observed this effect using microdialysis. In addition, synthetic cannabinoids/phytocannabinoids and opioids are well known to produce cross-tolerance to several shared neurobehavioral effects (Hine, 1985; Thorat and Bhargava, 1994; Manzanares et al., 1999; Vigano et al., 2005; Gerak et al., 2015). We found that after chronic WIN exposure, both WIN (Figure 1D) and heroin (Figure 1E) were less effective at increasing the frequency of DA release events in the NAc shell of adult male rats. If DA is important for drug reward
(Di Chiara et al., 2004) or to motivate drug seeking (Volkow et al., 2017) as is currently theorized, a diminished ability to evoke DA release could promote the use of larger quantities and more potent doses. These data support a recent PET imaging study demonstrating that cannabis-dependent patients show a deficit in striatal DA release after the investigators controlled for several comorbidities that may have influenced previous imaging studies (van de Giessen et al., 2017). In another noteworthy imaging study, Mason et al. (2021) used resting-state functional magnetic resonance imaging (fMRI) to determine functional connectivity 
between the NAc and other brain regions of interest in occasional and chronic cannabis users. Both groups received placebo and $300-\mu \mathrm{g} / \mathrm{kg}$ THC on separate days. In occasional users, THC produced a marked reduction in functional connectivity between the NAc and broad areas of the frontal, temporal, parietal and occipital lobes (Figure 1F) - a pattern the authors note is typical of increased DA neurotransmission. In chronic users, THC did not produce changes in functional connectivity associated with the NAc (Figure 1F). The occasional, but not chronic cannabis users, also reported increases in subjective high and showed impairments in a sustained attention task. From these observations, the authors conclude that excessive cannabis use may result in neuroadaptations in accumbal circuitry that reduce the neurobiological and behavioral response to acute cannabis impairment.

However, further studies are necessary to compare how synthetic cannabinoids, eCBs, and phytocannabinoids produce tolerance, whether each produces tolerance to the DA releasing effects of a CB1 agonist, and whether these effects vary with age, sex, or species. It is possible that a synthetic aminoalkylindole cannabinoid like WIN produce distinct effects on molecular, cellular, and/or behavioral tolerance in comparison to a phytocannabinoid like THC. Two complimentary molecular mechanism are thought to contribute to CB1 desensitization and downregulation (Nguyen et al., 2012; Nealon et al., 2019). One involves the recruitment of beta-arrestin 2 to GRKphosphorylated CB1s (Jin et al., 1999; Nguyen et al., 2012). The other is a distinct JNK-mediated form of molecular tolerance that appears to occur in an agonist specific manner (Nealon et al., 2019). Of note, it was recently reported that disrupting JNK signaling prevents several forms of behavioral tolerance induced by THC, but not by WIN (Henderson-Redmond et al., 2020). Thus, future studies are needed to determine how different cannabinoid ligands produce tolerance to distinct behavioral/physiological effects.

\section{CANNABINOIDS AND MOTIVATED ACTION UNDER A VARIETY OF REINFORCEMENT CONTINGENCIES}

\section{Response Reinforcement and Schedule-Controlled Behavior}

While many different behavioral approaches exist to study the effects of cannabinoids on behavior, this review will primarily focus on response reinforcement and operant behavior. Response reinforcement was first described by Thorndike (1927) as a law of effect-meaning that responses following a satisfying connection act upon it to alter its strength. Concepts associated with the law of effect were further explored in great detail following Skinner's inventions of the operant conditioning chamber and the cumulative recorder (Ferster and Skinner, 1957). The operant conditioning chamber allows experimenters to measure repeatable responses in the face of changing conditions. The cumulative recorder produced a graphical record of the animal's responses, allowing experimenters to study how changing conditions influence the probability of a response. Using this new technology, Ferster and Skinner (1957) reported that the pattern of responses can be greatly influenced by the reinforcement schedule. In the operant context, schedules can be thought of as the rules under which reinforcement is made available, or the contingencies of reinforcement. The observation that reinforcement schedules powerfully modify operant behavior had profound implications for our understanding of the phylogeny of behavior and neurobiology. In an evolutionary context, it is likely that patterns of behaviors were neurobiologically stampedin when they maximized the receipt of an advantageous outcome (e.g., food) in the face of changing environmental conditions (e.g., the periodic availability of food). Because the environment changes in recurring patterns, it would therefore be advantageous for the brain to produce complex patterns of behavior that adapt to the environmental rules governing reinforcement (Skinner, 1966). In the context of cannabinoid effects on the brain and behavior, it is equally important to recognize that a drug or neurochemical can produce unique effects on operant behavior under different schedules of reinforcement. This phenomenon was first described by Peter Dews, who used an operant conditioning chamber and cumulative recorder to demonstrate that injecting pigeons with the same dose of pentobarbital increased responding for food under a fixed-ratio scheduled but decreased responding for food under a fixed-interval schedule (Dews, 1955). Under a fixed ratio (FR) schedule, behavior is reinforced after the animal responds a pre-defined number of times. This contingency of reinforcement produces a bimodal step-like pattern in which the animal is either responding at a constant rate or at zero (Ferster and Skinner, 1957) (Figure 2A). Under a fixed interval (FI) schedule, behavior is reinforced after the animal responds after a pre-defined period of time. This contingency of reinforcement produces a scalloped-like pattern of responding (Dews, 1978) (Figure 2A). Because this review will focus on the interaction between cannabinoids and DA signaling in particular, it is also worth noting that DA pharmacology is well known to produce divergent behavioral effects under these two schedules of reinforcement. Equivalent doses of the DA releasers amphetamine and methamphetamine (Cho, 1990; Jones et al., 1998) both decrease response rate under an FR1 schedule and increase response rate under a FI schedule (Dews, 1958; McKearney and Barrett, 1978).

\section{DA Value Signals in Reinforcement and Goal-Directed Action}

In the awake and behaving animal, midbrain DA neurons fire in phasic bursts $(>20 \mathrm{~Hz})$ under a variety of conditions (Redgrave et al., 2016; Sharpe and Schoenbaum, 2018), including the presentation of rewarding stimuli (Stauffer et al., 2016). These phasic bursts of neural activity contribute to transient DA release events in the primary terminal field of the mesolimbic pathway, the nucleus accumbens (Dreyer et al., 2010). Currently, it is thought that transient DA signals within this brain region encode value as positive or negative reward prediction errors. In support of this theory, a series of in vivo electrophysiology studies demonstrated that phasic bursts of DA neural activity 
A

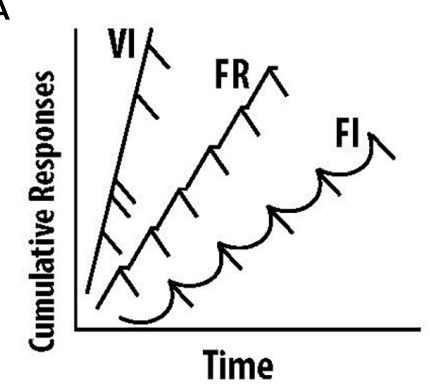

B

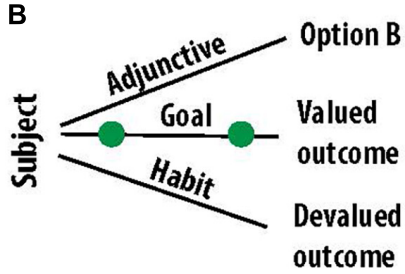

\section{Reinforcement schedules and behavioral output}

Vl: The variable-interval schedule produces high rates of behavioral output for reinforcement occuring at uncertain intervals and is known to promote habit formation.

FR: The fixed-ratio schedule produces consistent behavioral output preceding reinforcement and a consistent pause proceeding reinforcement.

Fl:The fixed-interval schedule results in behavioral output increasing over a consistent, recurring period of reinforcement availablility.

Adjunctive: Reinforcement irrelevant behavior that occurs most frequently in the first half of periodically-reinforced trial; thought to be exploratory in nature.

Goal-directed: Behavior that is motivated by the value of a desired outcome and its conditioned predictors (e.g., green circles preceding a valued food reward).

Habit: Behavior that persists despite the outcome that once reinforced it being devalued or removed.

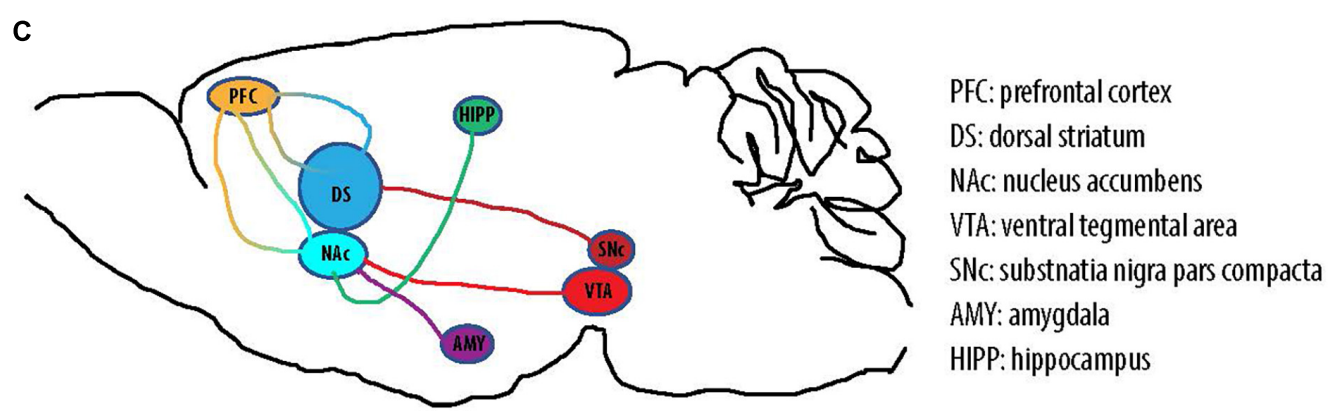

FIGURE 2 | Reinforcement schedules engender distinct behaviors and a depiction of two DA pathways. (A) The VI, FR, and FI schedules produce unique patterns of reinforced behavior. (B) The contingencies of reinforcement can produce adjunctive, goal-directed, or habitual behavior. (C) Illustrative projections associated with the nigrostriatal (dark red) and mesocorticolimbic (light red) DA pathways. DA in the NAc is thought to modulate converging input from brain regions including the amygdala (AMY), hippocampus (HIPP), and prefrontal cortex (PFC). Cortico-striatal loops are depicted in multicolor (orange-blue).

respond to gambles that guide economic decision making and integrate various factors that underlie value representations to influence choice (Lak et al., 2014, 2016; Stauffer et al., 2014, 2016). We recently tested the notion that transient DA value signals represent value and influence valuation during both positive and negative reinforcement (Figure 3) (Schelp et al., 2017; Pultorak et al., 2018; Oleson and Roberts, 2019). Positive reinforcement refers to an increase in behavior to receive an outcome (e.g., appetitive sugar pellet); negative reinforcement refers to an increase in behavior to avoid an outcome (e.g., electrical footshock). Using FSCV, we first demonstrated that the concentration of transient DA release events evoked by an appetitive sugar pellet or its conditioned predictor decreased with the price required to obtain it (Figure 3A) (Schelp et al., 2017). DA release events and behavioral output were measured as rats responded in a within-session behavioral economicsbased operant task. In this task, the unit-price (responses/mg sugar) to obtain reinforcement increased in fixed epochs over the course of each session. As illustrated by the representative cumulative response records in Figure 3B, under these response contingencies lever pressing increases across the fixed epochs (as price increases) until a maximal price is reached at which the animal is no longer willing to pay the required opportunity cost to obtain reinforcement. We then used optogenetics to augment DA release and found that increasing DA release at the reward predictive stimulus rendered animals more sensitive to price and decreased DA concentration at reward delivery, consistent with a negative reward prediction error (Schelp et al., 2017). Optogenetics is a neuroscientific technique that allows the experimenter to transiently turn on/off a neural population of interest by activating genetically introduced light sensitive ion channels (i.e., opsins) with a laser (Vlasov et al., 2018). In comparison to this animal's baseline cumulative record (light orange line) increasing DA release at reward delivery (purple line) resulted in the animal paying a higher price to continue seeking sugar; whereas, increasing DA release at the reward predictive cue (dark orange line) resulted in the animal giving up at a lower price (Figure 3B). We then converted the behavioral data into demand curves by calculating total sugar in each epoch and plotting it against the corresponding unit-price. Demand curves 


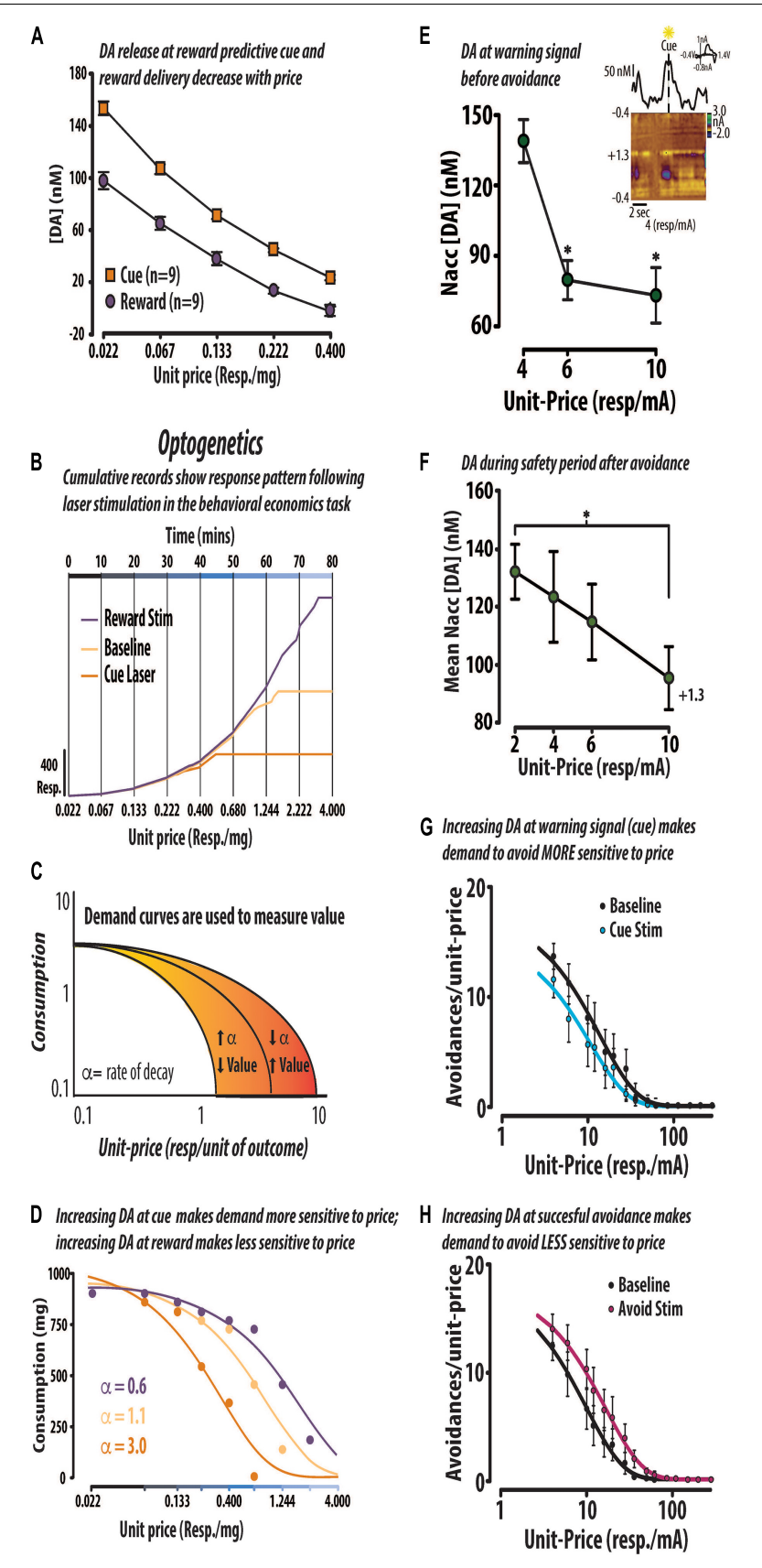

FIGURE 3 | DA value signals encode price and modify the maximal price rats will pay for positive or negative reinforcement. Positive reinforcement: DA (DA) concentration (mean \pm SEM) evoked by a reward predictive cue and delivery of a $45 \mathrm{mg}$ sugar pellet decreased across the first five prices in a within-session behavioral economics-based task. In this task, the unit-price (responses/mg sugar) increased across fixed epochs of time (A). Optogenetic stimulation alters price sensitivity in a representative rat. Cumulative response records from one animal responding in the behavioral economic task under baseline conditions (light orange), and those in which DA release is amplified at cue presentation (dark orange) and at reward delivery (purple) (B). Changes in value were assessed using demand curves which measure changes in consumption in response to changes in unit-price. We formally extracted a dependent measure of value (i.e., $\alpha$ ) which, represents the rate at which demand curve decay. Demand decays at a faster rate when the animal

(Continued)
FIGURE 3 | Continued

becomes more sensitive to price. As the animal is willing to pay less for the commodity, we would interpret the resulting increase in $\alpha$ as a decrease in value (C). The same data from the cumulative records in panel (B) are replotted in the form of demand curves to illustrate the optogenetic-induced shifts in value (D). Negative reinforcement: The concentration of DA evoked by a warning signal that predicted the opportunity to avoid decreased with the price to avoid. Inset: Representative avoidance trial shows that DA concentration began increasing in anticipation of warning signal presentation (E). The concentration of DA release events during the safety period decreased with price in trials in which the rat successfully avoided electrical foot shock (F). Optogenetic activation of VTA DA neurons at the warning signal made animals more sensitive to price, consistent with a negative reward prediction error (G). In contrast, optically stimulating DA neurons at successful avoidance made animals less sensitive to price, consistent with a positive reward prediction error (H). Republished from Schelp et al. (2017) and Pultorak et al. (2018). ${ }^{*} p<0.05$.

are a common tool used by economists to measure changes in valuation. If demand becomes more sensitive to price it is said to be more elastic, suggesting diminished value; if demand becomes less sensitive to price it is said to be more inelastic, suggesting enhanced value (Figure 3C). Replotting the same data from the aforementioned cumulative records revealed that enhancing DA release at cue presentation made demand for sugar more elastic, while enhancing DA release at reward delivery made demand for sugar more inelastic (Figure 3D). From these observations, we infer that valuation of the sugar pellet was decreased when the DA value signal was amplified at the reward predictive cue because the animal perceived that they received less than expected upon receiving the standard $45 \mathrm{mg}$ sugar pellet. By contrast, an amplified DA value signal at the receipt of the $45 \mathrm{mg}$ sugar pellet following a standard prediction might suggest to the animal that they received a better bargain than expected. Similar observations were observed during operant behavior maintained by the avoidance of electrical footshock (Wenzel et al., 2015; Pultorak et al., 2018). The concentration of DA release events-evoked by both a warning signal predicting the delivery of electrical footshock and by the successful avoidance of footshockdecreased with the price required to avoid it (Figures 3E,F) (Pultorak et al., 2018). Furthermore, optogenetically increasing DA release at the warning signal made the demand to avoid more sensitive to price (Figure 3G) whereas, increasing DA release at successful avoidance made demand for avoidance less sensitive to price (Figure 3H) (Pultorak et al., 2018). Taken together, these findings support the notion that transient DA signals can represent subjective value during both positive and negative reinforcement and causally modify reinforcement processes.

\section{ECB Signaling Modulates DA Value Signals and Reinforcement Under a Fixed Ratio Schedule}

Given the well-established role DA value signals play in reinforcement and motivating action (Schultz et al., 2015), we next began to question whether the brain's endogenous cannabinoid system capably modulates transient DA release events during goal-directed behavior. Inspiration for this research 
question originated from early psychopharmacological studies. It was reported that disrupting eCB signaling by treating rats with CB1 antagonists reduced food seeking (Ward and Dykstra, 2005) and generally diminished the effects that conditioned stimuli exert over goal-directed behavior (Stiglick and Kalant, 1982; Le Foll and Goldberg, 2005; Ward et al., 2007). Thus, we first assessed whether treating rats with a CB1 antagonist reduced conditioned DA release events during positive reinforcement. Two reinforcers were assessed: brain stimulation reward and appetitive food. In the case of brain stimulation reward, rats responded for electrical currents delivered to the origin of the mesolimbic DA pathway-the VTA, under a FR1 schedule of reinforcement. The availability of reinforcement was signaled to the rat by a cue light placed above the lever, which began to function as a conditioned stimulus. Under these conditions, the concentration of DA value signals evoked by the cue light increased across trials as reinforcement was strengthened (Day et al., 2007; Oleson et al., 2012). Once DA value signals were determined to be stable, we intravenously treated rats with vehicle and then a CB1 antagonist (SR141716; AKA, rimonabant). In comparison to vehicle, systemic administration of the CB1 antagonist rimonabant significantly decreased the DA value signal while concurrently delaying reinforced responding (Figure 4A). Identical trends were found when we measured DA value signals while rats responded for $45 \mathrm{mg}$ sugar pellets under a FR1 reinforcement schedule, demonstrating the reliability of these results during positive reinforcement (Oleson et al., 2012). And identical trends were found when we infused rimonabant directly into the VTA during brain stimulation reward (Figure 4B), suggesting that local eCB modulation of DA release in the midbrain is alone sufficient to modulate $D A$ value signals and reward seeking. To assess whether increasing eCB signaling facilitates positive reinforcement, we then treated rats with an enzymatic inhibitor that prevents metabolic degradation. We focused on MAGL inhibitors because FAAH inhibitors failed to influence reinforcement in our initial studies (Oleson et al., 2012, 2014) and 2AG is thought to be the principle $\mathrm{eCB}$ that augments DA release by activating CB1s on GABA terminals (Covey et al., 2017). We replicated our aforementioned approach by intravenously administered the MAGL inhibitor JZL184 while rats responded for brain stimulation reward under a FR1 schedule during ongoing FSCV measurements of DA value signals. In contrast to rimonabant, intravenous JZL184 amplified DA value signals while concurrently reducing response latencies (Figure 4C). The same trends were observed when JZL184 was infused directly in the VTA (Figure 4D). Using a new and improved iteration of MAGL inhibitor called MJN110, the Bass lab recently replicated these findings by demonstrating increasing 2AG facilitates cue-motivated reward seeking (Feja et al., 2020). To determine whether eCBs modulate DA value signals during negative reinforcement we also assessed whether systemic administration of a CB1 antagonist influences DA value signals during avoidance. Using a signaled active avoidance operant approach, we treated rats with the CB1 antagonist rimonabant while conducting FSCV. Avoidance was maintained under a FR1 schedule. A warning signal was provided 2s prior to the occurrence of electrical foot shock by illuminating a cue light placed directly above the lever. In comparison to vehicle treatment, intravenous rimonabant significantly decreased DA release time-locked to the warning signal while concurrently decreasing avoidance (Figure 4E) (Wenzel et al., 2018). We next sought to assess whether $2 \mathrm{AG}$ manipulations specifically modify the influence of DA value signals on negative reinforcement. To do this we administered microinfusions of either vehicle or tetrahydrolipstatin (THL) into the VTA of rats. THL is a potent inhibitor of the synthetic enzyme responsible for generating 2AG, DAGL (Ortar et al., 2008). As predicted, intrategmental THL significantly reduced avoidance and 2AG tissue content in comparison to vehicle treated rats (Figure 4F) (Wenzel et al., 2018). Finally, we used optogenetics to stimulate DA neurons during avoidance and found that restoring DA value signals in the presence of THL was sufficient to rescue avoidance (Wenzel et al., 2018). Together, these findings suggest that the eCB 2AG facilitates cue-motivated action by amplifying DA value signals originating from the VTA (Figure 4G) (Oleson and Cheer, 2014; Covey et al., 2017; Wenzel et al., 2018; Peters et al., 2021). These 2AG-modulated patterns of DA release and behavior are apparent during both positive and negative reinforcement when a conditioned stimulus signals the availability of a goal-directed outcome and reinforcement is available under a FR schedule.

\section{Increasing Cannabinoids Amplifies Temporally Engendered Patterns of DA Release and Accelerates Responding Under a Fixed Interval Schedule of Reinforcement}

Whereas FR schedules engender a bimodal response pattern consisting of recurring response-pause successions, the FI schedule engenders a scalloped response pattern. Rather than receiving reinforcement after meeting a fixed response requirement, on a FI schedule, reinforcement occurs at the end of a defined period of time. The lever does not retract during the interval, allowing the experimenter to observe the emergence of a scalloped temporal response pattern using a cumulative response recorder (Figure 5A). The scalloped response pattern results from the animal's lever pressing accelerating across the interval until a maximum terminal rate is reached at the interval terminus (Ferster and Skinner, 1957). In addition to engendering a unique pattern of behavior relative to the FR schedule, the FI schedule also produces a unique pattern of accumbal DA release. As illustrated in Figure 5C, a first peak of DA release can be observed when reinforcement (an appetitive food pellet) is delivered. After a brief pause in release, DA concentration then begins to rise with the onset of the FI before gradually decaying over its duration (Oleson and Cheer, 2014; Oleson et al., 2014). As DA concentration is inversely related to local response rate, we infer that under the contingencies of a FI schedule, DA concentration represents the primary interoceptive cue driving reinforcement: time (Oleson et al., 2014; Everett et al., 2020). To investigate how cannabinoids alter both the patterns of behavior and DA release engendered by the FI schedule, we applied FSCV while treating mice with the cannabinoid agonist WIN as they responded for appetitive food pellets (Oleson et al., 2014). To analyze 
A

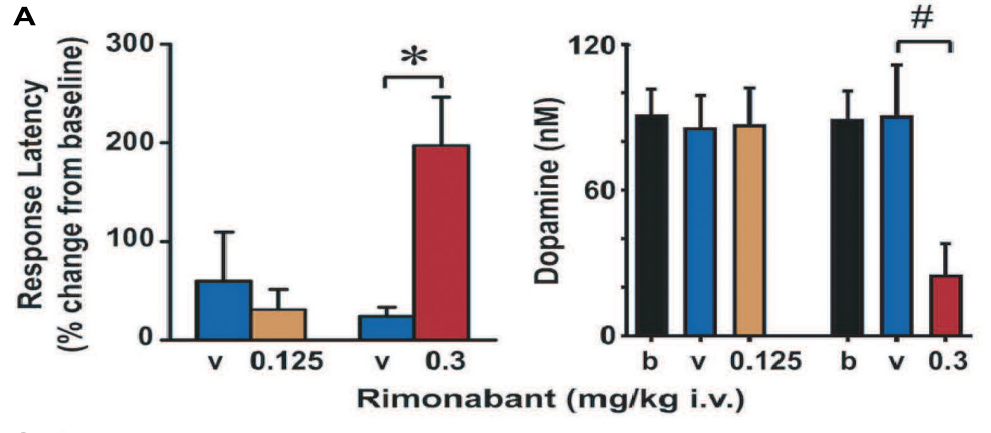

C

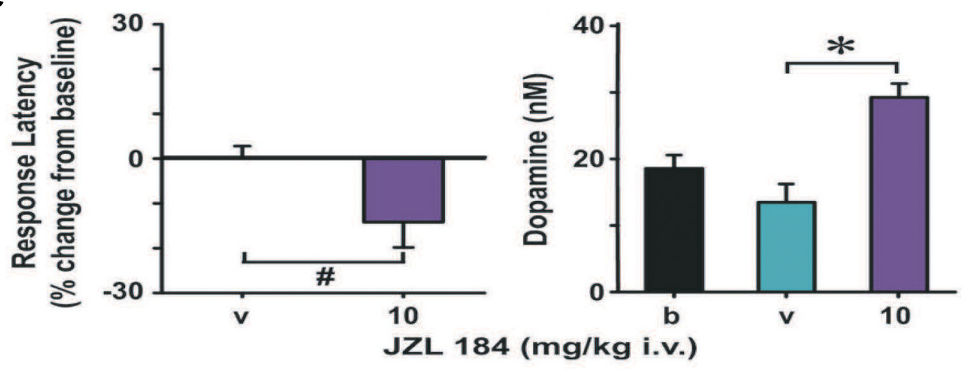

B

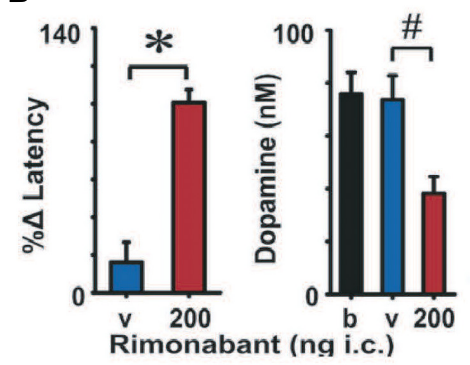

D

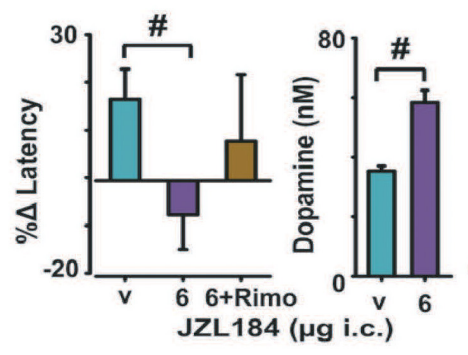

E

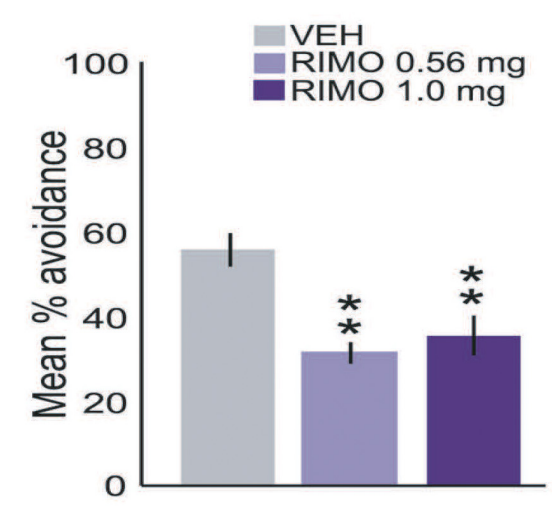

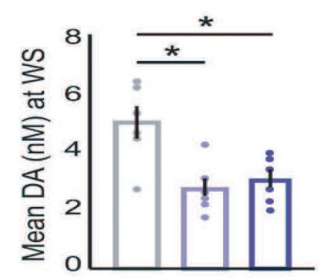

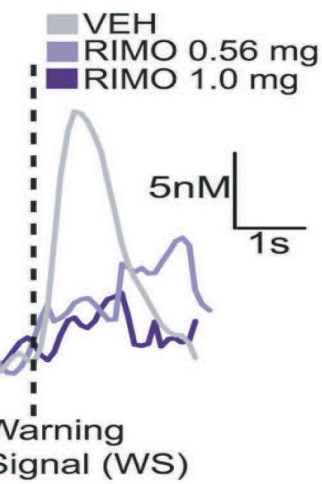

$\mathbf{F}$

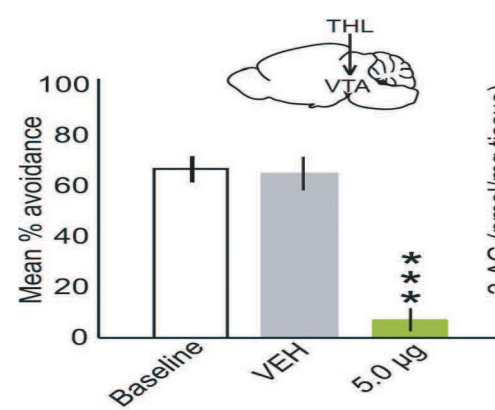

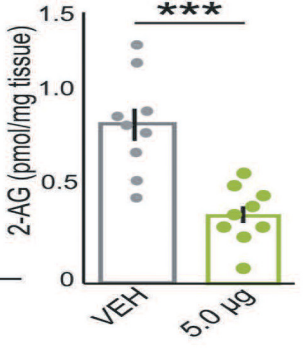

$\mathbf{G}$

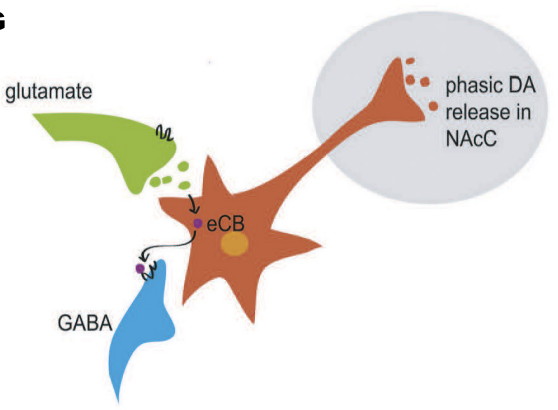

FIGURE 4 | Cannabinoids modulate DA value signals during positive and negative reinforcement maintained under an FR schedule. Positive reinforcement: Systemically treating (intravenous; IV) rats with the cannabinoid receptor antagonist rimonabant increased the latency to respond for brain stimulation reward and decreased the concentration of cue-evoked DA value signals (A). Intrategmental infusions (IC) of rimonabant recapitulated these effects on reward seeking and DA release, demonstrating that eCB modulation of DA neural activity in the VTA is alone sufficient to modulate DA release and positive reinforcement (B). Systemically increasing 2AG levels by pre-treating rats with JZL184 (IV) reduced the latency to respond for brain stimulation reward and increased the concentration of cue-evoked DA value signals (C). Intrategmental infusions (IC) of JZL184 recapitulated these effects, suggesting that the action of 2AG in the VTA is alone sufficient to modulate DA release and positive reinforcement (D). Negative reinforcement: Systemic rimonabant administration (IV) reduced the number of successful avoidance responses and the concentration of DA evoked by the warning signal (E). Inhibiting DAGL-induced synthesis of 2AG by infusing THL into the VTA decreased avoidance and reduced 2AG tissue content in the VTA (F). Taken together, these observations generally support a DSI-model of 2AG-modulation of DA value signals (G) during positive and negative reinforcement maintained under an FR schedule. Republished from Oleson et al. (2012) and Wenzel et al. (2018). $\#<0.05 ;{ }^{* *} p<0.001 ;{ }^{* \star *} p \leq 0.001$. 
how responding changed across the interval, we first calculated rate/terminal rate values by dividing the local response rate into five fixed epochs and then dividing each by the terminal rate (i.e., the maximal local response rate in the final epoch). We found that WIN accelerated local response rates across the interval in a dose- and CB1-dependent manner (Figure 5B). Similarly, WIN dose-dependently increased DA concentration across the duration of the interval in a CB1-dependent manner (Figure 5C). We also performed a more refined behavioral analysis by assessing the index of curvature of individual scalloped response patterns (Figure 5D) (Fry et al., 1960; Narayanan et al., 2012). Using the index of curvature analysis, a negative index of curvature is detected when the animal's scalloped response pattern accelerates prematurely; thereby suggesting that timing behavior is accelerated. By contrast, a slower acceleration of responding across the interval produces a positive index of curvature, suggesting that timing behavior is slowed (Fry et al., 1960; Narayanan et al., 2012). This additional analysis confirmed that WIN accelerated the timing of reinforced responding under a FI schedule while concurrently accelerating the temporally engendered pattern of DA release (Figure 5E). We then treated mice with enzymatic inhibitors to investigate whether specifically increasing the eCBs $2 \mathrm{AG}$ or anandamide modulate the scalloped response pattern observed during fixed interval reinforcement. We found that systemic treatment with the MAGL inhibitor JZL184, but not the FAAH inhibitor URB597 accelerated the temporal response pattern similarly to WIN (cf. Figures 5F,G,H vs. E,B) (Oleson et al., 2014). These data suggest that the eCB 2AG modulates goal-directed action under a variety of contingencies, including periodically reinforced behavior.

\section{ENDOCANNABINOIDS, EXPLORATORY/ADJUNCTIVE BEHAVIOR, AND HABITS}

\section{Endocannabinoids and Exploratory/Adjunctive Behavior From an Ethological Perspective}

We next consider these observations from a phylogenetic and ethological perspective. If cannabinoids amplify patterns of DA release and accelerate timing behavior under conditions of fixed periodic reinforcement, it is possible that they contribute to motivational switching in response to changing environmental conditions. After waiting a lengthy period of time for a primary food source, it may become advantageous to switch from seeking the desired option to foraging for alternative options. In the operant chamber, these foraging-like actions can be noted as reinforcement-irrelevant, or adjunctive behaviors (Falk, 1971, 1977). One proposed way to quantify adjunctive behavior in the operant chamber is the measure responding on a secondary inactive lever (Killeen and Fetterman, 1988). To assess whether cannabinoids influence adjunctive behavior, we reanalyzed the FI data and found that increasing 2AG using the MAGL inhibitor JZL184 (Figure 5I) or antagonizing CB1 with AM251 (Oleson et al., 2014) significantly reduced inactive lever presses. We interpret these findings to suggest that a basal $\mathrm{eCB}$ tone and a moderate concentration of accumbal DA provide the sweet spot of intermittency necessary to switch an animal's incentive to obtain a primary goal (e.g., food) to the pursuit of alternative options (e.g., foraging for an alternative food source) (Oleson et al., 2014). Additionally, sudden increases or decreases in eCB signaling can lead to perseverative goal seeking. In agreement with this supposition, cannabinoids have been reported to promote perseverative action and infiexibility (Hill et al., 2006; Jiao et al., 2011).

\section{The Variable Interval Schedule and Habit Formation}

Recent studies utilizing the variable interval (VI) schedule demonstrate that eCBs are critically involved in habit formation. As previously described, when reinforcement is delivered in fixed intervals, the animal learns to time the interval and accelerate their responding toward its culmination. By contrast, under a VI schedule, responding is reinforced after a random period of time has elapsed since the first response. Under these conditions, the cumulative response pattern is maintained at a high, constant rate-presumably because the animal is uncertain about the time of reward availability (Ferster and Skinner, 1957) (Figure 2A). In comparison to ratio schedules or the FI schedule, the VI schedule is known to produce habitual behavior (DeRusso et al., 2010). To determine if a behavior is habitual rather than goal-directed, experimenters determine if the instrumental action is driven by a valued outcome or devoid of its consequences (Figure 2B). To characterize and parse the purpose of action, Adams and Dickinson developed what is known as the devaluation test (Adams and Dickinson, 1981). After training an animal to respond for what was originally a valued outcome, the outcome is then devalued. In the case of food-maintained responding, the animal is either over-fed or subjected to food poisoning. If the animal's responding is significantly affected by devaluation, it is inferred that action is still directed toward a valued goal; however, if the animal's responding is insensitive to devaluation, it is inferred that action has become habitual. In the latter scenario, the habitual behavior is believed to be unresponsive to changes in outcome value and the contingency between action and outcome (Dickinson and Balleine, 1994).

\section{eCBs May Be Involved in Habit Formation}

Growing evidence suggests that $\mathrm{eCB}$ signaling is crucial for habit formation, although the precise roles each eCB play in habit formation and whether these roles differ at distinct loci in the brain remains to be determined. Hilário et al. (2007) first demonstrated a role for eCBs in habit formation. First, these authors confirmed that a history of responding under a VI-reinforcement schedule is particularly suited for establishing habitual responding. After providing mice with a history of responding for a sugar solution under either a VI schedule or a variable-ratio (i.e., VR) schedule, they were tested in a devaluation test. In this test all mice were given access to either a sugar solution (i.e., reinforcer from operant training) or 

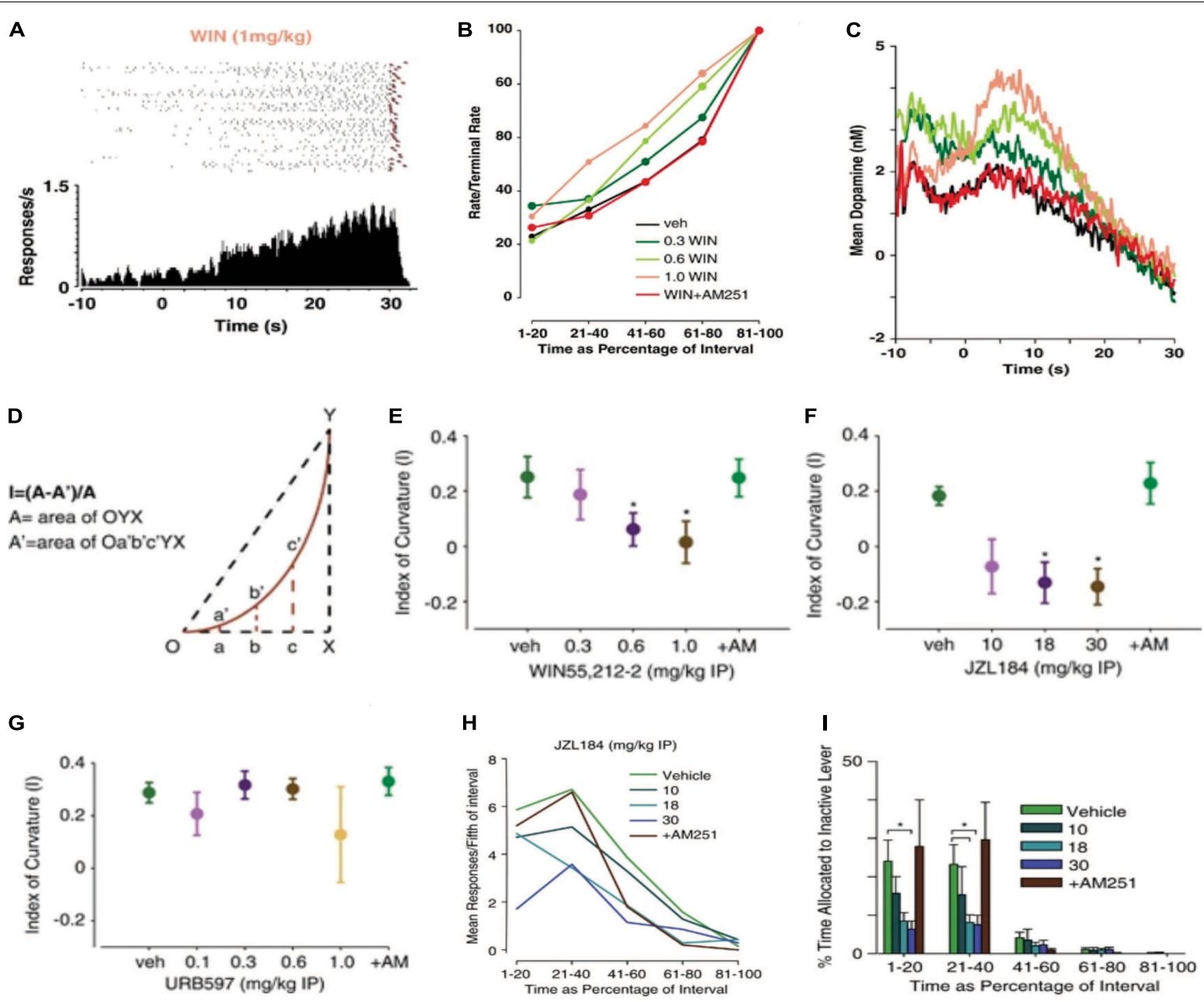

FIGURE 5 | Cannabinoids modulate a temporally engendered pattern DA release during reinforcement maintained under an Fl schedule and adjunctive behavior. An illustrative cumulative response pattern (top: raster plots; bottom: corresponding peri-event histograms) of a WIN-treated mouse responding for food reinforcement under a Fl schedule. The pattern of lever pressing lawfully increases in the Fl task to form a scalloped response pattern. The raster plot shows responses (black ticks) preceding food reinforcement (red triangle) across the $30 \mathrm{~s}$ interval. All trials are shown in chronological order as they occurred in a representative experimental session. The peri-event histogram shows the summation of responding under each corresponding raster plot. (A). WIN 55,212-2 accelerated the timing of scallop response pattern in a dose- and CB1-dependent manner. Mean behavioral response patterns following cannabinoid administration are plotted as a function of the interval duration (B). WIN amplified a temporally engendered pattern of DA release in a dose- and CB1-dependent manner. Mean DA concentration traces for each drug treatment conditions are plotted as a function of the interval (C). Cannabinoid-induced changes in interval timing were quantified by assessing the index of curvature-a computational measure of the extent and direction of change in the temporal response pattern produced by the FI schedule (D). WIN produced a negative index of curvature, suggesting an acceleration of timing behavior (E). Increasing 2AG with JZL184, but not increasing anandamide with URB597, accelerated interval timing $\mathbf{( F , G ) . ~ e C B - i n d u c e d ~ c h a n g e s ~ i n ~ r e i n f o r c e m e n t ~ i r r e l e v a n t ~ o r ~ a d j u n c t i v e ~ b e h a v i o r ~ w e r e ~ a s s e s s e d ~ b y ~ q u a n t i f y i n g ~ r e s p o n s e s ~ o n ~ a n ~ i n a c t i v e ~}$ lever. Mean responses on the inactive lever initially increase before declining through the interval (H). JZL184 significantly decreased the percentage of time spent responding on the inactive lever, suggesting that adjunctive behavior was reduced by elevating 2AG levels (I). These data show that cannabinoids module periodically reinforced behavior and DA release under an FI schedule and, might suggest that a delicate balance of 2AG and DA release are necessary to produce the sweet-spot of intermittency that produces adjunctive behavior. Reproduced from Oleson et al. (2014).

standard chow (home cage food) for $1 \mathrm{hr}$ preceding an extinction session. During the extinction session, mice were given access to the sugar-paired lever used in operant training; however, no scheduled consequences occurred when it was pressed. As predicted, they found that a history of responding under VI schedule, but not the VR schedule, resulted in sugar-sated mice persevering in their responses on the sugar-paired lever. The authors also conducted a separate exploration test in which mice were given access to the previously active lever and a novel level.
They found that in comparison to mice with a history under the VR schedule, mice with a history of responding under the VI schedule were more likely to engage with it. To test the effects of eCB signaling, the authors replicated their experimental approach using $\mathrm{CB} 1$ mutant mice and their wild-type littermates. After a history of responding for sugar under a VI schedule, wildtype (WT), heterozygous $C B^{+/-}$(HET) and homozygous $C B^{+/-}$ (HO) mice were given access to the regularly active lever in either a sugar-sated or non-sated state. As shown in Figure 6A, 


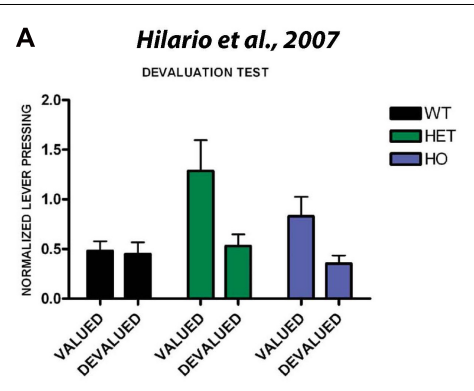

B
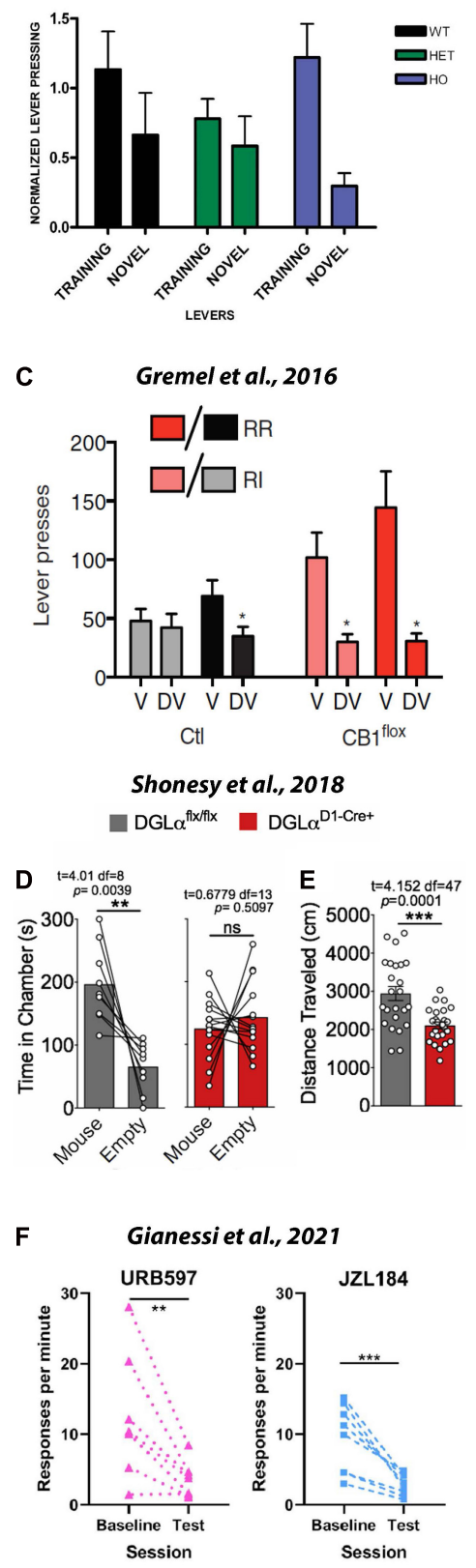

FIGURE 6 | CB1s are necessary for habit formation and adjunctive/exploratory behavior. To investigate the role of eCBs in habit formation and adjunctive behavior $\mathrm{WT}, \mathrm{CB} 1^{+/-}$, and $\mathrm{CB} 1^{-/-}$were trained on

(Continued)
FIGURE 6 | Continued

a variable interval schedule and then tested in devaluation and exploration tests. (A) Normalized lever pressing during the valued versus the devalued condition for $\mathrm{WT}, \mathrm{CB} 1^{+/-}$, and $\mathrm{CB} 1^{-/-}$mice. $\mathrm{CB} 1$ mutants showed sensitivity to sensory-specific satiety, suggesting that their actions were goal-directed rather than habitual. These data suggest that the CB1 and eCBs are necessary for habit formation. (B) Lever pressing (normalized) on the training lever versus a novel lever in $\mathrm{WT}, \mathrm{CB} 1^{+/-}$, and $\mathrm{CB}^{-/-}$mice. Relative to other groups, $\mathrm{CB} 1^{-/-}$mice responded less on the novel lever, suggesting that the CB1 and eCBs may be involved in adjunctive behavior. (Republished from Hilário et al., 2007). (C) Graph shows responses in the valued (V) and devalued (DV) states in $\mathrm{Rl}$ and $\mathrm{RR}$ training contexts. $\mathrm{R} R$, random ratio (aka $\mathrm{FR}$ ); RI, random interval (aka VI). During outcome devaluation procedures, control mice showed reduced lever pressing in the devalued state in the $R R$ context but not the RI context. However, mice that lacked CB1s on OFC projection neurons into the striatum responded less in the devalued state under both RR and RI conditions. These data suggest that CB1s in cortical-striatal loops are necessary for habit formation (Republished from Gremel et al., 2016). Mice lacking the enzyme for the synthesis of 2AG from D1 MSNs (D1-Cre+) showed decreased exploration of a novel conspecific (D) and a novel environment (E). These data suggest that 2AG in the striatum plays an important role during adjunctive behavior (Republished from Shonesy et al., 2018). (F) Surprisingly, blocking metabolism of AEA with URB597 and 2AG with JZL184 disrupted rather than promote habit formation. These latter findings might suggest that $A E A$ and $2 A G$ are not important in habit formation or that non-specific behavioral effects (e.g., increased motivation for food) can confound tests of habitual behavior. ${ }^{\star \star} p<0.01$; ${ }^{\star \star} p \leq 0.001$.

devaluing the sugar solution failed to affect responding on the previously sugar-paired lever. This finding supports the notion that a history of responding under the VI schedule produces habitual responding. However, both the HET and HO groups CB1 mutant mice showed sensitivity to sugar devaluation. As evidenced by the green and blue bars, providing ad libitum access to the sugar solution before the devaluation test resulted in both CB1 mutant groups responding less in the sated state, suggesting that habit formation is impaired in $\mathrm{CB} 1$ mutant mice. As illustrated in Figure 6B, in the exploration test they found that HO mice, but not HET or WT mice, failed to explore the novel level. Taken together, these data suggest that CB1 signaling may play an important role in habit formation and exploring novel options. These data are in agreement with our aforementioned finding that pretreating mice with AM251 reduced inactive lever responses; although, it remains unclear why increasing 2AG levels with JZL184 also reduced adjunctive, or exploratory behavior. One likely possibility is that systemically increasing $2 \mathrm{AG}$ produces an array of physiological and behavioral effects at different levels of distinct neural networks. By harnessing recent technical advances, investigators are beginning to target specific cellular populations and neural circuits responsible for habit formation, but many additional studies are required to completely understand the mechanisms involve.

\section{A Brief Introduction to the Nigrostriatal Habit Circuitry}

The majority of aforementioned DA studies measured its release in the primary terminal field of the mesocorticolimbic pathway (Figure 2C), the NAc. The NAc is typically thought of as a Pavlovian-motor interface that guides model-based goal-directed 
actions (Yin and Knowlton, 2006; Bornstein and Daw, 2011)including reward seeking, conditioned active avoidance, and periodically reinforced behavior. In contrast, habits are thought to mediated by interactions between the dorsal striatum and the cortex, or cortico-striatal loops (Figure 2C). The dorsal striatum is often divided into the dorsomedial (caudate in primates) and the dorsolateral (putamen in primates) striatum (Yin and Knowlton, 2006). The dorsomedial striatum is thought to guide model-based, goal-directed actions using environmental rules that dictate the contingencies of reinforcement. By contrast, the dorsolateral striatum is thought to play a role in guiding modelfree, habitual action using previously learned associations (Yin and Knowlton, 2006; Lee et al., 2014). This form of modelfree habitual action is thought to arise from sensorimotor loops that can be modified by $\mathrm{eCB}$ signaling and $\mathrm{DA}$ release at the level of the dorsal striatum. Whereas the NAc receives DAergic input from mesocorticolimbic pathway originating in the VTA, the dorsal striatum primarily receives DAergic input from the nigrostriatal pathway originating in the substantia nigra pars compacta (Figure 2C).

\section{eCB Modulation of Cortico-Striatal Input Into the Dorsal Striatum Gates Goal-Directed and Habitual Behavior}

Gremel et al. (2016) provided incisive insight into the role eCBs might play in orbitostriatal input into the dorsal striatum. The orbitofrontal cortex (OFC) is thought to contribute to cortico-striatal loops that may gate behavior between being goal-directed and habitual. Using viral technology to selectively knock-out CB1 from OFC neurons, they first demonstrated that OFC neurons projecting to the dorsomedial striatum exhibit greater activity during goal-directed behavior in a VR than in a VI task. Similar to Hilario, they further confirmed that VI training produced more habitual responding than VR training. They then used a retrograde virus and chemogenetics to selectively inhibit OFC projections into the dorsomedial striatum. While control mice reduced responding on both the VR and VI task when in the devalued (i.e., sugar-sated) state, chemogenetic inhibition of OFC input into the dorsomedial striatum did not reduce responding in either the VR or VI task (Figure 6C). To better assess the local contribution of OFC input in the dorsomedial striatum, they repeated their experiment but injected the clozapine-n-oxide used to induce chemogenetic suppression directly into the dorsal striatum rather than into the intraperitoneal space. They found that handling the WT mice during microinfusions abolished habitual responding; specifically, mice only responded on the sucrose-paired lever when in a sucrose-sated, or devalued state. However, when the microinfusion produced chemogenetic inhibition of OFC input into the dorsal striatum, responding on the previously sucrose-paired lever persisted in-spite of sucrose devaluation. Taken together, these data suggest that eCB-modulation of OFC input into the dorsal striatum might gate behavior between dorsomedial-mediated goal-directed behavior and dorsolateralmediated habitual behavior. Future studies are necessary to clarify the specific roles distinct eCBs play in modulating behavior; the specific eCBs involved, the circuit they are acting in, and the specific cell-type they are acting on are all important variables to consider in future studies.

\section{AG From D1-Expressing MSNs Mediates Exploratory Behavior and Perseverative Responding}

To provide cell-type and eCB specific data, Shonesy et al. (2018) investigated the effects of conditionally knocking down the primary synthetic enzyme of $2 \mathrm{AG}$ (i.e., DAGL) from striatal MSNs. The majority of MSNs in the dorsal striatum can be segregated into one of two populations. The D1-expressing neurons of the direct pathway are thought to promote action during reinforcement, whereas the D2-expressing neurons of the indirect pathway are thought to inhibit action during reinforcement (Kravitz et al., 2012). Shonesy et al. (2018) found that knocking down DAGL from the D2-expressing neurons of the indirect pathway failed to influence any of the behavioral outcomes they assessed. In contrast, they found that removing 2AG signaling from D1-expressing neurons of the direct pathway produced distinct behavioral effects depending on whether the conditional knock down occurred in the dorsal or ventral striatum. Specifically, they found that removing 2AG from dorsal striatal D1-containing MSNs reduced both social (Figure 6D) and spatial (Figure 6E) exploration of novelty. However, it should be noted that repetitive grooming occurred following removal of $2 \mathrm{AG}$ signaling from the ventral rather than the dorsal striatum. The authors also found that removing 2AG signaling from MSNs failed to influence operant behavior maintained under either fixed-ratio or progressive-ratio schedule. These paradoxical behavioral findings notwithstanding, Shonesy et al. (2018) also provided important information regarding the role of 2AG in modulating synaptic plasticity in striatal circuits. Using electrophysiology, they found that removing $2 \mathrm{AG}$ signaling from D1-MSNs reduced feedback inhibition at both glutamatergic and GABAergic MSN synapses and increased basal glutamatergic release onto D1-MSNs. Specifically, they found that KO of DAGL from D1-MSNs significantly increased the frequency of their excitatory post-synaptic currents, suggesting an impairment of eCB mediated feedback inhibition on glutamate release (i.e., DSE). They also found that the KO of DAGL from D1MSNs impaired DSI at these cells arising from GABAergic synapses, although GABAergic transmission was determined to be unchanged. Overall, these data suggest DAGL-KO from D1-MSNs excite dMSNs due to a loss of DSE. When this breakdown in feedback regulation occurs in the dorsal striatum, exploration of social and spatial novelty are impaired; when this breakdown occurs in the ventral striatum, perseverative grooming behavior is observed.

\section{Surprising Findings and Important Considerations Regarding the Overlap Between Measures of Appetitive Goal-Seeking and Habitual Responding}

While the aforementioned studies offer compelling evidence that increases in $2 \mathrm{AG}$ within the dorsal striatum act on $\mathrm{CB} 1 \mathrm{~s}$ 
to modulate habitual behavior, a recent study by Gianessi et al. (2021), suggest there is considerable nuance to this story that still needs to be considered. These investigators trained mice to respond for sucrose-sweetened grain pellets under a VI schedule and then tested for habitual responding using contingency degradation. As opposed to sating the mice with ad libitum sugar, the reinforcement contingency was degraded by allowing the animal to respond as if in the VI-task but lever presses resulted in no programmed consequence. Rather, reinforcers were delivered at equal intervals, matching the total number of reinforcers earned the previous day. The FAAH inhibitor URB597 was administered to test the effects of elevated AEA levels on habitual responding; the MAGL inhibitor JZL184 was administered to test the effects of elevated 2AG levels on habitual responding. Contrary to their predictions, they found that both drugs reduced responding during the test day following contingency degradation (Figure 6F). These findings paradoxically suggest that elevating neither anandamide nor $2 \mathrm{AG}$ strengthens habitual responding. Furthermore, they demonstrated that the effects of the CB1 antagonist/inverse agonist AM251 on habitual responding varied depending on the vehicle used and the relative time of drug pre-treatment. The authors first note that solubility of prepared cannabinoid solutions varies greatly across labs because these lipophilic compounds are not easily dissolved in water. They demonstrate that dissolving AM251 in a mixture of DMSO and TWEEN produced dose-dependent reductions in operant responding, but dissolving AM251 in DMSO alone did not. Thus, it is important to note differences in vehicle and drug preparation may drastically impact bioavailability when comparing cannabinoid studies. For example, while the Gianessi et al., 2021 study reported that $1 \mathrm{mg} / \mathrm{kg}$ AM251 reduced operant responding, the Hilario study reported that neither 3 nor $6 \mathrm{mg} / \mathrm{kg}$ AM251 did. Perhaps more importantly, Gianessi et al., 2019., also found that the timing of habitual testing relative to drug-treatment is important to consider during experimental design. When they assessed for habitual behavior immediately after a series of AM251 treatments, they observed a significant increase in responding. However, when they assessed for habitual behavior after allowing for AM251 to clear the system, responding was found to be decreased. From this observation, and their finding that AM251 reduced responding for sugar pellets, the authors concluded that mice increased responding after the series of AM251 treatments because they had not been reaching satiety across the VI training sessions and were therefore showing an increase in goal-directed appetitive behavior rather than habitual responding during the first contingency degradation session. It is also worth noting that this group also reported that when administered alone, JZL184 does not alter the expression of food habits (Gianessi et al., 2019) or alcohol habits (Gianessi et al., 2020). However, in the latter study Gianessi et al. (2020) did find that JZL184 increased motivation for food as assessed using a progressive ratio schedule. Thus, while compelling evidence suggests that $2 \mathrm{AG}$ may be important in gating goal-directed to habitual action, many more studies are required to reconcile the nodes of the neural circuitry involved, the role of specific receptors and cell-types being acted upon within each node, and the contributions of distinct eCBs. Furthermore, the potential confound of CB1-mediated changes in appetitive behavior on habitual testing underscores the importance of concurrently considering the literature on eCBmodulation of appetitive behaviors, habitual responding, and attentional processes.

\section{Transition From Reinforcement to Attentional Processes}

The manifestation of motivationally switching from a primary reinforcer to an alternative outcome and habit-formation likely involve the additional recruitment of attentional processes. And, when considering the neural substrates involved in motivational switching, it became readily apparent that this circuitry often overlaps with the neural substrates of attention (e.g., OFC-dorsal striatum) (O'Hare et al., 2018). Furthermore, mesocorticolimbic DA signaling is believed to modulate valuedriven goal-directed action, habit formation, and attentional processes. Thus, we next turn the focus of our review to the seemingly intertwined literature on cannabinoid and DAergic modulation of attentional processes.

\section{CANNABINOIDS AND DA BOTH MODULATE ATTENTIONAL PROCESSES AS WELL}

\section{Introduction to the Study of Attention and Attentional Processes}

The concept of attention has long historical roots in psychology and bears several definitions. While modern terminology surrounding attention may refer to disparate concepts such as arousal, vigilance, and distractibility, it may be broadly defined as selective activation of neural representations during information processing. Through this definition, attention may be best illustrated in relation to the highly related process of working memory. Whereas attention uploads information 'on-line' at any discrete timepoint, working memory stores and utilizes these activated representations during recall across small spans of time (Baddeley, 1986; Cowan, 1993; McElree, 2001; Oberauer, 2019). While attention has different aspects or components associated with it, including its most fundamental sensorybased component involuntarily elicited in response to salient environmental stimuli, the behavioral paradigms referenced below generally focus on attentional control. An executive function, attentional control incorporates top-down regulation of bottom-up sensory driven attentional processes to subserve appropriate attendance toward behaviorally relevant stimuli (Posner and Petersen, 1990; Cohen et al., 1993; Hopfinger et al., 2000; Fan et al., 2002). Proper allocation of attention within complex, changing environments is an evolutionarily conserved trait crucial for effective information processing (Matzel and Kolata, 2010; Chun et al., 2011), allowing an animal's behavior to be adaptively modified by external contingencies in order to successfully engage in signal detection and goal-directed decision making (Broadbent and Gregory, 1963; Endler, 1992; 
Verghese, 2001; Smith and Ratcliff, 2009; Asplund et al., 2010; Voloh et al., 2015). So, dysfunctions in attention weaken an individual's ability to allocate cognitive resources effectively to the task at hand. Therefore, deficits in attentional control are potential barriers to adaptive behavior and overall survivability of the organism, with pathologies affecting this executive function leading to maladaptive traits that negatively impact quality of life (Baddeley et al., 2001; Rueda et al., 2004; Williams-Gray et al., 2008; Burgess et al., 2010; Fajkowska and Derryberry, 2010; Schoorl et al., 2014; Stefanopoulou et al., 2014; Heeren and McNally, 2016).

\section{Cortical Regulation of Attentional Control}

Although the neuroanatomical loci of attention are many and work as an integrated network of multiple brain regions, attentional control is largely mediated by cortical regions. Spatial and visual attentional control, for instance, have been evidenced to be strongly regulated by frontoparietal regions that filter sensory information in a top-down fashion, with injury to these areas resulting in spatial neglect despite intact bottom-up, sensory-driven networks (Jeannerod, 1987; Karnath et al., 2001; Mort et al., 2003; Corbetta et al., 2005; Fiebelkorn et al., 2018). In terms of attentional command and action selection, the PFC and OFC have been shown to mediate selective attentional control during cognitive tasks, with the PFC regulating attentional focus during interference (Milham et al., 2001), redirection of attention based on task demands (Rossi et al., 2007), and attentional shifting across perceptual features (Owen et al., 1991; Birrell and Brown, 2000; Liston et al., 2009), while the OFC primarily serves redirecting attention during reinforcement switching within reversal learning (Hampshire and Owen, 2006). As the PFC is fundamental to cognitive control in general and regulates working memory, decision making, and other processes crucial to goal-directed behavior (Fuster, 2015), its involvement in attentional processes is perhaps self-evident. The OFC, on the other hand, has a more indirect relationship to attention as it is more associated with value encoding and behavioral inhibition (Teitelbaum, 1964; Gallagher et al., 1999; Izquierdo et al., 2004; Kim and Ragozzino, 2005; Jonker et al., 2015). Nonetheless, attention-based modulation of value encoding in the OFC has been recently supported, leaving an interesting role for the OFC in value-based decision making that may be under the control of attentional focus (Xie et al., 2018).

\section{DA and eCB Regulation of Cortical Function}

The multifaceted cortical functions of cognitive control are tightly regulated by both intra- and intercortical activity states mediated greatly by pyramidal cells, the principal neurons of the cortex. Far from being self-contained, pyramidal cell activity is impinged by numerous signaling molecules, including DA, which is projected in the cortex by rich innervations arising from the VTA (Lewis et al., 1986). DA regulates pyramidal cell function through numerous ways to primarily modulate glutamatergic and GABAergic signaling in the cortex (Law-Tho et al., 1994;
Zheng et al., 1999; Gao et al., 2001; Seamans et al., 2001a; FloresHernandez et al., 2002; Gao and Goldman-Rakic, 2003; Wang et al., 2003; Beazely et al., 2006; Liu et al., 2006; Onn et al., 2006; Li et al., 2009; Hu et al., 2010; Tritsch and Sabatini, 2012). Overall DA has a dampening effect on excitatory transmission in the PFC through a presynaptic mechanism, reducing the probability of glutamate release (Gao et al., 2001). DA also modulates inhibitory signaling in the PFC, biphasically altering inhibition of pyramidal cells via $\mathrm{G}_{i}$-coupled D2 DA receptor activation on presynaptic GABA cells and a complex interplay between signaling of postsynaptic pyramidal cell DA receptors D1 ( $\mathrm{G}_{s}$-coupled), D2, and D4 (Gi-coupled) (Seamans et al., 2001b; Wang et al., 2002; Trantham-Davidson et al., 2004). Pyramidal cell activity is modulated by DA in more direct ways too; postsynaptic mechanisms of intrinsic excitability have been shown to be adjusted in rats by VTA DA projections that modify spike frequency adaption and afterhyperpolarization potentials in the PFC (Buchta et al., 2017).

Cortical function is also mediated by $\mathrm{eCB}$ signaling. In the PFC, CB1 expression has been found to be preferential to GABAergic presynaptic terminals adjacent to glutamatergic ones, both synapsing onto dendrites of mGluR5-containing pyramidal cells. This places $\mathrm{CB} 1$ in a position to integrate and balance excitatory and inhibitory signaling during activitydependent eCB mobilization (Fitzgerald et al., 2019). This mGluR5-mediated integration of PFC pyramidal signaling may take place post-synaptically to directly increase pyramidal cell excitability and synaptic drive, or pre-synaptically as this ligand gated Gq protein-coupled receptor is capable of stimulating eCB production to induce DSI-mediated disinhibition of pyramidal cells via CB1 signaling (Kiritoshi et al., 2013). eCB signaling may also simultaneously modulate glutamate and DA in the PFC as systemic administration of the CB1 agonist WIN has been shown to increase transmission of both within this region (Polissidis et al., 2013). Furthermore, intra-PFC WIN administration induces bi-phasic functional effects in VTA DA cell activity, with low doses increasing and high doses decreasing spontaneous DA cell firing (Draycott et al., 2014). Although less characterized, $\mathrm{eCB}$ signaling within the OFC influences pyramidal function too. Similar to the PFC, postsynaptic mGluR5 activation has been shown to increase local eCB release and enhance CB1 signaling within GABAergic presynaptic terminals of the OFC (Lau et al., 2020). Interestingly, in the lateral aspect of the OFC, impaired astrocytic glutamate transport has been found to result in aberrant eCB tone and subsequent LTD of inhibition onto pyramidal cells, presumably via increased mGluR5 activation from excess extrasynaptic glutamate. Whether this eCB-mediated astrocytic regulation of mGluR5 activation is shared by PFC synapses remains to be investigated.

\section{DA and eCB Regulation of Attentional Processes}

The influence of cortical DA on cognition, including attentional processes, is a well-researched subject that has been intensely studied by neurobiologists and computational neuroscientists alike. Broadly, DA in the PFC facilitates integration of complex 
signals between sensorimotor networks by synchronizing different brain networks in response to both external signals and internal representations (Ott and Nieder, 2019). This is enabled by stabilizing neural representations in the cortex through gating sensory signals at the level of the PFC and gain changes of different pyramidal cell subpopulations, which support action selection and goal-directed behavior in stimuli-rich environments (Foote et al., 1975; Durstewitz et al., 2000; Mehta et al., 2000; Assad, 2003; Yantis and Serences, 2003; Maunsell and Treue, 2006; Scolari and Serences, 2009; Dang et al., 2012; Byers and Serences, 2014; Shafiei et al., 2019). As a neuromodulator, DA's influence via the signaling dynamics referenced above are tightly regulated at both the synaptic and systems level and are subject to the classic Yerkes-Dodson (inverted U-shaped curve) dose-response relationship, with hyper- or hypoDAergic levels resulting in cognitive dysfunction (Yerkes and Dodson, 1908; Vijayraghavan et al., 2007). This DA-sensitive nature of attentional control has been demonstrated by both human and rodent studies showing measures of inattentiveness correlated with low levels of DA release may be repaired by increasing DA transmission by means of neural stimulation or pharmacological manipulation (Turner et al., 2017; Fukai et al., 2019). In contrast, administering the D2 antagonist haloperidol to healthy human subjects increases involuntary directing of attention toward task-irrelevant events (Kähkönen et al., 2002). eCB signaling within the cortex must also walk a fine line to sustain attentional control and while local cortical CB1 dynamics are less studied than those within cortico-accumbens projections within this context, their effect on cognition is duly noted. In the PFC, viralinduced overexpression of $\mathrm{CB} 1$ results in impaired cognitive flexibility in the form of decreased reversal learning in rats (Klugmann et al., 2011). Within the OFC, the medial but not the lateral aspect has been found to display low levels of CB1 gene expression in rats with high impulsivity (Ucha et al., 2019). And, goal-directed behavior in mice has been shown to be regulated by a CB1-dependent mechanism in OFC projections to the dorsal striatum, with genetic knock out of CB1 here preventing habit formation of instrumental responding (Gremel et al., 2016).

\section{Common Methods to Investigate the Components of Attention}

While there are many components of attentional control, this review will focus on sustained attention, response control (impulsivity), attentional set-shifting and reversal learning as indices of attentional control as well as their respective deficits. Of the many factors that may influence attentional control, reversal learning - instrumental responding to swapped outcome contingencies between manipulanda - and impulsivity are both affective state-sensitive, pathology-related variables readily examined in the operant setting as adjuncts to more direct measures of attention itself (Puumala and Sirviö, 1998; Kenemans et al., 2005; Izquierdo and Jentsch, 2012; Linley et al., 2016; Paret and Bublatzky, 2020). While these two measures remain technically distinct from those of attention per se, they index prioritization of attentional demand to reward-associated stimuli (Mackintosh and Little, 1969; Oemisch et al., 2017).
Accordingly, their relationship to attention and its operant tests are discussed alongside attention itself. Because performance inconsistencies are more informative than absolute performance, and because anatomical and neurochemical specificity is more readily correlated to specific measures, focus will be given to impairments and enhancements of these measures under different pharmacological conditions. Limitations are inherent in each reported finding as no pure test of attention is currently accepted, although evidence supporting correlations between certain pathologies and specific attentional dysfunctions will be highlighted. As attention is both inherently sensitive and limited, unique internal (e.g., neurofunctional) and external (e.g., experiential) factors may affect its processing to either enhance or constrain different attentional components. Furthermore, individual differences in attentional control may result in differing perceptions and behavioral outputs across samples under identical environmental conditions (Dukas and Kamil, 2000; Derryberry and Reed, 2002; Mathews et al., 2004; Ólafsson et al., 2011; Sali et al., 2015; Yuan et al., 2019). Such factors will be considered here, focusing on how key mesocorticolimbic regions regulate commonly investigated attentional control processes while also relating changes in functional activity to pathology. The review will then culminate with $\mathrm{DA} / \mathrm{eCB}$ interactions evidenced to modulate these processes with special consideration toward gaps in the literature. To best frame the aforementioned components of attention, the behavioral tests most popularly used for their measurement will be introduced below, with the 5-Choice Serial Reaction Time Test (5-CSRTT) used to assess sustained attention and impulsivity and the Attentional Set Shifting Test (ASST) used to measure shifting attentional set and reversal learning.

\section{Operant Methods to Assess for Changes in Attentional Processes}

\section{The 5-Choice Serial Reaction Time Test (5-CSRTT)}

The 5-CSRTT for rodents was refurbished from a similar test of attentional processing during discrimination of visual stimuli in humans (Wilkinson, 1963; Carli et al., 1983). The paradigm consists of a food cup positioned in front of a hinged window, which once pushed open by the rodent initiates the behavioral session and delivery of the first food-based reward, usually a food pellet or measured amount of liquid sucrose. Additional manipulanda consists of five nose poke ports, each with their own cue lights positioned behind them as well as photobeams to detect individual nose pokes. After initial reward delivery following the opening of the food cup window, each successive delivery of reward is contingent upon a successful, exclusive nose poke through the port in which a cue light is randomly illuminated per trial. Responses for any port not signaled with an illuminated cue light may either terminate the trial without reward delivery or be tallied as non-rewarding errors within a lengthened response period (depending on the behavioral script ran at the time), after which the next trial begins. As the cue light is only briefly illuminated and responding via nose pokes is only allowed during a confined time period, a temporal domain is imposed onto the spatial 
domain defined by the five different manipulanda separated by the apparatus. This dual-domain aspect of the paradigm demands attention be afforded to both domains simultaneously but also allows experimenters to dissociate each as they see fit, for instance by expanding the spatial separation of cues by exclusively illuminating peripheral ports or modifying time periods of cue illumination and/or delay periods. The dualdomain component of the task also allows multiple aspects of attention to be measured within a single experimental session. For instance, errors counted across nose-poke responses within unilluminated ports, considered inaccurate responses, are interpreted as lapses in sustained attention. Additional demands of 'attentional load' placed on the animal may be measured by modifying the temporal domain to increase uncertainty and/or duration of cue illumination. Another type of error may also be measured by tallying responses made during a brief inter-trial interval period programed before cue illumination at the onset of each trial (Figure 7A). These premature responses are interpreted as lapses in inhibitory control, or impulsivity. Other types of errors may also be measured by additional modifications programmed into the paradigm, though this review will focus on those of inaccurate and premature responding as a bulk of literature supports both $\mathrm{DA}$ and eCBs mediate these aspects of the task as commonly used with rodents.

\section{The Attentional Set Shifting Test (ASST)}

Like the 5-CSRTT, the ASST for rodents was adapted from behavioral assessments originally designed for human subjects. The most commonly cited comparison is with the Wisconsin Card Sorting Test (WCST), though a more direct comparison may be made with the Cambridge Neuropsychological Automated Testing Battery (CANTAB). Both are used to investigate 'behavioral flexibility' in healthy and abnormal neurological states by measuring the ability to shift attention from one reward-predictive perceptual feature to another following an unexpected switch (Berg, 1948; Grant and Berg, 1948; Weinberger et al., 1986; Sahakian and Owen, 1992; Paolo et al., 1995; West, 1996; Nieuwenstein et al., 2001; Barceló and Knight, 2002; Ridderinkhof et al., 2002; Romine et al., 2004; Nagahama et al., 2005). Specifically, the CANTAB design involves two-choice discriminations between either simple or complex exemplars to assess attentional bias toward a feature of perceptual stimuli, or dimension. One exemplar initially predicts reward faithfully at onset of the task and constitutes a single dimension (e.g., shape), while the other non-predictive exemplar is a presentation of a separate stimulus within the same dimension, in this case a separate shape. Once subjects learn this simple discrimination, a complex discrimination must be made after introduction of a second dimension (e.g., line segments) overlaying the first dimension in each exemplar that remains reward-predictive (shape). As both exemplars now consist of separate stimuli constituting two different dimensions (e.g., two different shapes with two superimposed line segments), the reward-predictive stimuli may be 'shifted' within the same dimension or to the other dimension. Changing stimuli while retaining reward-predictability to the initial dimension (shape) is labeled an 'intradimensional shift' (ID shift), while switching the reward-predictive dimension (shape $\rightarrow$ line segments) is labeled an 'extradimensional shift' (ED shift). Adding another level of analysis, each of these test components is followed by a reversal learning test, in which the reward-predictive stimuli of the two exemplars is reversed while the relevant dimension stays the same.

The ASST adapted for rodents has been designed as both a reward-digging task, in which exemplars comprise different combinations of digging materials and odors as dimensions (Figure 7B, panel A), and an instrumental operant task, in which reward delivery associations may be switched between two different levers and their respective cue light illumination settings (on/off) (Figure 7B, panel B). In these tasks, a bias toward one of the two dimensions is considered formation of an attentional set, expressed as relatively quicker and more accurate responding during intradimensional shifts than either extradimensional shifts or the initial simple discrimination test (Birrell and Brown, 2000). Attentional sets are therefore interpreted as information stores maintaining the reward-associative value of a perceptual feature that leads to relative ignorance toward other features (Folk et al., 1992).

In addition to assessing attentional sets, the separate reversal learning tests allow dissociation and detection of deficits relating to this ability alone. While similar to attentional set-shifting, reversal learning is considered a less complex but important process that relies on inhibition of previously rewarding actions (Jones and Mishkin, 1972). Because shifting attentional set requires a higher demand of attentional orientation and an aspect of learned irrelevance - accurately responding to rearrangement of complex, multidimensional stimulus pairings not correlated with reward - it is widely considered to be more cognitively challenging than reversal learning (Dias et al., 1996; Bissonette et al., 2008; Nilsson et al., 2015). Owing to its regulation of complex cognitive functions, it is logical that the PFC has been found to be critical to attentional set-shifting, with the non-human primate lateral PFC and homologous rodent medial PFC specifically evidenced to mediate this process (Dias et al., 1996; Birrell and Brown, 2000). Conversely, reversal learning is specifically impaired following damage to the OFC of both monkeys and rodents, perhaps owing to this region's encoding of reward value during decision-making processes that may influence response inhibition toward previously rewarding actions (Dias et al., 1997; McAlonan and Brown, 2003).

\section{DA and eCB Signaling Effects on 5-CSRTT Performance}

While both mesocorticolimbic DA and eCB signaling have been shown to affect 5-CSRTT performance, their influence on sustained attention and impulsivity may be separable. DA has been shown to play a crucial role in controlling inhibitory responding, with converging data indicating elevating synaptic DA increases impulsivity by activation of both D1 and D2 receptors (van Gaalen et al., 2006; Baarendse and Vanderschuren, 2012; Xue et al., 2018). In rodents, impulsivity has been linked to DA signaling specifically within the medial PFC and NAc 
A

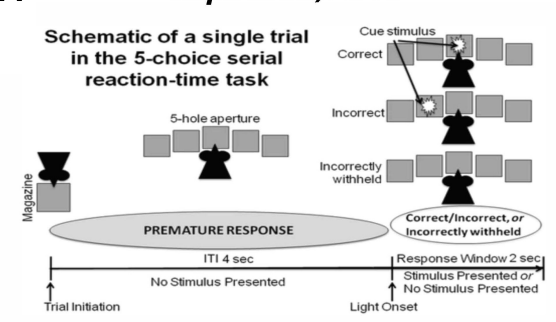

B

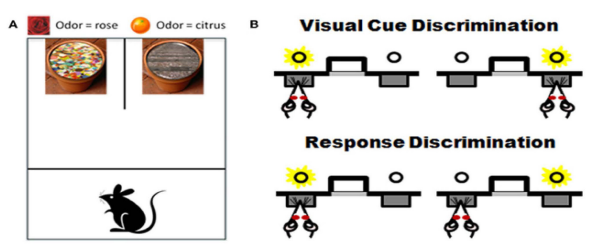

C

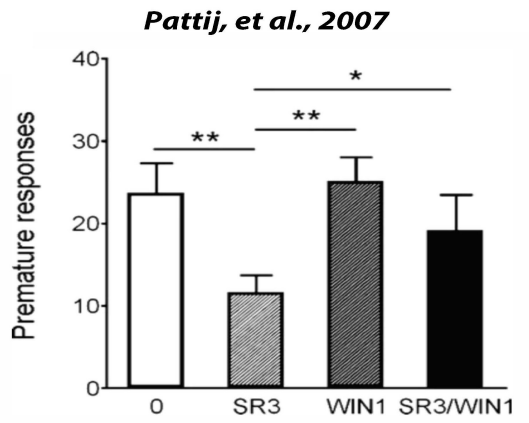

D

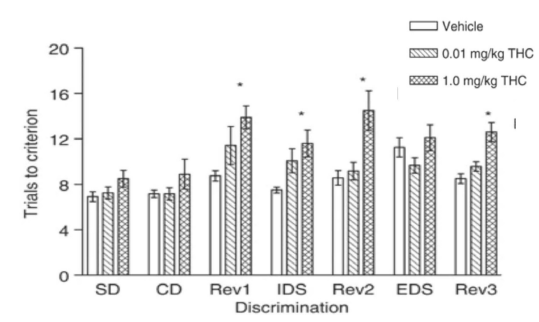

E

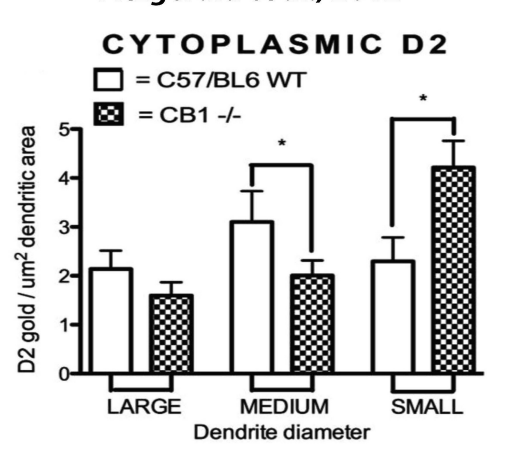

FIGURE 7 | Cannabinoids modulate attentional processes. (A) Schematic of a single trial in the 5-choice serial reaction time task (5-CSRTT). Animals are trained to perform a nose poke when one of five cue lights is presented in any (Continued)
FIGURE 7 | Continued

of the five nose-poke apertures following a fixed inter-trial interval (ITI), usually 4-6 s in length. Premature responses are tallied when made during this ITI. Responses made in one of the four nose pokes not illuminated is counted as an error of sustained attention. Reproduced from Cope et al. (2016). (B) Task schematics of two common set-shifting assessments for rodents. Panel (A) shows a schematic of the apparatus and examples of the stimuli used in the "dig" set-shifting task. Each pot has a unique odor (i.e., rose on left and citrus on right) and is filled with a unique digging medium (sequins on left, gravel on right). Only one stimulus feature is relevant to the location of a buried food reward in each phase of testing. Panel (B) shows a schematic of set-shift procedures performed in an operant version of the task. Rats are first trained to choose between two extended levers based on a light cue that is associated with one of the levers. After reaching criterion performance on that discrimination, there is an unsignaled change in rule and now the rat must ignore the light and choose levers based on their spatial location. Reproduced from Bizon et al. (2012). (C) Effect of CB1 antagonist/reverse agonist on impulsivity. Coadministration of WIN55,212-2 at $1.0 \mathrm{mg} / \mathrm{kg}$ (WIN1) prevents the effects of $3.0 \mathrm{mg} / \mathrm{kg}$ SR14716A (SR3) on inhibitory control in the 5-CSRTT. Reproduced from Pattij et al. (2007a). (D) Effect of acute THC administration on reversal learning. At $30 \mathrm{~min}$ before the start of the task, rats were administered vehicle, $0.01 \mathrm{mg} / \mathrm{kg}$ THC, or $1.0 \mathrm{mg} / \mathrm{kg} \mathrm{THC}$ and the number of trials to reach criterion performance was recorded for a series of discriminations (SD, simple discrimination; $\mathrm{CD}$, compound discrimination; Rev1,2,3, first, second, and third reversal stages; IDS, intradimensional shift; EDS, extradimensional shift). Animals in the $1 \mathrm{mg} / \mathrm{kg}$ THC treatment group exhibited marked deficits in performance at each of the reversal stages but not in the EDS stage. Reproduced from Egerton et al. (2005). (E) Altered compartmentalization of D2 immunogold stain in dendrites containing immunoperoxidase labeling for parvalbumin in the $\mathrm{PL}$ of the $\mathrm{CB} 1^{-/-}$mice. Cluster analysis reveals a significant change in compartmental distribution of D2 immunogold in parvalbumin dendrites of $\mathrm{CB} 1^{-/}-$mice. D2 immunogold density was assessed as particles of D2 immunogold/square $\mu \mathrm{m}$ dendritic area. In $\mathrm{CB} 1^{-/-}$mice relative to $\mathrm{CB} 1^{+/+}$controls, a significant $(p<0.05)$ increase in D2 immunogold was observed in small dendrites, while a decrease in D2 immunogold per $\mu \mathrm{m}$ dendritic area was observed in medium parvalbumin dendrites in $\mathrm{CB}_{1}-/-$ mice relative to controls. Reproduced from Fitzgerald et al. (2012). ${ }^{*} p<0.01 ;{ }^{* *} p \leq 0.001$.

core and shell (Cole and Robbins, 1987; Miller and Cohen, 2001; Chudasama and Robbins, 2004; Dalley et al., 2004; Economidou et al., 2012). eCB tone may also be primed to modulate impulsivity as the synthetic $\mathrm{CB} 1$ antagonist rimonabant dose-dependently decrease it in rats, an effect occluded by coadministered WIN 55 (Pattij et al., 2007a) (Figure 7C). CB1 activity likely mediates its influence on impulsivity through regulating DA signaling as the $\mathrm{CB} 1$ antagonist rimonabant dosedependently attenuates the impulsivity-inducing effects of the psychostimulants d-amphetamine and cocaine (Wiskerke et al., 2011; Hernandez et al., 2014). Additionally, THC and WIN administered twice daily across 2 weeks results in reduced DA turnover exclusively in the PFC and not in the dorsal nor ventral striatum of rats, with effects lasting up to at least 14 days postabstinence (Verrico et al., 2003). This study is interesting in light of evidence supporting that response inhibition is regulated by cortical substrates and that protracted abstinence from chronic THC administration selectively impairs response inhibition in rats (Eagle and Baunez, 2010; Irimia et al., 2015). Collectively, these data suggest that following chronic cannabinoid exposure, long-term adaptations of DA function within the PFC increase likelihood of impulsivity. 
In contrast to CB1-dependent effects on impulsivity, cannabinergic effects on more direct measures of attention in the 5-CSRTT are relatively null. Accordingly, modest impairments in sustained attention have been found to be reversed after 2 weeks abstinence following chronic THC administration in rats, with more pronounced increases in impulsivity persisting after 5 weeks of abstinence (Irimia et al., 2015). The distinction between impulsivity- and sustained attention-related effects of DA signaling have been scrutinized more than those by eCB signaling though results are conflicting. DA-dependent effects on 5-CSRTT performance differ based on pharmacological modality of altered activity (chemogenetics vs. psychostimulants), individual differences in baseline task performance between subjects and region-specificity of manipulations made within the mesocorticolimbic system. These variables notwithstanding, evidence reveals DA signaling regulates sustained attention albeit to a lesser degree than impulsivity. In general, sustained attention is enhanced following local D1 receptor agonism in the medial PFC and NAc as well as after increased neuronal activation of the VTA via selective pharmacological manipulation of modified $\mathrm{G}_{i}$-coupled muscarinic GPCRs (i.e., chemogenetics) (Granon et al., 2000; van Gaalen et al., 2006; Pattij et al., 2007b; Baarendse and Vanderschuren, 2012; Boekhoudt et al., 2017; Xue et al., 2018; Fitzpatrick et al., 2019). Yet, multiple pharmacological and biological variables must be accounted for when manipulating DA function for behavioral output in general, though perhaps more so with cognitive tasks susceptible to numerous factors. Further dissecting any dissociable effects of chemogenetics from other types of DAergic manipulations, as well differentiating region-specific effects, may prove useful to probe DA's attentional functions within the 5-CSRTT.

\section{DA and eCB Signaling Effects on ASST Performance}

The effects of both mesocorticolimbic DA and eCB signaling on ASST performance diverge by the task's separate components, with DA impacting both shifting attentional set and reversal learning and cannabinergic effects restricted to reversal learning. Converging lines of evidence suggest that D1 signaling within the medial PFC in rodents and the homologous DLPFC in primates is central to attentional set formation and shifting in the ASST (Dias et al., 1997; Ragozzino et al., 1999; Birrell and Brown, 2000; Stuss et al., 2000; Stefani et al., 2003; Tunbridge et al., 2004; Fletcher et al., 2005; Floresco et al., 2008; Nagano-Saito et al., 2008; Parsegian et al., 2011) while D2 and DAT signaling within the OFC and striatum support reversal learning, respectively (Cools et al., 2009; Izquierdo et al., 2010; Cheng and Li, 2013). Indeed, cognitive flexibility training has been shown to enhance measures of prelimbic DA and therapeutic cognitive benefits in rats (Chaby et al., 2019), while ADHD and schizophrenia patients, both strongly associated with dysregulated cortical DA function, display attentional dysfunctions particularly related to shifting attentional set similar to patients with frontal lobe damage (Pantelis et al., 1999; Luna-Rodriguez et al., 2018). In terms of OFC DA, low but not high doses of methylphenidate remediate the impairment of both attentional-set formation and reversal learning in the spontaneously hypertensive rat (SHR) model of ADHD (Cao et al., 2012), though this effect on reversal learning specifically is occluded by intra-OFC injections of the D2 antagonist haloperidol (Cheng and Li, 2013).

Insight into the cannabinergic effects on ASST, on the other hand, are far outnumbered by those of DA, though these limited studies suggest eCBs may be more important for reversal learning than shifting attentional set. Egerton et al. (2005) first demonstrated that acute THC in rats impairs reversal learning while sparing extradimensional set-shifting ability in the ASST (Figure 7D). This selective effect on reversal learning by THC has been corroborated in non-human primates in the CANTAB test (WrightJr., Vandewater et al., 2013). Reversal learning has also been shown to be impaired in rats by $\mathrm{THC}$ in an olfactory go/no-go discrimination task and by adolescent WIN exposure in the ASST (Sokolic et al., 2011; Gomes et al., 2015). Surprisingly, cannabinoid-induced deficits to ASST may violate notions of a PFC/OFC task-specific dichotomy as overexpression of $\mathrm{CB} 1$ specific to the medial PFC has been shown to selectively impair reversal learning in rats, a cognitive component of the ASST typically associated with OFC function (Klugmann et al., 2011). Also surprising is a recent finding that intra-PFC injection of cannabidiol (CBD), but not similarly administered THC, impairs shifting of attentional set in rats (Szkudlarek et al., 2019). While its pharmacodynamic profile is complicated, it is worth noting that $\mathrm{CBD}$ functions as a negative allosteric modulator at CB1 (Laprairie et al., 2015).

Finally, several studies using rats prenatally treated with methylazoxymethanol acetate (MAM) as a developmental model of schizophrenia suggest persistent psychotomimetic effects related to mesocortical neuroadaptations may result from aberrant eCB signaling during adolescence (Renard et al., 2017). Both MAM and pubertal WIN have been shown to impair reversal learning in the ASST, as well as enhance mobility effects of d-amphetamine administration and an increased number of spontaneously active VTA DA neurons (Gomes et al., 2015). Somewhat remarkably, cannabinoid effects on MAM treatment are suggested to be transgenerational as adolescent WIN exposure also increases VTA DA population activity, decreased burst firing and sensitization to d-amphetamine locomotor responses in Figure 2 generation MAM-treated rats (Aguilar et al., 2018).

These results bring into question both the locus of reversal learning and the neural mechanisms underlining its impairment by cannabinoids. Also important are considerations of dissimilarities between DA manipulations and ASST models, since like most laboratory-controlled behaviors, performance variations may be attributed to different protocols. This is underlined by cannabinoid administration having been suggested to impact visual discrimination in general, which may broadly affect performance in operant chamber-based ASST paradigms (Arguello and Jentsch, 2004; Hill et al., 2006). Future research of reversal learning following cannabinoid exposure and manipulation should take such details into account. 


\section{Comparable Studies Targeting Separate Signaling Systems May Benefit Analysis of DA/eCB Interaction and Attentional Dysfunction}

To assist in clarifying DA/eCB interactions and their effects on attention, a few effective approaches may be noted. Behavioral effects of DA/eCB interactions have been demonstrated combining targeted pharmacological manipulations with measures of negative affect, showing anxiolytic effects of CB1 activation in the amygdala is D1 and D2 dependent (Zarrindast et al., 2011). Additional work with conditional knock-out mice with CB1 expression constitutively removed from D1-expressing neurons revealed CB1/D1 interactions modify negative affect as well (Terzian et al., 2011). Another comparative pharmacology study reported acute cannabis decreases while cocaine increases reversal learning performance in human subjects (Spronk et al., 2016). Interestingly, recent data combining chemical lesions of the medial forebrain bundle and single-unit electrophysiological recordings suggests the hypoDAergic states associated with many neuropsychiatric disorders affecting attention may themselves cause impairments in CB1 functional modulation of both sensorimotor and executive networks (Antonazzo et al., 2020). This novel conception expands the operative role for DA as not only a modulator of glutamate and GABA transmission, but also as a newfound gatekeeper of CB1's own robust modulation of transmission in substrates important for attentional and behavioral control. Future studies in the causality of CB1 functional modification within DA-affected pathologies and related changes to attentional processes are certainly warranted.

Finally, DA/eCB interactions may also be investigated at the level of GABAergic interneurons. Many of the previously described alterations to mesocorticolimbic functional dynamics may involve FSI that are either directly targeted by eCBs or are ultimately subject to eCB-dependent adaptations, with attentional processing being impacted by both. In the PFC, parvalbumin expressing FSIs critically gate pyramidal activity and are sensitive to DA signaling. Furthermore, levels of dendritic D2 expression in PFC parvalbumin cells have been demonstrated to be regulated by CB1 signaling (Fitzgerald et al., 2012) (Figure 7E). CB1-expressing FSIs in the striatum are also associated with cognitive functions, strongly associated with impulsive behavior and most recently suggested to gate attention toward reward-predicting visual features (Caprioli et al., 2014; Wright et al., 2017; Pisansky et al., 2019; Boroujeni et al., 2020). As eCB-sensitive FSIs in both cortical and striatal regions hold strong potential as a nexus for DA/eCB overlap, studies investigating their role in cannabinoid-modulated attentional processes may clarify much detail lacking in the field.

\section{CONCLUSION}

\section{Summary of Conclusion}

In this review, we describe recent scientific studies suggesting cannabinoids modulate transient DA release events in a manner that may influence motivational and attentional processes alike.
While we've acknowledged that DA/eCB interactions still need to be better investigated across multiple overlapping neural circuits, we would like to close by further considering the intertwined relationship between DA transients, motivation and attention. And finally, we offer some speculation into the clinical implications these findings may offer the treatment of neurobehavioral symptoms in psychiatric medicine.

\section{Complex Interactions Complicate the Relationship Between DA and the Neural Circuitry of Motivation and Attention}

Transient DA release events, the neural substrates of motivation, and the neural substrates of attention interact within a tangled thicket of intertwined circuits-the nodes of which likely influence each other and can be differentially modulated by eCBs at multiple levels. First, it is important to recognize that activation of either subcortical nodes of pre-attentive visual processing (e.g., the superior colliculus) or cortical nodes of attentional visual processing (e.g., V1) are sufficient to evoke transient DA release events in the striatum of the basal ganglia (Redgrave et al., 2008, 2016; Takakuwa et al., 2017, 2018). Thus, it becomes difficult to definitively know whether a striatal DA transient truly reflects the value of a desired outcome within a motivational context (as was the general assumption of this review), is the result of an animal responding to a pre-attentive visual stimulus or is the result of an animal giving a visual stimulus attentional consideration. Furthermore, it is becoming abundantly clear that DA transient release events are accompanied by the corelease of additional neurotransmitters (e.g., GABA, glutamate) from the same DA neuron, which may profoundly impact the post-synaptic effects of DA (Tritsch et al., 2016; Morales and Margolis, 2017). In addition, a wide array of discrete neural circuits converge on midbrain DA neurons and their striatalterminals within the basal ganglia (Morales and Margolis, 2017). It is likely that these discrete circuits can be differentially modulated by eCBs to influence neural input onto DA neurons, the generation of action potentials within DA neurons, and/or the concentrations of neurotransmitter released from the terminals of DA neurons. Following this multifaceted level of modulation, the transient DA release events are then integrated with other neural signals encoding various functions of motivation and attention within nuclei of the basal ganglia to ultimately influence the generation of behavioral action (Den Ouden et al., 2012). Difficulty in dissociating such neural representations has been considered before and ascribed to confounding neural signals of reward expectancy and attentional allocation (Maunsell, 2004). Indeed, DA value signals and motivational states are commonly recognized variables that capably modulate shifts in attention (Engelmann and Pessoa, 2007; Mohanty et al., 2008; Sali et al., 2014; Bourgeois et al., 2016; Anderson, 2019). And, at the level of behavioral output, common measures of both motivation and attention are highly DA-sensitive. This makes dissociating DA's contribution to their different components somewhat difficult as most experimental assessments of attention are dependent on the subject's motivation. Take, for example, individual differences in DA function and their effect on cognitive 
measures demanding attention in a clinical setting. Healthy individuals with relatively lower DA synthesis capacity have been found to exert relatively low cognitive effort, while increasing their DA levels with methylphenidate and the D2 antagonist sulpiride has been reported to enhance their reward perception and motivation for cognitive engagement (Westbrook et al., 2020). This observation of a low DA-low effort relationship may be applied to preclinical settings and aligns with a study in mice reporting that chemogenetic inhibition of VTA DA neurons decreased motivated responding in a 5-CSRTT but not measures of attentional processing per se-suggesting an apparent dissociation (Fitzpatrick et al., 2019). However, it has also been reported that increasing DA levels through chemogenetic excitation of the VTA, using selective activation of modified $\mathrm{G}_{q}$-coupled muscarinic GPCRs, impairs sustained attention in the 5-CSRTT (Boekhoudt et al., 2017). While separate types of neural DA manipulations were utilized between these studies (cf. inhibitory $\mathrm{G}_{i}$ vs. excitatory $\mathrm{G}_{q}$ DREADDs), the seeming contradiction may indicate the difficulty in separating the components of motivation and attention by performing DA manipulations in operant tasks.

\section{Clinical Implications and Considerations}

The interrelated nature of motivation and attention may be an asset to research as much as a liability, and cannabinoid modulation of either may underline therapeutic targets for both constructs. In the clinical context, $\mathrm{DA} / \mathrm{eCB}$ interactions may play a specialized role in ADHD patients to impact both motivation and attention. Impaired activity in both motivational and attentional networks typical in ADHD patients are stabilized by pharmacologically increasing brain DA concentration; furthermore, while cannabinoids generally negatively affect measures of impulsivity and attention, they uniquely enhance them in ADHD patients (Rubia et al., 2009; Cooper et al., 2017). Commonalities between motivation and attention in the preclinical setting may be found in the 5CSRTT and impulsivity's translatability to compulsive behavior, as cannabinergic regulation of this particular trait may be applied to constructs other than attentional dysfunction. For example, modulation of impulsivity through CB1 antagonism has been correlated with decreases in both alcohol and nicotine intake in rats, offering potential for therapies targeting $\mathrm{eCB}$ tone in addiction-related disorders (De Bruin et al., 2011). DA’s role in

\section{REFERENCES}

Adams, C. D., and Dickinson, A. (1981). Instrumental responding following reinforcer devaluation. Q. J. Exper. Psychol. Sec. B 33, 109-121. doi: 10.1080/ 14640748108400816

Aguilar, D. D., Giuffrida, A., and Lodge, D. J. (2018). Adolescent synthetic cannabinoid exposure produces enduring changes in dopamine neuron activity in a rodent model of schizophrenia susceptibility. Int. J. Neuropsychopharmacol. 21, 393-403. doi: 10.1093/ijnp/pyy003

Alger, B. E., and Kim, J. (2011). Supply and demand for endocannabinoids. Trends Neurosci. 34, 304-315. doi: 10.1016/j.tins.2011.03.003

Amar, M. B. (2006). Cannabinoids in medicine: a review of their therapeutic potential. J. Ethnopharmacol. 105, 1-25. doi: 10.1016/j.jep.2006.02.001 this broadly applicable trait is also noted. In humans, decreased $\mathrm{D} 2 / \mathrm{D} 3$ binding and increased d-amphetamine-induced striatal DA release has been correlated with high levels of trait impulsivity and drug cravings (Buckholtz et al., 2010). Strongly modulated by both DA and eCBs, FSIs in the NAc are one candidate as a mediator of impulsive behavior through $\mathrm{DA} / \mathrm{eCB}$ interaction, directly gating medium spiny neuron activity to regulate tracking of reward-predicting cues and inhibit premature responding (Caprioli et al., 2014; Wright et al., 2017; Pisansky et al., 2019; Boroujeni et al., 2020).

Generalizing this example of impulsivity to other behavioral components linked by motivation and attention, it is possible to conceive of various constructs impacted by both, and in turn, their susceptibility to eCB-modulated DA function. In this sense, interrogation of $\mathrm{DA} / \mathrm{eCB}$ interactions within substrates known to modulate either motivation or attention might share explanatory potential across translatable constructs, particularly substance use disorders. Such studies may assess cannabinoidinduced changes to motivational and attentional processes through modifications of DA-mediated reward value signals, which have been shown to influence both types of measures. Yet, for clear dissociations between each measure, it will be important to characterize the separate neural representations contributing to their respective behavioral outputs. It is also important to note that while distinct measures of motivation and attention have been studied under conditions of cannabinoid exposure, there remains much to be learned about how these measures overlap within the context of $\mathrm{DA} / \mathrm{eCB}$ interactions.

\section{AUTHOR CONTRIBUTIONS}

EO and DG conceptualized this review and equally shared in the majority of the writing. LH performed a secondary writing contribution that was lesser, but significant. All authors contributed to the article and approved the submitted version.

\section{FUNDING}

Funding for this work was provided by NSF grant IOS-1557755, NIH grant R03DA038734, Boettcher Young Investigator Award, and NARSAD Young Investigator Award to EO.

Anderson, B. A. (2019). Neurobiology of value-driven attention. Curr. Opin. Psychol. 29, 27-33. doi: 10.1016/j.copsyc.2018.11.004

Andre, C. M., Hausman, J.-F., and Guerriero, G. (2016). Cannabis sativa: the plant of the thousand and one molecules. Front. Plant Sci. 7:19. doi: 10.3389/fpls.2016. 00019-

Antonazzo, M., Gomez-Urquijo, S. M., Ugedo, L., and Morera-Herreras, T. (2020). Dopaminergic denervation impairs cortical motor and associative/limbic information processing through the basal ganglia and its modulation by the CB1 receptor. Neurobiol. Dis. 148:105214. doi: 10.1016/j.nbd.2020.10 5214

Arguello, P. A., and Jentsch, J. D. (2004). Cannabinoid CB1 receptor-mediated impairment of visuospatial attention in the rat. Psychopharmacology 177, 141150. doi: $10.1007 / \mathrm{s} 00213-004-1953-0$ 
Asplund, C. L., Todd, J. J., Snyder, A. P., and Marois, R. (2010). A central role for the lateral prefrontal cortex in goal-directed and stimulus-driven attention. Nat. Neurosci. 13, 507-512. doi: 10.1038/nn.2509

Assad, J. A. (2003). Neural coding of behavioral relevance in parietal cortex. Curr. Opin. Neurobiol. 13, 194-197. doi: 10.1016/s0959-4388(03)00045-x

Baarendse, P. J., and Vanderschuren, L. J. (2012). Dissociable effects of monoamine reuptake inhibitors on distinct forms of impulsive behavior in rats. Psychopharmacology 219, 313-326. doi: 10.1007/s00213-011-2576-x

Baddeley, A. (1986). "Working memory. Oxford: Oxford University Press/Clarendon Press.

Baddeley, A. D., Baddeley, H., Bucks, R., and Wilcock, G. (2001). Attentional control in Alzheimer's disease. Brain 124, 1492-1508.

Barceló, F., and Knight, R. T. (2002). Both random and perseverative errors underlie WCST deficits in prefrontal patients. Neuropsychologia 40, 349-356. doi: 10.1016/s0028-3932(01)00110-5

Beaulieu, J.-M., and Gainetdinov, R. R. (2011). The physiology, signaling, and pharmacology of dopamine receptors. Pharmacol. Rev. 63, 182-217. doi: 10. $1124 /$ pr.110.002642

Beazely, M. A., Tong, A., Wei, W. L., Van Tol, H., Sidhu, B., and Macdonald, J. F. (2006). D2-class dopamine receptor inhibition of NMDA currents in prefrontal cortical neurons is platelet-derived growth factor receptordependent. J. Neurochem. 98, 1657-1663. doi: 10.1111/j.1471-4159.2006.04 064.x

Bello, E. P., Mateo, Y., Gelman, D. M., Noaín, D., Shin, J. H., Low, M. J., et al. (2011). Cocaine supersensitivity and enhanced motivation for reward in mice lacking dopamine D 2 autoreceptors. Nat. Neurosci. 14:1033. doi: 10.1038/nn.2862

Berg, E. A. (1948). A simple objective technique for measuring flexibility in thinking. J. Gen. Psychol. 39, 15-22. doi: 10.1080/00221309.1948.9918159

Birrell, J. M., and Brown, V. J. (2000). Medial frontal cortex mediates perceptual attentional set shifting in the rat. J. Neurosci. 20, 4320-4324. doi: 10.1523/ jneurosci.20-11-04320.2000

Bissonette, G. B., Martins, G. J., Franz, T. M., Harper, E. S., Schoenbaum, G., and Powell, E. M. (2008). Double dissociation of the effects of medial and orbital prefrontal cortical lesions on attentional and affective shifts in mice. J. Neurosci. 28, 11124-11130. doi: 10.1523/jneurosci.2820-08.2008

Bizon, J. L., Foster, T. C., Alexander, G. E., and Glisky, E. L. (2012). Characterizing cognitive aging of working memory and executive function in animal models. Front. Aging Neurosci. 4:19.

Black, N., Stockings, E., Campbell, G., Tran, L. T., Zagic, D., Hall, W. D., et al. (2019). Cannabinoids for the treatment of mental disorders and symptoms of mental disorders: a systematic review and meta-analysis. Lancet Psychiatry 6, 995-1010. doi: 10.1016/s2215-0366(19)30401-8

Boekhoudt, L., Voets, E. S., Flores-Dourojeanni, J. P., Luijendijk, M. C., Vanderschuren, L. J., and Adan, R. A. (2017). Chemogenetic activation of midbrain dopamine neurons affects attention, but not impulsivity, in the five-choice serial reaction time task in rats. Neuropsychopharmacology 42, 1315-1325. doi: 10.1038/npp.2016.235

Bornstein, A. M., and Daw, N. D. (2011). Multiplicity of control in the basal ganglia: computational roles of striatal subregions. Curr. Opin. Neurobiol. 21, 374-380. doi: 10.1016/j.conb.2011.02.009

Boroujeni, K. B., Oemisch, M., Hassani, S. A., and Womelsdorf, T. (2020). Fast spiking interneuron activity in primate striatum tracks learning of attention cues. Proc. Natl. Acad. Sci. 117, 18049-18058. doi: 10.1073/pnas.2001348117

Bossong, M. G., Mehta, M. A., Van Berckel, B. N., Howes, O. D., Kahn, R. S., and Stokes, P. R. (2015). Further human evidence for striatal dopamine release induced by administration of 9-tetrahydrocannabinol (THC): selectivity to limbic striatum. Psychopharmacology 232, 2723-2729. doi: 10.1007/s00213015-3915-0

Bossong, M. G., Van Berckel, B. N., Boellaard, R., Zuurman, L., Schuit, R. C., Windhorst, A. D., et al. (2009). $\Delta$ 9-tetrahydrocannabinol induces dopamine release in the human striatum. Neuropsychopharmacology 34:759. doi: 10.1038/ npp. 2008.138

Bourgeois, A., Chelazzi, L., and Vuilleumier, P. (2016). How motivation and reward learning modulate selective attention. Prog. Brain Res. 229, 325-342. doi: 10.1016/bs.pbr.2016.06.004

Brady, A. M., and O'Donnell, P. (2004). Dopaminergic modulation of prefrontal cortical input to nucleus accumbens neurons in vivo. J. Neurosci. 24, 1040-1049. doi: 10.1523/jneurosci.4178-03.2004
Breivogel, C. S., Sim, L. J., and Childers, S. R. (1997). Regional differences in cannabinoid receptor/G-protein coupling in rat brain. J. Pharmacol. Exper. Ther. 282, 1632-1642.

Breton, J. M., Charbit, A. R., Snyder, B. J., Fong, P. T., Dias, E. V., Himmels, P., et al. (2019). Relative contributions and mapping of ventral tegmental area dopamine and GABA neurons by projection target in the rat. J. Comp. Neurol. 527, 916-941. doi: $10.1002 / \mathrm{cne} .24572$

Broadbent, D. E., and Gregory, M. (1963). Division of attention and the decision theory of signal detection. Proc. R. Soc. Lond. B Biol. Sci. 158, 222-231. doi: 10.1098/rspb.1963.0044

Buchta, W. C., Mahler, S. V., Harlan, B., Aston-Jones, G. S., and Riegel, A. C. (2017). Dopamine terminals from the ventral tegmental area gate intrinsic inhibition in the prefrontal cortex. Physiol. Rep. 5:e13198. doi: 10.14814/phy2.13198

Buckholtz, J. W., Treadway, M. T., Cowan, R. L., Woodward, N. D., Li, R., Ansari, M. S., et al. (2010). Dopaminergic network differences in human impulsivity. Science 329, 532-532. doi: 10.1126/science. 1185778

Budygin, E. A., Oleson, E. B., Lee, Y. B., Blume, L. C., Bruno, M. J., Howlett, A. C., et al. (2017). Acute depletion of D2 receptors from the rat substantia nigra alters dopamine kinetics in the dorsal striatum and drug responsivity. Front. Behav. Neurosci. 10:248. doi: 10.3389/fnbeh.2016.00248

Burgess, G. C., Depue, B. E., Ruzic, L., Willcutt, E. G., Du, Y. P., and Banich, M. T. (2010). Attentional control activation relates to working memory in attention-deficit/hyperactivity disorder. Biol. Psychiatry 67, 632-640. doi: 10. 1016/j.biopsych.2009.10.036

Byers, A., and Serences, J. T. (2014). Enhanced attentional gain as a mechanism for generalized perceptual learning in human visual cortex. J. Neurophysiol. 112, 1217-1227. doi: 10.1152/jn.00353.2014

Cachope, R., Mateo, Y., Mathur, B. N., Irving, J., Wang, H.-L., Morales, M., et al. (2012). Selective activation of cholinergic interneurons enhances accumbal phasic dopamine release: setting the tone for reward processing. Cell Rep. 2, 33-41. doi: 10.1016/j.celrep.2012.05.011

Cadoni, C., Valentini, V., and Di Chiara, G. (2008). Behavioral sensitization to $\Delta 9$-tetrahydrocannabinol and cross-sensitization with morphine: differential changes in accumbal shell and core dopamine transmission. J. Neurochem. 106, 1586-1593. doi: 10.1111/j.1471-4159.2008.05503.x

Cao, A.-H., Yu, L., Wang, Y.-W., Wang, J.-M., Yang, L.-J., and Lei, G.-F. (2012). Effects of methylphenidate on attentional set-shifting in a genetic model of attention-deficit/hyperactivity disorder. Behav. Brain Funct. 8:10. doi: 10.1186/ 1744-9081-8-10

Caprioli, D., Sawiak, S. J., Merlo, E., Theobald, D. E., Spoelder, M., Jupp, B., et al. (2014). Gamma aminobutyric acidergic and neuronal structural markers in the nucleus accumbens core underlie trait-like impulsive behavior. Biol. Psychiatry 75, 115-123. doi: 10.1016/j.biopsych.2013.07.013

Carli, M., Robbins, T., Evenden, J., and Everitt, B. (1983). Effects of lesions to ascending noradrenergic neurones on performance of a 5-choice serial reaction task in rats; implications for theories of dorsal noradrenergic bundle function based on selective attention and arousal. Behav. Brain Res. 9, 361-380. doi: 10.1016/0166-4328(83)90138-9

Casajuana Kögel, C., López-Pelayo, H., Balcells-Olivero, M. M., Colom, J., and Gual, A. (2018). Psychoactive constituents of cannabis and their clinical implications: a systematic review. Adicciones 30, 140-151.

Castillo, P. E., Younts, T. J., Chávez, A. E., and Hashimotodani, Y. (2012). Endocannabinoid signaling and synaptic function. Neuron 76, 70-81. doi: 10.1016/j.neuron.2012.09.020

Chaby, L. E., Karavidha, K., Lisieski, M. J., Perrine, S. A., and Liberzon, I. (2019). Cognitive flexibility training improves extinction retention memory and enhances cortical dopamine with and without traumatic stress exposure. Front. Behav. Neurosci. 13:24. doi: 10.3389/fnbeh.2019.00024

Chen, J., Marmur, R., Pulles, A., Paredes, W., and Gardner, E. L. (1993). Ventral tegmental microinjection of $\Delta 9$-tetrahydrocannabinol enhances ventral tegmental somatodendritic dopamine levels but not forebrain dopamine levels: evidence for local neural action by marijuana’s psychoactive ingredient. Brain Res. 621, 65-70. doi: 10.1016/0006-8993(93)90298-2

Chen, J., Paredes, W., Li, J., Smith, D., Lowinson, J., and Gardner, E. L. (1990). $\Delta$ 9-tetrahydrocannabinol produces naloxone-blockable enhancement of presynaptic basal dopamine efflux in nucleus accumbens of conscious, freelymoving rats as measured by intracerebral microdialysis. Psychopharmacology 102, 156-162. doi: 10.1007/bf02245916 
Cheng, J.-T., and Li, J.-S. (2013). Intra-orbitofrontal cortex injection of haloperidol removes the beneficial effect of methylphenidate on reversal learning of spontaneously hypertensive rats in an attentional set-shifting task. Behav. Brain Res. 239, 148-154. doi: 10.1016/j.bbr.2012.11.006

Cho, A. K. (1990). Ice: a new dosage form of an old drug. Science 249, 631-634. doi: 10.1126/science.249.4969.631

Chudasama, Y., and Robbins, T. W. (2004). Dopaminergic modulation of visual attention and working memory in the rodent prefrontal cortex. Neuropsychopharmacology 29, 1628-1636. doi: 10.1038/sj.npp.1300490

Chun, M. M., Golomb, J. D., and Turk-Browne, N. B. (2011). A taxonomy of external and internal attention. Ann. Rev. Psychol. 62, 73-101. doi: 10.1146/ annurev.psych.093008.100427

Cohen, R. A., Sparling-Cohen, Y. A., and O'donnell, B. F. (1993). The neuropsychology of attention. Cham: Springer.

Cole, B., and Robbins, T. (1987). Amphetamine impairs the discriminative performance of rats with dorsal noradrenergic bundle lesions on a 5-choice serial reaction time task: new evidence for central dopaminergic-noradrenergic interactions. Psychopharmacology 91, 458-466. doi: 10.1007/bf00216011

Cools, R., Frank, M. J., Gibbs, S. E., Miyakawa, A., Jagust, W., and D’esposito, M. (2009). Striatal dopamine predicts outcome-specific reversal learning and its sensitivity to dopaminergic drug administration. J. Neurosci. 29, 1538-1543. doi: 10.1523/jneurosci.4467-08.2009

Cooper, R. E., Williams, E., Seegobin, S., Tye, C., Kuntsi, J., and Asherson, P. (2017). Cannabinoids in attention-deficit/hyperactivity disorder: a randomisedcontrolled trial. Eur. Neuropsychopharmacol. 27, 795-808. doi: 10.1016/j. euroneuro.2017.05.005

Cope, Z. A, Halberstadt, A. L., van Enkhuizen, J., Flynn, A. D., Breier, M., Swerdlow, N. R., et al. (2016). Premature responses in the five-choice serial reaction time task reflect rodents' temporal strategies: evidence from no-light and pharmacological challenges. Psychopharmacology 233, 3513-3525.

Corbetta, M., Kincade, M. J., Lewis, C., Snyder, A. Z., and Sapir, A. (2005). Neural basis and recovery of spatial attention deficits in spatial neglect. Nat. Neurosci. 8, 1603-1610. doi: 10.1038/nn1574

Covey, D. P., Mateo, Y., Sulzer, D., Cheer, J. F., and Lovinger, D. M. (2017). Endocannabinoid modulation of dopamine neurotransmission. Neuropharmacology 124, 52-61. doi: 10.1016/j.neuropharm.2017.04.033

Cowan, N. (1993). Activation, attention, and short-term memory. Mem. Cogn. 21, 162-167. doi: 10.3758/bf03202728

Cristino, L., Bisogno, T., and Di Marzo, V. (2020). Cannabinoids and the expanded endocannabinoid system in neurological disorders. Nat. Rev. Neurol. 16, 9-29. doi: 10.1038/s41582-019-0284-z

Dalley, J. W., Cardinal, R. N., and Robbins, T. W. (2004). Prefrontal executive and cognitive functions in rodents: neural and neurochemical substrates. Neurosci. Biobehav. Rev. 28, 771-784. doi: 10.1016/j.neubiorev.2004.09.006

D’Ambra, T. E., Estep, K. G., Bell, M. R., Eissenstat, M. A., Josef, K. A., Ward, S. J., et al. (1992). Conformationally restrained analogs of pravadoline: nanomolar potent, enantioselective,(aminoalkyl) indole agonists of the cannabinoid receptor. J. Med. Chem. 35, 124-135. doi: 10.1021/jm00079a016

Dang, L. C., O'neil, J. P., and Jagust, W. J. (2012). Dopamine supports coupling of attention-related networks. J. Neurosci. 32, 9582-9587. doi: 10.1523/jneurosci. 0909- 12.2012

Day, J. J., Roitman, M. F., Wightman, R. M., and Carelli, R. M. (2007). Associative learning mediates dynamic shifts in dopamine signaling in the nucleus accumbens. Nat. Neurosci. 10, 1020-1028. doi: 10.1038/nn1923

De Bruin, N., Lange, J., Kruse, C., Herremans, A., Schoffelmeer, A., Van Drimmelen, M., et al. (2011). SLV330, a cannabinoid CB1 receptor antagonist, attenuates ethanol and nicotine seeking and improves inhibitory response control in rats. Behav. Brain Res. 217, 408-415. doi: 10.1016/j.bbr.2010.11.013

Den Ouden, H. E., Kok, P., and De Lange, F. P. (2012). How prediction errors shape perception, attention, and motivation. Front. Psychol. 3:548. doi: 10.3389/fpsyg. 2012.00548

Derryberry, D., and Reed, M. A. (2002). Anxiety-related attentional biases and their regulation by attentional control. J. Abnormal Psychol. 111:225. doi: 10.1037/ 0021-843x.111.2.225

DeRusso, A., Fan, D., Gupta, J., Shelest, O., Costa, R. M., and Yin, H. H. (2010). Instrumental uncertainty as a determinant of behavior under interval schedules of reinforcement. Front. Integ. Neurosci. 4:17. doi: 10.3389/fnint.2010. 00017
Devane, W. A., Hanus, L., Breuer, A., Pertwee, R. G., Stevenson, L. A., Griffin, G., et al. (1992). Isolation and structure of a brain constituent that binds to the cannabinoid receptor. Science 258, 1946-1949. doi: 10.1126/science.1470919

Dews, P. (1978). Studies on responding under fixed-interval schedules of reinforcement: II. The scalloped pattern of the cumulative record. J. Exper. Anal. Behav. 29, 67-75. doi: 10.1901/jeab.1978.29-67

Dews, P. B. (1955). Studies on behavior. I. Differential sensitivity to pentobarbital of pecking performance in pigeons depending on the schedule of reward. J. Pharmacol. Exper. Ther. 113, 393-401.

Dews, P. B. (1958). Studies on behavior. IV. Stimulant actions of methamphetamine. J. Pharmacol. Exper. Ther. 122, 137-147.

Di Chiara, G., Bassareo, V., Fenu, S., De Luca, M. A., Spina, L., Cadoni, C., et al. (2004). Dopamine and drug addiction: the nucleus accumbens shell connection. Neuropharmacology 47, 227-241. doi: 10.1016/j.neuropharm.2004.06.032

Diana, M., Melis, M., and Gessa, G. (1998). Increase in meso-prefrontal dopaminergic activity after stimulation of CB1 receptors by cannabinoids. Eur. J. Neurosci. 10, 2825-2830. doi: 10.1111/j.1460-9568.1998.00292.x

Dias, R., Robbins, T. W., and Roberts, A. C. (1996). Dissociation in prefrontal cortex of affective and attentional shifts. Nature 380, 69-72. doi: 10.1038/ $380069 \mathrm{a} 0$

Dias, R., Robbins, T., and Roberts, A. C. (1997). Dissociable forms of inhibitory control within prefrontal cortex with an analog of the Wisconsin Card Sort Test: restriction to novel situations and independence from "on-line" processing. J. Neurosci. 17, 9285-9297. doi: 10.1523/jneurosci.17-23-09285.1997

Dickinson, A., and Balleine, B. (1994). Motivational control of goal-directed action. Anim. Learn. Behav. 22, 1-18. doi: 10.3758/bf03199951

Draycott, B., Loureiro, M., Ahmad, T., Tan, H., Zunder, J., and Laviolette, S. R. (2014). Cannabinoid transmission in the prefrontal cortex bi-phasically controls emotional memory formation via functional interactions with the ventral tegmental area. J. Neurosci. 34, 13096-13109. doi: 10.1523/jneurosci. 1297-14.2014

Dreyer, J. K., Herrik, K. F., Berg, R. W., and Hounsgaard, J. D. (2010). Influence of phasic and tonic dopamine release on receptor activation. J. Neurosci. 30, 14273-14283. doi: 10.1523/jneurosci.1894-10.2010

Dukas, R., and Kamil, A. C. (2000). The cost of limited attention in blue jays. Behav. Ecol. 11, 502-506. doi: 10.1093/beheco/11.5.502

Durstewitz, D., Seamans, J. K., and Sejnowski, T. J. (2000). Dopamine-mediated stabilization of delay-period activity in a network model of prefrontal cortex. J. Neurophysiol. 83, 1733-1750. doi: 10.1152/jn.2000.83.3.1733

Eagle, D. M., and Baunez, C. (2010). Is there an inhibitory-response-control system in the rat? Evidence from anatomical and pharmacological studies of behavioral inhibition. Neurosci. Biobehav. Rev. 34, 50-72. doi: 10.1016/j.neubiorev.2009. 07.003

Economidou, D., Theobald, D. E., Robbins, T. W., Everitt, B. J., and Dalley, J. W. (2012). Norepinephrine and dopamine modulate impulsivity on the five-choice serial reaction time task through opponent actions in the shell and core subregions of the nucleus accumbens. Neuropsychopharmacology 37, 2057-2066. doi: $10.1038 /$ npp. 2012.53

Egerton, A., Brett, R. R., and Pratt, J. A. (2005). Acute $\Delta$ 9-Tetrahydrocannabinolinduced deficits in reversal learning: neural correlates of affective inflexibility. Neuropsychopharmacology 30, 1895-1905. doi: 10.1038/sj.npp.1300715

Endler, J. A. (1992). Signals, signal conditions, and the direction of evolution. Am. Nat. 139, S125-S153.

Engelmann, J. B., and Pessoa, L. (2007). Motivation sharpens exogenous spatial attention. Emotion 7:668. doi: 10.1037/1528-3542.7.3.668

Everett, T. J., Gomez, D. M., Hamilton, L. R., and Oleson, E. B. (2020). Endocannabinoid modulation of dopamine release during reward seeking, interval timing, and avoidance. Prog. Neuropsychopharmacol. Biol. Psychiatry 104:110031. doi: 10.1016/j.pnpbp.2020.110031

Fadda, P., Scherma, M., Spano, M. S., Salis, P., Melis, V., Fattore, L., et al. (2006). Cannabinoid self-administration increases dopamine release in the nucleus accumbens. Neuroreport 17, 1629-1632. doi: 10.1097/01.wnr.0000236853. $40221.8 \mathrm{e}$

Fajkowska, M., and Derryberry, D. (2010). Psychometric properties of attentional control scale: the preliminary study on a Polish sample. Polish Psychol. Bull. 41, 1-7. doi: 10.2478/s10059-010-0001-7

Falk, J. L. (1971). The nature and determinants of adjunctive behavior. Physiol. Behav. 6, 577-588. doi: 10.1016/0031-9384(71)90209-5 
Falk, J. L. (1977). The origin and functions of adjunctive behavior. Anim. Learn. Behav. 5, 325-335. doi: 10.3758/bf03209574

Fan, J., Mccandliss, B. D., Sommer, T., Raz, A., and Posner, M. I. (2002). Testing the efficiency and independence of attentional networks. J. Cogn. Neurosci. 14, 340-347. doi: 10.1162/089892902317361886

Feja, M., Leigh, M. P., Baindur, A. N., Mcgraw, J. J., Wakabayashi, K. T., Cravatt, B. F., et al. (2020). The novel MAGL inhibitor MJN110 enhances responding to reward-predictive incentive cues by activation of CB1 receptors. Neuropharmacology 162:107814. doi: 10.1016/j.neuropharm.2019.107814

Ferland, J.-M. N., and Hurd, Y. L. (2020). Deconstructing the neurobiology of cannabis use disorder. Nat. Neurosci. 23, 600-610. doi: 10.1038/s41593-0200611-0

Ferster, C. B., and Skinner, B. F. (1957). Schedules of reinforcement. AppletonCentury-Crofts.

Fiebelkorn, I. C., Pinsk, M. A., and Kastner, S. (2018). A dynamic interplay within the frontoparietal network underlies rhythmic spatial attention. Neuron 99 , 842-853. doi: 10.1016/j.neuron.2018.07.038

Fitzgerald, M. L., Chan, J., Mackie, K., Lupica, C. R., and Pickel, V. M. (2012). Altered dendritic distribution of dopamine D2 receptors and reduction in mitochondrial number in parvalbumin-containing interneurons in the medial prefrontal cortex of cannabinoid-1 (CB1) receptor knockout mice. J. Comp. Neurol. 520, 4013-4031. doi: 10.1002/cne.23141

Fitzgerald, M. L., Mackie, K., and Pickel, V. M. (2019). Ultrastructural localization of cannabinoid $\mathrm{CB} 1$ and mGluR5 receptors in the prefrontal cortex and amygdala. J. Comp. Neurol. 527, 2730-2741. doi: 10.1002/cne. 24704

Fitzpatrick, C. M., Runegaard, A. H., Christiansen, S. H., Hansen, N. W., Jørgensen, S. H., Mcgirr, J. C., et al. (2019). Differential effects of chemogenetic inhibition of dopamine and norepinephrine neurons in the mouse 5-choice serial reaction time task. Prog. Neuro-Psychopharmacol. Biol. Psychiatry 90, 264-276. doi: 10.1016/j.pnpbp.2018.12.004

Fletcher, P. J., Tenn, C. C., Rizos, Z., Lovic, V., and Kapur, S. (2005). Sensitization to amphetamine, but not PCP, impairs attentional set shifting: reversal by a D 1 receptor agonist injected into the medial prefrontal cortex. Psychopharmacology 183:190. doi: 10.1007/s00213-005-0157-6

Floresco, S. B., Block, A. E., and Maric, T. (2008). Inactivation of the medial prefrontal cortex of the rat impairs strategy set-shifting, but not reversal learning, using a novel, automated procedure. Behav. Brain Res. 190, 85-96. doi: 10.1016/j.bbr.2008.02.008

Flores-Hernandez, J., Cepeda, C., Hernandez-Echeagaray, E., Calvert, C. R., Jokel, E. S., Fienberg, A. A., et al. (2002). Dopamine enhancement of NMDA currents in dissociated medium-sized striatal neurons: role of D1 receptors and DARPP32. J. Neurophysiol. 88, 3010-3020. doi: 10.1152/jn.00361.2002

Folk, C. L., Remington, R. W., and Johnston, J. C. (1992). Involuntary covert orienting is contingent on attentional control settings. J. Exper. Psychol. Hum. Percept. Perform. 18:1030. doi: 10.1037/0096-1523.18.4.1030

Foote, S. L., Freedman, R., and Oliver, A. P. (1975). Effects of putative neurotransmitters on neuronal activity in monkey auditory cortex. Brain Res. 86, 229-242. doi: 10.1016/0006-8993(75)90699-x

Fortin, D. A., and Levine, E. S. (2007). Differential effects of endocannabinoids on glutamatergic and GABAergic inputs to layer 5 pyramidal neurons. Cerebral Cortex 17, 163-174. doi: 10.1093/cercor/bhj133

Frau, R., Miczán, V., Traccis, F., Aroni, S., Pongor, C. I., Saba, P., et al. (2019). Prenatal THC exposure produces a hyperdopaminergic phenotype rescued by pregnenolone. Nat. Neurosci. 22, 1975-1985. doi: 10.1038/s41593-019-0512-2

Freund, T. F., Katona, I., and Piomelli, D. (2003). Role of endogenous cannabinoids in synaptic signaling. Physiol. Rev. 83, 1017-1066. doi: 10.1152/physrev.00004. 2003

Fry, W., Kelleher, R. T., and Cook, L. (1960). A mathematical index of performance on fixed-interval schedules of reinforcement. J. Exper. Analysis Behav. 3:193. doi: 10.1901/jeab.1960.3-193

Fukai, M., Bunai, T., Hirosawa, T., Kikuchi, M., Ito, S., Minabe, Y., et al. (2019). Endogenous dopamine release under transcranial direct-current stimulation governs enhanced attention: a study with positron emission tomography. Transl. Psychiatry 9, 1-10.

Fusco, F. R., Martorana, A., Giampa, C., De March, Z., Farini, D., D’angelo, V., et al. (2004). Immunolocalization of CB1 receptor in rat striatal neurons: a confocal microscopy study. Synapse 53, 159-167. doi: 10.1002/syn.20047
Fuster, J. (2015). The prefrontal cortex. Cambridge, MA: Academic Press.

Gallagher, M., Mcmahan, R. W., and Schoenbaum, G. (1999). Orbitofrontal cortex and representation of incentive value in associative learning. J. Neurosci. 19, 6610-6614. doi: 10.1523/jneurosci.19-15-06610.1999

Gangarossa, G., Perez, S., Dembitskaya, Y., Prokin, I., Berry, H., and Venance, L. (2020). BDNF controls bidirectional endocannabinoid plasticity at corticostriatal synapses. Cerebral Cortex 30, 197-214. doi: 10.1093/cercor/ bhz081

Gao, W.-J., and Goldman-Rakic, P. S. (2003). Selective modulation of excitatory and inhibitory microcircuits by dopamine. Proc. Natl. Acad. Sci. 100, 28362841. doi: 10.1073/pnas.262796399

Gao, W.-J., Krimer, L. S., and Goldman-Rakic, P. S. (2001). Presynaptic regulation of recurrent excitation by D1 receptors in prefrontal circuits. Proc. Natl. Acad. Sci. 98, 295-300. doi: 10.1073/pnas.98.1.295

Gerak, L. R., Zanettini, C., Koek, W., and France, C. P. (2015). Cross-tolerance to cannabinoids in morphine-tolerant rhesus monkeys. Psychopharmacology 232, 3637-3647. doi: 10.1007/s00213-015-4023-x

Gessa, G., Melis, M., Muntoni, A., and Diana, M. (1998). Cannabinoids activate mesolimbic dopamine neurons by an action on cannabinoid CB1 receptors. Eur. J. Pharmacol. 341, 39-44. doi: 10.1016/s0014-2999(97)01442-8

Gianessi, C. A., Groman, S. M., and Taylor, J. R. (2019). Bi-directional modulation of food habit expression by the endocannabinoid system. Eur. J. Neurosci. 49, 1610-1622. doi: 10.1111/ejn.14330

Gianessi, C. A., Groman, S. M., and Taylor, J. R. (2021). The effects of fatty acid amide hydrolase inhibition and monoacylglycerol lipase inhibition on habit formation in mice. Eur. J. Neurosci.

Gianessi, C. A., Groman, S. M., Thompson, S. L., Jiang, M., Van Der Stelt, M. and Taylor, J. R. (2020). Endocannabinoid contributions to alcohol habits and motivation: relevance to treatment. Addict. Biol. 25:e12768.

Gomes, F. V., Guimarães, F. S., and Grace, A. A. (2015). Effects of pubertal cannabinoid administration on attentional set-shifting and dopaminergic hyper-responsivity in a developmental disruption model of schizophrenia. Int. J. Neuropsychopharmacol. 18:yu018.

Gomez, D. M., Everett, T. J., Hamilton, L. R., Ranganath, A., Cheer, J. F., and Oleson, E. B. (2020). Chronic cannabinoid exposure produces tolerance to the dopamine releasing effects of WIN 55,212-2 and heroin in adult male rats. Neuropharmacology 182:108374. doi: 10.1016/j.neuropharm.2020.108374

Grace, A. A. (1991). Phasic versus tonic dopamine release and the modulation of dopamine system responsivity: a hypothesis for the etiology of schizophrenia. Neuroscience 41, 1-24. doi: 10.1016/0306-4522(91)90196-u

Grace, A. A., and Bunney, B. S. (1984). The control of firing pattern in nigral dopamine neurons: burst firing. J. Neurosci. 4, 2877-2890. doi: 10.1523/ jneurosci.04-11-02877.1984

Grace, A. A., Floresco, S. B., Goto, Y., and Lodge, D. J. (2007). Regulation of firing of dopaminergic neurons and control of goal-directed behaviors. Trends Neurosci. 30, 220-227. doi: 10.1016/j.tins.2007.03.003

Granon, S., Passetti, F., Thomas, K. L., Dalley, J. W., Everitt, B. J., and Robbins, T. W. (2000). Enhanced and impaired attentional performance after infusion of D1 dopaminergic receptor agents into rat prefrontal cortex. J. Neurosci. 20, 1208-1215. doi: 10.1523/jneurosci.20-03-01208.2000

Grant, D. A., and Berg, E. (1948). A behavioral analysis of degree of reinforcement and ease of shifting to new responses in a Weigl-type card-sorting problem. J. Exper. Psychol. 38:404. doi: 10.1037/h0059831

Gremel, C. M., Chancey, J. H., Atwood, B. K., Luo, G., Neve, R., Ramakrishnan, C., et al. (2016). Endocannabinoid modulation of orbitostriatal circuits gates habit formation. Neuron 90, 1312-1324. doi: 10.1016/j.neuron.2016.04.043

Hama, A., and Sagen, J. (2009). Sustained antinociceptive effect of cannabinoid receptor agonist WIN 55,212-2 over time in rat model of neuropathic spinal cord injury pain. J. Rehabil. Res. Dev. 46:135. doi: 10.1016/b978-0-323-48566$1.00017-6$

Hampshire, A., and Owen, A. M. (2006). Fractionating attentional control using event-related fMRI. Cerebral Cortex 16, 1679-1689. doi: 10.1093/cercor/bhj116

Heeren, A., and McNally, R. J. (2016). An integrative network approach to social anxiety disorder: The complex dynamic interplay among attentional bias for threat, attentional control, and symptoms. J. Anxiety Disord. 42, 95-104. doi: 10.1016/j.janxdis.2016.06.009

Henderson-Redmond, A. N., Nealon, C. M., Davis, B. J., Yuill, M. B., Sepulveda, D. E., Blanton, H. L., et al. (2020). c-Jun N terminal kinase signaling 
pathways mediate cannabinoid tolerance in an agonist-specific manner. Neuropharmacology 164:107847. doi: 10.1016/j.neuropharm.2019.107847

Hernandez, G., Oleson, E. B., Gentry, R. N., Abbas, Z., Bernstein, D. L., Arvanitogiannis, A., et al. (2014). Endocannabinoids promote cocaine-induced impulsivity and its rapid dopaminergic correlates. Biol. Psychiatry 75, 487-498. doi: 10.1016/j.biopsych.2013.09.005

Hilário, M. R., Clouse, E., Yin, H. H., and Costa, R. M. (2007). Endocannabinoid signaling is critical for habit formation. Front. Integ. Neurosci. 1:6. doi: 10.3389/ neuro.07.006

Hill, M. N., Froese, L. M., Morrish, A. C., Sun, J. C., and Floresco, S. B. (2006). Alterations in behavioral flexibility by cannabinoid CB 1 receptor agonists and antagonists. Psychopharmacology 187, 245-259. doi: 10.1007/s00213-006$0421-4$

Hindley, G., Beck, K., Borgan, F., Ginestet, C. E., Mccutcheon, R., Kleinloog, D., et al. (2020). Psychiatric symptoms caused by cannabis constituents: a systematic review and meta-analysis. Lancet Psychiatry 7, 344-353. doi: 10. 1016/s2215-0366(20)30074-2

Hine, B. (1985). Morphine and $\Delta$ 9-tetrahydrocannabinol: two-way cross tolerance for antinociceptive and heart-rate responses in the rat. Psychopharmacology 87, 34-38. doi: 10.1007/bf00431774

Hirvonen, J., Goodwin, R., Li, C.-T., Terry, G., Zoghbi, S., Morse, C., et al. (2012). Reversible and regionally selective downregulation of brain cannabinoid $\mathrm{CB}$ 1 receptors in chronic daily cannabis smokers. Mol. Psychiatry 17, 642-649. doi: $10.1038 / \mathrm{mp} .2011 .82$

Hopfinger, J. B., Buonocore, M. H., and Mangun, G. R. (2000). The neural mechanisms of top-down attentional control. Nat. Neurosci. 3, 284-291. doi: $10.1038 / 72999$

Hu, J.-L., Liu, G., Li, Y.-C., Gao, W.-J., and Huang, Y.-Q. (2010). Dopamine D1 receptor-mediated NMDA receptor insertion depends on Fyn but not Src kinase pathway in prefrontal cortical neurons. Mol. Brain 3, 1-14.

Iannotti, F. A., and Vitale, R. M. (2021). The endocannabinoid system and PPARs: focus on their signalling crosstalk, action and transcriptional regulation. Cells 10:586. doi: 10.3390/cells10030586

Irimia, C., Polis, I. Y., Stouffer, D., and Parsons, L. H. (2015). Persistent effects of chronic $\triangle 9$-THC exposure on motor impulsivity in rats. Psychopharmacology 232, 3033-3043. doi: 10.1007/s00213-015-3942-x

Izquierdo, A., and Jentsch, J. D. (2012). Reversal learning as a measure of impulsive and compulsive behavior in addictions. Psychopharmacology 219, 607-620. doi: 10.1007/s00213-011-2579-7

Izquierdo, A., Belcher, A. M., Scott, L., Cazares, V. A., Chen, J., O’dell, S. J., et al. (2010). Reversal-specific learning impairments after a binge regimen of methamphetamine in rats: possible involvement of striatal dopamine. Neuropsychopharmacology 35, 505-514. doi: 10.1038/npp.2009.155

Izquierdo, A., Suda, R. K., and Murray, E. A. (2004). Bilateral orbital prefrontal cortex lesions in rhesus monkeys disrupt choices guided by both reward value and reward contingency. J. Neurosci. 24, 7540-7548. doi: 10.1523/jneurosci. 1921-04.2004

Jeannerod, M. (1987). Neurophysiological and neuropsychological aspects of spatial neglect. Amsterdam: Elsevier.

Jiao, X., Pang, K. C., Beck, K. D., Minor, T. R., and Servatius, R. J. (2011). Avoidance perseveration during extinction training in Wistar-Kyoto rats: an interaction of innate vulnerability and stressor intensity. Behav. Brain Res. 221, 98-107. doi: 10.1016/j.bbr.2011.02.029

Jin, W., Brown, S., Roche, J. P., Hsieh, C., Celver, J. P., Kovoor, A., et al. (1999). Distinct domains of the CB1 cannabinoid receptor mediate desensitization and internalization. J. Neurosci. 19, 3773-3780. doi: 10.1523/jneurosci.19-1003773.1999

Jones, B., and Mishkin, M. (1972). Limbic lesions and the problem of stimulusreinforcement associations. Exper. Neurol. 36, 362-377. doi: 10.1016/00144886(72)90030- 1

Jones, S. R., Gainetdinov, R. R., Wightman, R. M., and Caron, M. G. (1998). Mechanisms of amphetamine action revealed in mice lacking the dopamine transporter. J. Neurosci. 18, 1979-1986. doi: 10.1523/jneurosci.18-06-01979. 1998

Jonker, F. A., Jonker, C., Scheltens, P., and Scherder, E. J. (2015). The role of the orbitofrontal cortex in cognition and behavior. Rev. Neurosci. 26, 1-11. doi: 10.1515/revneuro-2014-0043
Jordan, C. J., and Xi, Z.-X. (2019). Progress in brain cannabinoid CB2 receptor research: from genes to behavior. Neurosci. Biobehav. Rev. 98, 208-220. doi: 10.1016/j.neubiorev.2018.12.026

Julian, M., Martin, A., Cuellar, B., De Fonseca, F. R., Navarro, M., Moratalla, R., et al. (2003). Neuroanatomical relationship between type 1 cannabinoid receptors and dopaminergic systems in the rat basal ganglia. Neuroscience 119, 309-318. doi: 10.1016/s0306-4522(03)00070-8

Kaczocha, M., and Haj-Dahmane, S. (2021). Mechanisms of endocannabinoid transport in the brain. Br. J. Pharmacol.

Kähkönen, S., Ahveninen, J., Pekkonen, E., Kaakkola, S., Huttunen, J., Ilmoniemi, R. J., et al. (2002). Dopamine modulates involuntary attention shifting and reorienting: an electromagnetic study. Clin. Neurophysiol. 113, 1894-1902. doi: 10.1016/s1388-2457(02)00305-x

Karnath, H.-O., Ferber, S., and Himmelbach, M. (2001). Spatial awareness is a function of the temporal not the posterior parietal lobe. Nature 411, 950-953. doi: $10.1038 / 35082075$

Kenemans, J., Bekker, E., Lijffijt, M., Overtoom, C., Jonkman, L., and Verbaten, M. (2005). Attention deficit and impulsivity: selecting, shifting, and stopping. Int. J. Psychophysiol. 58, 59-70. doi: 10.1016/j.ijpsycho.2005.03.009

Khan, S. S., and Lee, F. J. (2014). Delineation of domains within the cannabinoid $\mathrm{CB} 1$ and dopamine $\mathrm{D} 2$ receptors that mediate the formation of the heterodimer complex. J. Mol. Neurosci. 53, 10-21. doi: 10.1007/s12031-013-0181-7

Killeen, P. R., and Fetterman, J. G. (1988). A behavioral theory of timing. Psychol. Rev. 95:274. doi: 10.1037/0033-295x.95.2.274

Kim, J., and Ragozzino, M. E. (2005). The involvement of the orbitofrontal cortex in learning under changing task contingencies. Neurobiol. Learn. Mem. 83, 125-133. doi: 10.1016/j.nlm.2004.10.003

Kiritoshi, T., Sun, H., Ren, W., Stauffer, S. R., Lindsley, C. W., Conn, P. J., et al. (2013). Modulation of pyramidal cell output in the medial prefrontal cortex by mGluR5 interacting with CB1. Neuropharmacology 66, 170-178. doi: 10.1016/ j.neuropharm.2012.03.024

Klugmann, M., Goepfrich, A., Friemel, C. M., and Schneider, M. (2011). AAVmediated overexpression of the CB1 receptor in the mPFC of adult rats alters cognitive flexibility, social behavior, and emotional reactivity. Front. Behav. Neurosci. 5:37. doi: 10.3389/fnbeh.2011.00037

Kravitz, A. V., Tye, L. D., and Kreitzer, A. C. (2012). Distinct roles for direct and indirect pathway striatal neurons in reinforcement. Nat. Neurosci. 15:816. doi: 10.1038/nn.3100

Lak, A., Stauffer, W. R., and Schultz, W. (2014). Dopamine prediction error responses integrate subjective value from different reward dimensions. Proc. Natl. Acad. Sci. 111, 2343-2348. doi: 10.1073/pnas.1321596111

Lak, A., Stauffer, W. R., and Schultz, W. (2016). Dopamine neurons learn relative chosen value from probabilistic rewards. Elife 5:e18044.

Lammel, S., Lim, B. K., and Malenka, R. C. (2014). Reward and aversion in a heterogeneous midbrain dopamine system. Neuropharmacology 76, 351-359. doi: 10.1016/j.neuropharm.2013.03.019

Lange, M., Daldrup, T., Remmers, F., Szkudlarek, H., Lesting, J., Guggenhuber, S., et al. (2017). Cannabinoid CB1 receptors in distinct circuits of the extended amygdala determine fear responsiveness to unpredictable threat. Mol. Psychiatry 22, 1422-1430. doi: 10.1038/mp.2016.156

Laprairie, R., Bagher, A., Kelly, M., and Denovan-Wright, E. (2015). Cannabidiol is a negative allosteric modulator of the cannabinoid CB1 receptor. Br. J. Pharmacol. 172, 4790-4805. doi: 10.1111/bph.13250

Lau, B. K., Murphy-Royal, C., Kaur, M., Qiao, M., Gordon, G. R., Bains, J., et al. (2020). Obesity-induced astrocyte dysfunction impairs heterosynaptic plasticity in the orbitofrontal cortex. Available Online at SSRN: http://dx.doi.org/10.2139/ ssrn.3651096

Law-Tho, D., Hirsch, J., and Crepel, F. (1994). Dopamine modulation of synaptic transmission in rat prefrontal cortex: an in vitro electrophysiological study. Neurosci. Res. 21, 151-160. doi: 10.1016/0168-0102(94) 90157-0

Le Foll, B., and Goldberg, S. R. (2005). Cannabinoid CB1 receptor antagonists as promising new medications for drug dependence. J. Pharmacol. Exper. Ther. 312, 875-883. doi: 10.1124/jpet.104.077974

Lee, S. W., Shimojo, S., and O'doherty, J. P. (2014). Neural computations underlying arbitration between model-based and model-free learning. Neuron 81, 687-699. doi: 10.1016/j.neuron.2013.11.028 
Lerner, T. N., and Kreitzer, A. C. (2012). RGS4 is required for dopaminergic control of striatal LTD and susceptibility to parkinsonian motor deficits. Neuron 73 , 347-359. doi: 10.1016/j.neuron.2011.11.015

Levey, A. I., Hersch, S. M., Rye, D. B., Sunahara, R. K., Niznik, H. B., Kitt, C. A., et al. (1993). Localization of D1 and D2 dopamine receptors in brain with subtypespecific antibodies. Proc. Natl. Acad. Sci. 90, 8861-8865. doi: 10.1073/pnas.90. 19.8861

Lewis, D., Campbell, M., Foote, S., and Morrison, J. (1986). The monoaminergic innervation of primate neocortex. Hum. Neurobiol. 5, 181-188.

Li, Y.-C., Xi, D., Roman, J., Huang, Y.-Q., and Gao, W.-J. (2009). Activation of glycogen synthase kinase- $3 \beta$ is required for hyperdopamine and D2 receptormediated inhibition of synaptic NMDA receptor function in the rat prefrontal cortex. J. Neurosci. 29, 15551-15563. doi: 10.1523/jneurosci.3336-09.2009

Linley, S. B., Gallo, M. M., and Vertes, R. P. (2016). Lesions of the ventral midline thalamus produce deficits in reversal learning and attention on an odor texture set shifting task. Brain Res. 1649, 110-122. doi: 10.1016/j.brainres.2016.08.022

Liston, C., Mcewen, B. S., and Casey, B. (2009). Psychosocial stress reversibly disrupts prefrontal processing and attentional control. Proc. Natl. Acad. Sci. 106, 912-917. doi: 10.1073/pnas.0807041106

Little, P., Compton, D., Johnson, M., Melvin, L., and Martin, B. (1988). Pharmacology and stereoselectivity of structurally novel cannabinoids in mice. J. Pharmacol. Exper. Ther. 247, 1046-1051.

Liu, Q. R., Pan, C. H., Hishimoto, A., Li, C. Y., Xi, Z. X., Llorente-Berzal, A., et al. (2009). Species differences in cannabinoid receptor 2 (CNR2 gene): identification of novel human and rodent CB2 isoforms, differential tissue expression and regulation by cannabinoid receptor ligands. Genes Brain Behav. 8, 519-530. doi: 10.1111/j.1601-183x.2009.00498.x

Liu, W., Yuen, E. Y., Allen, P. B., Feng, J., Greengard, P., and Yan, Z. (2006). Adrenergic modulation of NMDA receptors in prefrontal cortex is differentially regulated by RGS proteins and spinophilin. Proc. Natl. Acad. Sci. 103, 1833818343. doi: $10.1073 /$ pnas.0604560103

Lu, H.-C., and Mackie, K. (2016). An introduction to the endogenous cannabinoid system. Biol. Psychiatry 79, 516-525. doi: 10.1016/j.biopsych.2015.07.028

Luna-Rodriguez, A., Wendt, M., Auch Koerner, J. K., Gawrilow, C., and Jacobsen, T. (2018). Selective impairment of attentional set shifting in adults with ADHD. Behav. Brain Funct. 14:18.

Maccarrone, M. (2020). Missing pieces to the endocannabinoid puzzle. Trends mol. Med. 26, 263-272. doi: 10.1016/j.molmed.2019.11.002

Mackintosh, N., and Little, L. (1969). Selective attention and response strategies as factors in serial reversal learning. Can. J. Psychol. 23:335. doi: 10.1037/h0082821

Manzanares, J., Corchero, J., Romero, J., Fernández-Ruiz, J. J., Ramos, J. A., and Fuentes, J. A. (1999). Pharmacological and biochemical interactions between opioids and cannabinoids. Trends Pharmacol. Sci. 20, 287-294. doi: 10.1016/ s0165-6147(99)01339-5

Marichal-Cancino, B. A., Fajardo-Valdez, A., Ruiz-Contreras, A. E., Mendez-Díaz, M., and Prospero-García, O. (2017). Advances in the physiology of GPR55 in the central nervous system. Curr. Neuropharmacol. 15, 771-778.

Marichal-Cancino, B. A., Sánchez-Fuentes, A., Méndez-Díaz, M., Ruiz-Contreras, A. E., and Prospéro-García, O. (2016). Blockade of GPR55 in the dorsolateral striatum impairs performance of rats in a T-maze paradigm. Behav. Pharmacol. 27, 393-396. doi: 10.1097/fbp.0000000000000185

Marsicano, G., Goodenough, S., Monory, K., Hermann, H., Eder, M., Cannich, A., et al. (2003). CB1 cannabinoid receptors and on-demand defense against excitotoxicity. Science 302, 84-88. doi: 10.1126/science.1088208

Marzo, V. D., and Petrocellis, L. D. (2006). Plant, synthetic, and endogenous cannabinoids in medicine. Annu. Rev. Med. 57, 553-574. doi: 10.1146/annurev. med.57.011205.135648

Mason, N. L., Theunissen, E. L., Hutten, N. R., Tse, D. H., Toennes, S. W., Jansen, J. F., et al. (2021). Reduced responsiveness of the reward system is associated with tolerance to cannabis impairment in chronic users. Addict. Biol. 26: e12870.

Mateo, Y., Johnson, K. A., Covey, D. P., Atwood, B. K., Wang, H.-L., Zhang, S., et al. (2017). Endocannabinoid actions on cortical terminals orchestrate local modulation of dopamine release in the nucleus accumbens. Neuron 96, 1112-1126. doi: 10.1016/j.neuron.2017.11.012

Mathews, A., Yiend, J., and Lawrence, A. D. (2004). Individual differences in the modulation of fear-related brain activation by attentional control. J. Cogn. Neurosci. 16, 1683-1694. doi: 10.1162/0898929042947810
Matsuda, L. A., Lolait, S. J., Brownstein, M. J., Young, A. C., and Bonner, T. I. (1990). Structure of a cannabinoid receptor and functional expression of the cloned cDNA. Nature 346, 561-564. doi: 10.1038/346561a0

Mátyás, F., Urbán, G. M., Watanabe, M., Mackie, K., Zimmer, A., Freund, T. F., et al. (2008). Identification of the sites of 2-arachidonoylglycerol synthesis and action imply retrograde endocannabinoid signaling at both GABAergic and glutamatergic synapses in the ventral tegmental area. Neuropharmacology 54, 95-107. doi: 10.1016/j.neuropharm.2007.05.028

Matzel, L. D., and Kolata, S. (2010). Selective attention, working memory, and animal intelligence. Neurosci. Biobehav. Rev. 34, 23-30. doi: 10.1016/j. neubiorev.2009.07.002

Maunsell, J. H. (2004). Neuronal representations of cognitive state: reward or attention? Trends Cogn. Sci. 8, 261-265. doi: 10.1016/j.tics.2004.04.003

Maunsell, J. H., and Treue, S. (2006). Feature-based attention in visual cortex. Trends Neurosci. 29, 317-322. doi: 10.1016/j.tins.2006.04.001

Mavrikaki, M., Markaki, E., Nomikos, G. G., and Panagis, G. (2010). Chronic WIN55, 212-2 elicits sustained and conditioned increases in intracranial selfstimulation thresholds in the rat. Behav. brain Res. 209, 114-118. doi: 10.1016/ j.bbr.2010.01.024

McAlonan, K., and Brown, V. J. (2003). Orbital prefrontal cortex mediates reversal learning and not attentional set shifting in the rat. Behav. Brain Res. 146, 97-103. doi: 10.1016/j.bbr.2003.09.019

McElree, B. (2001). Working memory and focal attention. J. Exper. Psychol. Learn. Mem. Cogn. 27:817. doi: 10.1037/0278-7393.27.3.817

McKearney, J., and Barrett, J. (1978). "Schedule-controlled behavior and the effects of drugs," in Contemporary research in behavioral pharmacology, eds D. E. Blackman and D. J. Sanger (New York: Plenum Press).

Mechoulam, R., Ben-Shabat, S., Hanus, L., Ligumsky, M., Kaminski, N. E., Schatz, A. R., et al. (1995). Identification of an endogenous 2-monoglyceride, present in canine gut, that binds to cannabinoid receptors. Biochem. Pharmacol. 50, 83-90. doi: 10.1016/0006-2952(95)00109-d

Mehta, M. A., Owen, A. M., Sahakian, B. J., Mavaddat, N., Pickard, J. D., and Robbins, T. W. (2000). Methylphenidate enhances working memory by modulating discrete frontal and parietal lobe regions in the human brain. J. Neurosci. 20:RC65.

Melis, M., Carta, G., Pistis, M., and Banni, S. (2013a). Physiological role of peroxisome proliferator-activated receptors type alpha on dopamine systems. CNS Neurol. Disord. Drug Targets 12, 70-77. doi: 10.2174/ 1871527311312010012

Melis, M., De Felice, M., Lecca, S., Fattore, L., and Pistis, M. (2013b). Sex-specific tonic 2-arachidonoylglycerol signaling at inhibitory inputs onto dopamine neurons of Lister Hooded rats. Front. Integ. Neurosci. 7:93. doi: 10.3389/fnint. 2013.00093

Melis, M., Perra, S., Muntoni, A. L., Pillolla, G., Lutz, B., Marsicano, G., et al. (2004). Prefrontal cortex stimulation induces 2-arachidonoyl-glycerolmediated suppression of excitation in dopamine neurons. J. Neurosci. 24, 10707-10715. doi: 10.1523/jneurosci.3502-04.2004

Milham, M., Banich, M., Webb, A., Barad, V., Cohen, N., Wszalek, T., et al. (2001). The relative involvement of anterior cingulate and prefrontal cortex in attentional control depends on nature of conflict. Cogn. Brain Res. 12, 467-473. doi: 10.1016/s0926-6410(01)00076-3

Miller, E. K., and Cohen, J. D. (2001). An integrative theory of prefrontal cortex function. Ann. Rev. Neurosci. 24, 167-202. doi: 10.1146/annurev.neuro.24.1. 167

Mohanty, A., Gitelman, D. R., Small, D. M., and Mesulam, M. M. (2008). The spatial attention network interacts with limbic and monoaminergic systems to modulate motivation-induced attention shifts. Cerebral Cortex 18, 2604-2613. doi: 10.1093/cercor/bhn021

Monory, K., Blaudzun, H., Massa, F., Kaiser, N., Lemberger, T., Schütz, G., et al. (2007). Genetic dissection of behavioural and autonomic effects of $\Delta 9$ tetrahydrocannabinol in mice. PLoS Biol. 5:e269. doi: 10.1371/journal.pbio. 0050269

Morales, M., and Margolis, E. B. (2017). Ventral tegmental area: cellular heterogeneity, connectivity and behaviour. Nat. Rev. Neurosci. 18:73. doi: 10 . 1038/nrn.2016.165

Morales, M., and Root, D. H. (2014). Glutamate neurons within the midbrain dopamine regions. Neuroscience 282, 60-68. doi: 10.1016/j.neuroscience.2014. 05.032 
Mort, D. J., Malhotra, P., Mannan, S. K., Rorden, C., Pambakian, A., Kennard, C., et al. (2003). The anatomy of visual neglect. Brain 126, 1986-1997. doi: $10.1093 /$ brain/awg200

Nagahama, Y., Okina, T., Suzuki, N., Nabatame, H., and Matsuda, M. (2005). The cerebral correlates of different types of perseveration in the Wisconsin Card Sorting Test. J. Neurol. Neurosurg. Psychiatry 76, 169-175. doi: 10.1136/jnnp. 2004.039818

Nagano-Saito, A., Leyton, M., Monchi, O., Goldberg, Y. K., He, Y., and Dagher, A. (2008). Dopamine depletion impairs frontostriatal functional connectivity during a set-shifting task. J. Neurosci. 28, 3697-3706. doi: 10.1523/jneurosci. 3921-07.2008

Narayanan, N. S., Land, B. B., Solder, J. E., Deisseroth, K., and Dileone, R. J. (2012). Prefrontal D1 dopamine signaling is required for temporal control. Proc. Natl. Acad. Sci. 109, 20726-20731. doi: 10.1073/pnas.1211258109

Navarrete, F., García-Gutiérrez, M. S., Jurado-Barba, R., Rubio, G., Gasparyan, A., Austrich-Olivares, A., et al. (2020). Endocannabinoid system components as potential biomarkers in psychiatry. Front. Psychiatry 11:315. doi: 10.3389/fpsyt. 2020.00315

Nealon, C. M., Henderson-Redmond, A. N., Hale, D. E., and Morgan, D. J. (2019). Tolerance to WIN55, 212-2 is delayed in desensitization-resistant S426A/S430A mice. Neuropharmacology 148, 151-159. doi: 10.1016/j.neuropharm.2018.12. 026

Nguyen, P. T., Schmid, C. L., Raehal, K. M., Selley, D. E., Bohn, L. M., and SimSelley, L. J. (2012). $\beta$-Arrestin2 regulates cannabinoid CB1 receptor signaling and adaptation in a central nervous system region-dependent manner. Biol. Psychiatry 71, 714-724. doi: 10.1016/j.biopsych.2011.11.027

Nieuwenstein, M. R., Aleman, A., and De Haan, E. H. (2001). Relationship between symptom dimensions and neurocognitive functioning in schizophrenia: a metaanalysis of WCST and CPT studies. J. Psychiatric Res. 35, 119-125. doi: 10.1016/ s0022-3956(01)00014-0

Nilsson, S. R., Alsiö, J., Somerville, E. M., and Clifton, P. G. (2015). The rat's not for turning: dissociating the psychological components of cognitive inflexibility. Neurosci. Biobehav. Rev. 56, 1-14. doi 10.1016/j.neubiorev.2015. 06.015

O'Hare, J., Calakos, N., and Yin, H. H. (2018). Recent insights into corticostriatal circuit mechanisms underlying habits. Curr. Opin. Behav. Sci. 20, 40-46. doi: 10.1016/j.cobeha.2017.10.001

Oberauer, K. (2019). Working memory and attention-A conceptual analysis and review. J. Cogn. 2:36.

O’Donnell, P., Greene, J., Pabello, N., Lewis, B. L., and Grace, A. A. (1999). Modulation of cell firing in the nucleus accumbens. Ann. N. Y. Acad. Sci. 877, $157-175$.

Oemisch, M., Watson, M. R., Womelsdorf, T., and Schubö, A. (2017). Changes of attention during value-based reversal learning are tracked by $\mathrm{N} 2 \mathrm{pc}$ and feedback-related negativity. Front. Hum. Neurosci. 11:540. doi: 10.3389/fnhum. 2017.00540

Ohno-Shosaku, T., and Kano, M. (2014). Endocannabinoid-mediated retrograde modulation of synaptic transmission. Curr. Opin. Neurobiol. 29, 1-8. doi: 10.1016/j.conb.2014.03.017

Ohno-Shosaku, T., Tsubokawa, H., Mizushima, I., Yoneda, N., Zimmer, A., and Kano, M. (2002). Presynaptic cannabinoid sensitivity is a major determinant of depolarization-induced retrograde suppression at hippocampal synapses. J. Neurosci. 22, 3864-3872. doi: 10.1523/jneurosci.22-10-03864.2002

Ólafsson, R. P., Smári, J., Guð̋mundsdóttir, F., Ólafsdóttir, G., Harðardóttir, H. L., and Einarsson, S. M. (2011). Self reported attentional control with the Attentional Control Scale: Factor structure and relationship with symptoms of anxiety and depression. J. Anxiety Disord. 25, 777-782. doi: 10.1016/j.janxdis. 2011.03.013

Oleson, E. B., and Cheer, J. F. (2014). "SWEET LEAF: Neurochemical Advances Reveal How Cannabinoids Affect Brain Dopamine ConcentrationS," in Compendium of In Vivo Monitoring In Real-time Molecular NeuroscienceVolume 1: Fundamentals And Applications, eds G. S. Wilson and A. C. Michael (Singapore: World Scientific Publishing Co.), 251. doi: 10.1142/ 9789814619776_0011

Oleson, E. B., and Roberts, J. B. (2019). The power of price compels you: behavioral economic insights into dopamine-based valuation of rewarding and aversively motivated behavior. Brain Res. 1713, 32-41. doi: 10.1016/j.brainres.2018. 11.043
Oleson, E. B., Beckert, M. V., Morra, J. T., Lansink, C. S., Cachope, R., Abdullah, R. A., et al. (2012). Endocannabinoids shape accumbal encoding of cuemotivated behavior via $\mathrm{CB} 1$ receptor activation in the ventral tegmentum. Neuron 73, 360-373. doi: 10.1016/j.neuron.2011.11.018

Oleson, E. B., Cachope, R., Fitoussi, A., Tsutsui, K., Wu, S., Gallegos, J. A., et al. (2014). Cannabinoid receptor activation shifts temporally engendered patterns of dopamine release. Neuropsychopharmacology 39:1441. doi: 10.1038/npp. 2013.340

Onn, S.-P., Wang, X.-B., Lin, M., and Grace, A. A. (2006). Dopamine D1 and D4 receptor subtypes differentially modulate recurrent excitatory synapses in prefrontal cortical pyramidal neurons. Neuropsychopharmacology 31, 318-338. doi: 10.1038/sj.npp.1300829

Ortar, G., Bisogno, T., Ligresti, A., Morera, E., Nalli, M., and Di Marzo, V. (2008). Tetrahydrolipstatin analogues as modulators of endocannabinoid 2arachidonoylglycerol metabolism. J. med. Chem. 51, 6970-6979. doi: 10.1021/ jm800978m

Ott, T., and Nieder, A. (2019). Dopamine and cognitive control in prefrontal cortex. Trends Cogn. Sci. 23, 213-234. doi: 10.1016/j.tics.2018.12.006

Owen, A. M., Roberts, A. C., Polkey, C. E., Sahakian, B. J., and Robbins, T. W. (1991). Extra-dimensional versus intra-dimensional set shifting performance following frontal lobe excisions, temporal lobe excisions or amygdalohippocampectomy in man. Neuropsychologia 29, 993-1006. doi: 10.1016/00283932(91)90063-e

Pantelis, C., Barber, F. Z., Barnes, T. R., Nelson, H. E., Owen, A. M., and Robbins, T. W. (1999). Comparison of set-shifting ability in patients with chronic schizophrenia and frontal lobe damage. Schizophrenia Res. 37, 251-270. doi: 10.1016/s0920-9964(98)00156-x

Paolo, A. M., Tröster, A. I., Axelrod, B. N., and Koller, W. C. (1995). Construct validity of the WCST in normal elderly and persons with Parkinson's disease. Arch. Clin. Neuropsychol. 10, 463-473. doi: 10.1016/0887-6177(95)00052-6

Paret, C., and Bublatzky, F. (2020). Threat rapidly disrupts reward reversal learning. Behav. Res. Ther. 131:103636. doi: 10.1016/j.brat.2020.103636

Parsegian, A., Glen, W. B. Jr., Lavin, A., and See, R. E. (2011). Methamphetamine self-administration produces attentional set-shifting deficits and alters prefrontal cortical neurophysiology in rats. Biol. Psychiatry 69, 253-259. doi: 10.1016/j.biopsych.2010.09.003

Pattij, T., Janssen, M. C., Schepers, I., González-Cuevas, G., De Vries, T. J., and Schoffelmeer, A. N. (2007a). Effects of the cannabinoid CB 1 receptor antagonist rimonabant on distinct measures of impulsive behavior in rats. Psychopharmacology 193, 85-96. doi: 10.1007/s00213-007-0773-4

Pattij, T., Janssen, M. C., Vanderschuren, L. J., Schoffelmeer, A. N., and Van Gaalen, M. M. (2007b). Involvement of dopamine D 1 and D 2 receptors in the nucleus accumbens core and shell in inhibitory response control. Psychopharmacology 191, 587-598. doi: 10.1007/s00213-006-0533-x

Peters, K. Z., Oleson, E. B., and Cheer, J. F. (2021). A brain on cannabinoids: the role of dopamine release in reward seeking and addiction. Cold Spring Harbor Perspec. Med. 11:a039305. doi: 10.1101/cshperspect.a039305

Pisansky, M. T., Lefevre, E. M., Retzlaff, C. L., Trieu, B. H., Leipold, D. W., and Rothwell, P. E. (2019). Nucleus accumbens fast-spiking interneurons constrain impulsive action. Biol. Psychiatry 86, 836-847. doi: 10.1016/j.biopsych.2019.07. 002

Pistis, M., Ferraro, L., Pira, L., Flore, G., Tanganelli, S., Gessa, G. L., et al. (2002). $\Delta$ 9-Tetrahydrocannabinol decreases extracellular GABA and increases extracellular glutamate and dopamine levels in the rat prefrontal cortex: an in vivo microdialysis study. Brain Res. 948, 155-158. doi: 10.1016/s00068993(02)03055-x

Polissidis, A., Galanopoulos, A., Naxakis, G., Papahatjis, D., Papadopoulou-Daifoti, Z., and Antoniou, K. (2013). The cannabinoid CB1 receptor biphasically modulates motor activity and regulates dopamine and glutamate release region dependently. Int. J. Neuropsychopharmacol. 16, 393-403. doi: 10.1017/ s1461145712000156

Posner, M. I., and Petersen, S. E. (1990). The attention system of the human brain. Ann. Rev. Neurosci. 13, 25-42.

Pultorak, K. J., Schelp, S. A., Isaacs, D. P., Krzystyniak, G., and Oleson, E. B. (2018). A transient dopamine signal represents avoidance value and causally influences the demand to avoid. eNeuro 5, ENEURO.58-ENEURO.18.

Puumala, T., and Sirviö, J. (1998). Changes in activities of dopamine and serotonin systems in the frontal cortex underlie poor choice accuracy and impulsivity 
of rats in an attention task. Neuroscience 83, 489-499. doi: 10.1016/s03064522(97)00392-8

Radwan, M. M., Elsohly, M. A., Slade, D., Ahmed, S. A., Khan, I. A., and Ross, S. A. (2009). Biologically active cannabinoids from high-potency Cannabis sativa. J. Nat. Products 72, 906-911.

Ragozzino, M. E., Wilcox, C., Raso, M., and Kesner, R. P. (1999). Involvement of rodent prefrontal cortex subregions in strategy switching. Behav. Neurosci. 113:32. doi: 10.1037/0735-7044.113.1.32

Redgrave, P., Gurney, K., and Reynolds, J. (2008). What is reinforced by phasic dopamine signals? Brain Res. Rev. 58, 322-339. doi: 10.1016/j.brainresrev.2007. 10.007

Redgrave, P., Vautrelle, N., Overton, P., and Reynolds, J. (2016). Phasic dopamine signaling in action selection and reinforcement learning. Handbook Behav. Neurosci. 24, 707-723. doi: 10.1016/b978-0-12-802206-1.00034-9

Renard, J., Rosen, L. G., Loureiro, M., De Oliveira, C., Schmid, S., Rushlow, W. J., et al. (2017). Adolescent cannabinoid exposure induces a persistent subcortical hyper-dopaminergic state and associated molecular adaptations in the prefrontal cortex. Cerebral Cortex 27, 1297-1310.

Ridderinkhof, K. R., Span, M. M., and Van Der Molen, M. W. (2002). Perseverative behavior and adaptive control in older adults: performance monitoring, rule induction, and set shifting. Brain Cogn. 49, 382-401. doi: 10.1006/brcg.2001. 1506

Riegel, A. C., and Lupica, C. R. (2004). Independent presynaptic and postsynaptic mechanisms regulate endocannabinoid signaling at multiple synapses in the ventral tegmental area. J. Neurosci. 24, 11070-11078. doi: 10.1523/jneurosci. 3695-04.2004

Romine, C. B., Lee, D., Wolfe, M. E., Homack, S., George, C., and Riccio, C. A. (2004). Wisconsin Card Sorting Test with children: a meta-analytic study of sensitivity and specificity. Arch. Clin. Neuropsychol. 19, 1027-1041. doi: 10. 1016/j.acn.2003.12.009

Rossi, A. F., Bichot, N. P., Desimone, R., and Ungerleider, L. G. (2007). Topdown attentional deficits in macaques with lesions of lateral prefrontal cortex. J. Neurosci. 27, 11306-11314. doi: 10.1523/jneurosci.2939-07.2007

Rubia, K., Halari, R., Cubillo, A., Mohammad, A.-M., Brammer, M., and Taylor, E. (2009). Methylphenidate normalises activation and functional connectivity deficits in attention and motivation networks in medication-naive children with ADHD during a rewarded continuous performance task. Neuropharmacology 57, 640-652. doi: 10.1016/j.neuropharm.2009.08.013

Rueda, M. R., Posner, M. I., and Rothbart, M. K. (2004). "Attentional control and self-regulation," in Handbook of self-regulation: Research, theory, and applications, Vol. 2, eds R. F. Baumeister and K. D. Vohs (New York City, NY: The Guilford Press), 283-300.

Russo, E. B. (2019). The case for the entourage effect and conventional breeding of clinical cannabis: no “strain," no gain. Front. Plant Sci. 9:1969. doi: 10.3389/fpls. 2018.01969

Sahakian, B. J., and Owen, A. (1992). Computerized assessment in neuropsychiatry using CANTAB: discussion paper. J. R. Soc. Med. 85:399.

Sali, A. W., Anderson, B. A., and Yantis, S. (2014). The role of reward prediction in the control of attention. J. Exper. Psychol. Hum. Percep. Perform. 40:1654. doi: $10.1037 / \mathrm{a} 0037267$

Sali, A. W., Anderson, B. A., and Yantis, S. (2015). Learned states of preparatory attentional control. J. Exp. Psychol. Learn. Mem. Cogn. 41:1790. doi: 10.1037/ $\mathrm{xlm} 0000146$

Schelp, S. A., Pultorak, K. J., Rakowski, D. R., Gomez, D. M., Krzystyniak, G., Das, R., et al. (2017). A transient dopamine signal encodes subjective value and causally influences demand in an economic context. Proc. Natl. Acad. Sci. 114, E11303-E11312.

Schoorl, M., Putman, P., Van Der Werff, S., and Van Der Does, A. W. (2014). Attentional bias and attentional control in posttraumatic stress disorder. J. Anxiety Disord. 28, 203-210. doi: 10.1016/j.janxdis.2013.10.001

Schultz, W., Carelli, R. M., and Wightman, R. M. (2015). Phasic dopamine signals: from subjective reward value to formal economic utility. Curr. Opin. Behav. Sci. 5, 147-154. doi: 10.1016/j.cobeha.2015.09.006

Scolari, M., and Serences, J. T. (2009). Adaptive allocation of attentional gain. J. Neurosci. 29, 11933-11942. doi: 10.1523/jneurosci.5642-08.2009

Seamans, J. K., Durstewitz, D., Christie, B. R., Stevens, C. F., and Sejnowski, T. J. (2001a). Dopamine D1/D5 receptor modulation of excitatory synaptic inputs to layer V prefrontal cortex neurons. Proc. Natl. Acad. Sci. 98, 301-306. doi: 10.1073/pnas.98.1.301

Seamans, J. K., Gorelova, N., Durstewitz, D., and Yang, C. R. (2001b). Bidirectional dopamine modulation of GABAergic inhibition in prefrontal cortical pyramidal neurons. J. Neurosci. 21, 3628-3638. doi: 10.1523/jneurosci.21-10-03628.2001

Shafiei, G., Zeighami, Y., Clark, C. A., Coull, J. T., Nagano-Saito, A., Leyton, M., et al. (2019). Dopamine signaling modulates the stability and integration of intrinsic brain networks. Cerebral Cortex 29, 397-409. doi: 10.1093/cercor/ bhy264

Shan, Q., Christie, M. J., and Balleine, B. W. (2015). Plasticity in striatopallidal projection neurons mediates the acquisition of habitual actions. Eur. J. Neurosci. 42, 2097-2104. doi: 10.1111/ejn.12971

Sharpe, M. J., and Schoenbaum, G. (2018). Evaluation of the hypothesis that phasic dopamine constitutes a cached-value signal. Neurobiol. Learn. Mem. 153, 131-136. doi: 10.1016/j.nlm.2017.12.002

Shonesy, B. C., Parrish, W. P., Haddad, H. K., Stephenson, J. R., Báldi, R., Bluett, R. J., et al. (2018). Role of striatal direct pathway 2-arachidonoylglycerol signaling in sociability and repetitive behavior. Biol. Psychiatry 84, 304-315. doi: 10.1016/j.biopsych.2017.11.036

Shonesy, B. C., Stephenson, J. R., Marks, C. R., and Colbran, R. J. (2020). Cyclic AMP-dependent protein kinase and D1 dopamine receptors regulate diacylglycerol lipase- $\alpha$ and synaptic 2 -arachidonoyl glycerol signaling. J. Neurochem. 153, 334-345. doi: 10.1111/jnc.14972

Sim, L. J., Hampson, R. E., Deadwyler, S. A., and Childers, S. R. (1996). Effects of chronic treatment with $\Delta$ 9-tetrahydrocannabinol on cannabinoid-stimulated [35S] GTP $\gamma$ S autoradiography in rat brain. J. Neurosci. 16, 8057-8066. doi: 10.1523/jneurosci.16-24-08057.1996

Simonyan, K. (2019). Recent advances in understanding the role of the basal ganglia. F1000 Res. 8:F1000.

Skinner, B. F. (1966). The phylogeny and ontogeny of behavior. Science 153, 1205-1213.

Smith, P. L., and Ratcliff, R. (2009). An integrated theory of attention and decision making in visual signal detection. Psychol. Rev. 116:283. doi: 10.1037/a00 15156

Sokolic, L., Long, L. E., Hunt, G. E., Arnold, J. C., and Mcgregor, I. S. (2011). Disruptive effects of the prototypical cannabinoid $\Delta 9$-tetrahydrocannabinol and the fatty acid amide inhibitor URB-597 on go/no-go auditory discrimination performance and olfactory reversal learning in rats. Behav. Pharmacol. 22, 191-202. doi: 10.1097/fbp.0b013e328345c82b

Solinas, M., Justinova, Z., Goldberg, S. R., and Tanda, G. (2006). Anandamide administration alone and after inhibition of fatty acid amide hydrolase (FAAH) increases dopamine levels in the nucleus accumbens shell in rats. J. Neurochem. 98, 408-419. doi: 10.1111/j.1471-4159.2006.03880.x

Spronk, D. B., Van Der Schaaf, M. E., Cools, R., De Bruijn, E. R., Franke, B., Van Wel, J. H., et al. (2016). Acute effects of cocaine and cannabis on reversal learning as a function of COMT and DRD2 genotype. Psychopharmacology 233, 199-211. doi: 10.1007/s00213-015-4141-5

Stauffer, W. R., Lak, A., and Schultz, W. (2014). Dopamine reward prediction error responses reflect marginal utility. Curr. Biol. 24, 2491-2500. doi: 10.1016/j.cub. 2014.08.064

Stauffer, W. R., Lak, A., Kobayashi, S., and Schultz, W. (2016). Components and characteristics of the dopamine reward utility signal. J. Compar. Neurol. 524, 1699-1711. doi: $10.1002 / \mathrm{cne} .23880$

Stefani, M. R., Groth, K., and Moghaddam, B. (2003). Glutamate receptors in the rat medial prefrontal cortex regulate set-shifting ability. Behav. Neurosci. 117:728. doi: 10.1037/0735-7044.117.4.728

Stefanopoulou, E., Hirsch, C. R., Hayes, S., Adlam, A., and Coker, S. (2014). Are attentional control resources reduced by worry in generalized anxiety disorder? J. Abnormal Psychol. 123:330. doi: 10.1037/a0036343

Stiglick, A., and Kalant, H. (1982). Learning impairment in the radial-arm maze following prolonged cannabis treatment in rats. Psychopharmacology 77, 117123. doi: $10.1007 / \mathrm{bf} 00431932$

Stuss, D., Levine, B., Alexander, M., Hong, J., Palumbo, C., Hamer, L., et al. (2000). Wisconsin Card Sorting Test performance in patients with focal frontal and posterior brain damage: effects of lesion location and test structure on separable cognitive processes. Neuropsychologia 38, 388-402. doi: 10.1016/ s0028-3932(99)00093-7 
Sugiura, T., Kondo, S., Sukagawa, A., Nakane, S., Shinoda, A., Itoh, K., et al. (1995). 2-Arachidonoylgylcerol: a possible endogenous cannabinoid receptor ligand in brain. Biochem. Biophys. Res. Commun. 215, 89-97. doi: 10.1006/bbrc.1995. 2437

Swanson, L. (1982). The projections of the ventral tegmental area and adjacent regions: a combined fluorescent retrograde tracer and immunofluorescence study in the rat. Brain Res. Bull. 9, 321-353. doi: 10.1016/0361-9230(82)901459

Szabo, B., Siemes, S., and Wallmichrath, I. (2002). Short communication inhibition of GABAergic neurotransmission in the ventral tegmental area by cannabinoids. Eur. J. Neurosci. 15, 2057-2061. doi: 10.1046/j.1460-9568.2002. 02041.x

Szkudlarek, H. J., Desai, S. J., Renard, J., Pereira, B., Norris, C., Jobson, C. E., et al. (2019). $\Delta$-9-Tetrahydrocannabinol and cannabidiol produce dissociable effects on prefrontal cortical executive function and regulation of affective behaviors. Neuropsychopharmacology 44, 817-825. doi: 10.1038/s41386-018-0282-7

Takakuwa, N., Kato, R., Redgrave, P., and Isa, T. (2017). Emergence of visuallyevoked reward expectation signals in dopamine neurons via the superior colliculus in V1 lesioned monkeys. Elife 6:e24459.

Takakuwa, N., Redgrave, P., and Isa, T. (2018). Cortical visual processing evokes short-latency reward-predicting cue responses in primate midbrain dopamine neurons. Sci. Rep. 8, 1-9.

Tanda, G., Pontieri, F. E., and Di Chiara, G. (1997). Cannabinoid and heroin activation of mesolimbic dopamine transmission by a common $\mu 1$ opioid receptor mechanism. Science 276, 2048-2050. doi: 10.1126/science.276.5321. 2048

Teitelbaum, H. (1964). A comparison of effects of orbitofrontal and hippocampal lesions upon discrimination learning and reversal in the cat. Exper. Neurol. 9, 452-462. doi: 10.1016/0014-4886(64)90053-6

Tepper, J. M., Tecuapetla, F., Koós, T., and Ibáñez-Sandoval, O. (2010). Heterogeneity and diversity of striatal GABAergic interneurons. Front. Neuroanat. 4:150. doi: 10.3389/fnana.2010.00150

Tepper, J. M., Wilson, C. J., and Koós, T. (2008). Feedforward and feedback inhibition in neostriatal GABAergic spiny neurons. Brain Res. Rev. 58, 272-281. doi: 10.1016/j.brainresrev.2007.10.008

Terzian, A. L., Drago, F., Wotjak, C. T., and Micale, V. (2011). The dopamine and cannabinoid interaction in the modulation of emotions and cognition: assessing the role of cannabinoid CB1 receptor in neurons expressing dopamine D1 receptors. Front. Behav. Neurosci. 5:49. doi: 10.3389/fnbeh.2011.00049

Thorat, S. N., and Bhargava, H. N. (1994). Evidence for a bidirectional crosstolerance between morphine and $\Delta 9$-tetrahydrocannabinol in mice. Eur. J. Pharmacol. 260, 5-13. doi: 10.1016/0014-2999(94)90003-5

Thorndike, E. L. (1927). The law of effect. Am. J. Psychol. 39, 212-222. doi: $10.2307 / 1068202$

Toczek, M., and Malinowska, B. (2018). Enhanced endocannabinoid tone as a potential target of pharmacotherapy. Life Sci. 204, 20-45. doi: 10.1016/j.lfs. 2018.04.054

Trantham-Davidson, H., Neely, L. C., Lavin, A., and Seamans, J. K. (2004). Mechanisms underlying differential D1 versus D2 dopamine receptor regulation of inhibition in prefrontal cortex. J. Neurosci. 24, 10652-10659. doi: 10.1523/jneurosci.3179-04.2004

Tritsch, N. X., and Sabatini, B. L. (2012). Dopaminergic modulation of synaptic transmission in cortex and striatum. Neuron 76, 33-50. doi: 10.1016/j.neuron. 2012.09.023

Tritsch, N. X., Ding, J. B., and Sabatini, B. L. (2012). Dopaminergic neurons inhibit striatal output through non-canonical release of GABA. Nature 490:262. doi: $10.1038 /$ nature11466

Tritsch, N. X., Granger, A. J., and Sabatini, B. L. (2016). Mechanisms and functions of GABA co-release. Nat. Rev. Neurosci. 17, 139-145. doi: 10.1038/nrn.2015.21

Tunbridge, E., Bannerman, D., Sharp, T., and Harrison, P. (2004). Catechol-omethyltransferase inhibition improves set-shifting performance and elevates stimulated dopamine release in the rat prefrontal cortex. J. Neurosci. 24, 5331-5335. doi: 10.1523/jneurosci.1124-04.2004

Turner, K. M., Peak, J., and Burne, T. H. (2017). Baseline-dependent effects of amphetamine on attention are associated with striatal dopamine metabolism. Sci. rep. 7, 1-10.

Ucha, M., Roura-Martínez, D., Contreras, A., Pinto-Rivero, S., Orihuel, J., Ambrosio, E., et al. (2019). Impulsive action and impulsive choice are differentially associated with gene expression variations of the GABAA receptor alfa 1 subunit and the CB1 receptor in the lateral and medial orbitofrontal cortices. Front. Behav. Neurosci. 13:22. doi: 10.3389/fnbeh.2019.00022

van de Giessen, E., Weinstein, J. J., Cassidy, C. M., Haney, M., Dong, Z., Ghazzaoui, R., et al. (2017). Deficits in striatal dopamine release in cannabis dependence. Mol. Psychiatry 22, 68-75. doi: 10.1038/mp.2016.21

van der Stelt, M., Trevisani, M., Vellani, V., De Petrocellis, L., Moriello, A. S., Campi, B., et al. (2005). Anandamide acts as an intracellular messenger amplifying Ca2+ influx via TRPV1 channels. EMBO J. 24, 3026-3037. doi: 10.1038/sj.emboj.7600784

van Gaalen, M. M., Brueggeman, R. J., Bronius, P. F., Schoffelmeer, A. N., and Vanderschuren, L. J. (2006). Behavioral disinhibition requires dopamine receptor activation. Psychopharmacology 187, 73-85. doi: 10.1007/s00213-0060396-1

Verghese, P. (2001). Visual search and attention: a signal detection theory approach. Neuron 31, 523-535.

Verrico, C. D., Jentsch, J. D., and Roth, R. H. (2003). Persistent and anatomically selective reduction in prefrontal cortical dopamine metabolism after repeated, intermittent cannabinoid administration to rats. Synapse 49, 61-66. doi: 10. 1002/syn. 10215

Vigano, D., Rubino, T., and Parolaro, D. (2005). Molecular and cellular basis of cannabinoid and opioid interactions. Pharmacol. Biochem. Behav. 81, 360-368. doi: 10.1016/j.pbb.2005.01.021

Vijayraghavan, S., Wang, M., Birnbaum, S. G., Williams, G. V., and Arnsten, A. F. (2007). Inverted-U dopamine D1 receptor actions on prefrontal neurons engaged in working memory. Nat. Neurosci. 10, 376-384. doi: 10.1038/ nn 1846

Vlasov, K., Van Dort, C. J., and Solt, K. (2018). Optogenetics and chemogenetics. Methods Enzymol. 603, 181-196. doi: 10.1016/bs.mie.2018.01.022

Volkow, N. D., Wise, R. A., and Baler, R. (2017). The dopamine motive system: implications for drug and food addiction. Nat. Rev. Neurosci. 18, 741. doi: 10.1038/nrn.2017.130

Volkow, N., and Morales, M. (2015). The brain on drugs: from reward to addiction. Cell 162, 712-725. doi: 10.1016/j.cell.2015.07.046

Voloh, B., Valiante, T. A., Everling, S., and Womelsdorf, T. (2015). Theta-gamma coordination between anterior cingulate and prefrontal cortex indexes correct attention shifts. Proc. Natl. Acad. Sci. 112, 8457-8462. doi: 10.1073/pnas. 1500438112

Voruganti, L. N., Slomka, P., Zabel, P., Mattar, A., and Awad, A. G. (2001). Cannabis induced dopamine release: an in-vivo SPECT study. Psychiatry Res. Neuroimag. 107, 173-177. doi: 10.1016/s0925-4927(01)00104-4

Wang, H., Treadway, T., Covey, D. P., Cheer, J. F., and Lupica, C. R. (2015). Cocaine-induced endocannabinoid mobilization in the ventral tegmental area. Cell Rep. 12, 1997-2008. doi: 10.1016/j.celrep.2015.08.041

Wang, X., Zhong, P., and Yan, Z. (2002). Dopamine D4 receptors modulate GABAergic signaling in pyramidal neurons of prefrontal cortex. J. Neurosci. 22, 9185-9193. doi: 10.1523/jneurosci.22-21-09185.2002

Wang, X., Zhong, P., Gu, Z., and Yan, Z. (2003). Regulation of NMDA receptors by dopamine D4 signaling in prefrontal cortex. J. Neurosci. 23, 9852-9861. doi: 10.1523/jneurosci.23-30-09852.2003

Ward, S. J., Walker, E. A., and Dykstra, L. A. (2007). Effect of cannabinoid $\mathrm{CB} 1$ receptor antagonist $\mathrm{SR} 141714 \mathrm{~A}$ and $\mathrm{CB} 1$ receptor knockout on cue-induced reinstatement of Ensure§and corn-oil seeking in mice. Neuropsychopharmacology 32, 2592-2600. doi: 10.1038/sj.npp.1301384

Ward, S., and Dykstra, L. (2005). The role of CB1 receptors in sweet versus fat reinforcement: effect of $\mathrm{CB} 1$ receptor deletion, $\mathrm{CB} 1$ receptor antagonism (SR141716A) and CB1 receptor agonism (CP-55940). Behav. Pharmacol. 16, 381-388. doi: 10.1097/00008877-200509000-00010

Weinberger, D. R., Berman, K. F., and Zec, R. F. (1986). Physiologic dysfunction of dorsolateral prefrontal cortex in schizophrenia: I. Regional cerebral blood flow evidence. Arch. Gen. Psychiatry 43, 114-124. doi: 10.1001/archpsyc.1986. 01800020020004

Wenzel, J. M., Oleson, E. B., Gove, W. N., Cole, A. B., Gyawali, U., Dantrassy, H. M., et al. (2018). Phasic dopamine signals in the nucleus accumbens that cause active avoidance require endocannabinoid mobilization in the midbrain. Curr. Biol. 28, 1392-1404. doi: 10.1016/j.cub.2018.03.037

Wenzel, J. M., Rauscher, N. A., Cheer, J. F., and Oleson, E. B. (2015). A role for phasic dopamine release within the nucleus accumbens in encoding aversion: 
a review of the neurochemical literature. ACS Chem. Neurosci. 6, 16-26. doi: $10.1021 / \mathrm{cn} 500255 \mathrm{p}$

West, R. L. (1996). An application of prefrontal cortex function theory to cognitive aging. Psychol. Bull. 120:272. doi: 10.1037/0033-2909.120.2.272

Westbrook, A., Van Den Bosch, R., Määttä, J., Hofmans, L., Papadopetraki, D., Cools, R., et al. (2020). Dopamine promotes cognitive effort by biasing the benefits versus costs of cognitive work. Science 367, 1362-1366. doi: 10.1126/ science.aaz5891

Whitlow, C. T., Freedland, C. S., and Porrino, L. J. (2003). Functional consequences of the repeated administration of $\Delta 9$-tetrahydrocannabinol in the rat. Drug Alcohol Depend. 71, 169-177. doi: 10.1016/s0376-8716(03)00135-2

Wiley, J. L., and Martin, B. R. (2003). Cannabinoid pharmacological properties common to other centrally acting drugs. Eur. J. Pharmacol. 471, 185-193. doi: 10.1016/s0014-2999(03)01856-9

Wilkinson, R. T. (1963). Interaction of noise with knowledge of results and sleep deprivation. J. Exper. Psychol. 66:332. doi: 10.1037/h0044161

Williams-Gray, C. H., Hampshire, A., Barker, R. A., and Owen, A. M. (2008). Attentional control in Parkinson's disease is dependent on COMT val158met genotype. Brain 131, 397-408. doi: 10.1093/brain/awm313

Wilson, R. I., and Nicoll, R. A. (2002). Endocannabinoid signaling in the brain. Science 296, 678-682. doi: 10.1126/science.1063545

Winters, B. D., Krüger, J. M., Huang, X., Gallaher, Z. R., Ishikawa, M., Czaja, K., et al. (2012). Cannabinoid receptor 1-expressing neurons in the nucleus accumbens. Proc. Natl. Acad. Sci. 109, E2717-E2725.

Wise, R. A. (2004). Dopamine, learning and motivation. Nat. Rev. Neurosci. 5, 483-494. doi: 10.1038/nrn1406

Wiskerke, J., Stoop, N., Schetters, D., Schoffelmeer, A. N., and Pattij, T. (2011). Cannabinoid CB1 receptor activation mediates the opposing effects of amphetamine on impulsive action and impulsive choice. PloS One 6:e25856. doi: 10.1371/journal.pone.0025856

Wright, M. J. Jr., Vandewater, S. A., Parsons, L. H., and Taffe, M. A. (2013). $\Delta$ 9Tetrahydrocannabinol impairs reversal learning but not extradimensional shifts in rhesus macaques. Neuroscience 235, 51-58. doi: 10.1016/ j.neuroscience.2013.01.018

Wright, W. J., Schlüter, O. M., and Dong, Y. (2017). A feedforward inhibitory circuit mediated by CB1-expressing fast-spiking interneurons in the nucleus accumbens. Neuropsychopharmacology 42, 1146-1156. doi: 10.1038/npp.2016. 275

Wu, X., and French, E. D. (2000). Effects of chronic $\Delta$ 9-tetrahydrocannabinol on rat midbrain dopamine neurons: an electrophysiological assessment. Neuropharmacology 39, 391-398. doi: 10.1016/s0028-3908(99)00140-9

Xie, Y., Nie, C., and Yang, T. (2018). Covert shift of attention modulates the value encoding in the orbitofrontal cortex. Elife 7:e31507.

Xue, Z., Siemian, J. N., Johnson, B. N., Zhang, Y., and Li, J.-X. (2018). Methamphetamine-induced impulsivity during chronic methamphetamine treatment in rats: effects of the TAAR 1 agonist RO5263397. Neuropharmacology 129, 36-46. doi: 10.1016/j.neuropharm.2017.11.012

Yantis, S., and Serences, J. T. (2003). Cortical mechanisms of space-based and object-based attentional control. Curr. Opin. Neurobiol. 13, 187-193. doi: 10. 1016/s0959-4388(03)00033-3

Yerkes, R. M., and Dodson, J. D. (1908). The relation of strength of stimulus to rapidity of habit-formation. J. Compar. Neurol. Psychol. 18, 459-482. doi: $10.1002 /$ cne. 920180503

Yin, H. H., and Knowlton, B. J. (2006). The role of the basal ganglia in habit formation. Nat. Rev. Neurosci. 7:464. doi: 10.1038/nrn1919

Yoo, J. H., Zell, V., Gutierrez-Reed, N., Wu, J., Ressler, R., Shenasa, M. A., et al. (2016). Ventral tegmental area glutamate neurons co-release GABA and promote positive reinforcement. Nat. Commun. 7, 1-13.

Yuan, J., Mao, N., Chen, R., Zhang, Q., and Cui, L. (2019). Social anxiety and attentional bias variability: electrophysiological evidence of attentional control deficits. NeuroReport 30, 887-892. doi: 10.1097/wnr.00000000000 01294

Zarrindast, M. R., Mahboobi, S., Sadat-Shirazi, M.-S., and Ahmadi, S. (2011). Anxiolytic-like effect induced by the cannabinoid $\mathrm{CB} 1$ receptor agonist, arachydonilcyclopropylamide (ACPA), in the rat amygdala is mediated through the D1 and D2 dopaminergic systems. J. Psychopharmacol. 25, 131-140. doi: $10.1177 / 0269881110376688$

Zhang, S., Qi, J., Li, X., Wang, H.-L., Britt, J. P., Hoffman, A. F., et al. (2015). Dopaminergic and glutamatergic microdomains in a subset of rodent mesoaccumbens axons. Nat. Neurosci. 18:386. doi: 10.1038/nn. 3945

Zheng, P., Zhang, X.-X., Bunney, B., and Shi, W.-X. (1999). Opposite modulation of cortical N-methyl-D-aspartate receptor-mediated responses by low and high concentrations of dopamine. Neuroscience 91, 527-535. doi: 10.1016/s03064522(98)00604-6

Zou, S., and Kumar, U. (2018). Cannabinoid receptors and the endocannabinoid system: signaling and function in the central nervous system. Int. J. Mol. Sci. 19:833. doi: $10.3390 /$ ijms 19030833

Conflict of Interest: The authors declare that the research was conducted in the absence of any commercial or financial relationships that could be construed as a potential conflict of interest.

Copyright (c) 2021 Oleson, Hamilton and Gomez. This is an open-access article distributed under the terms of the Creative Commons Attribution License (CC BY). The use, distribution or reproduction in other forums is permitted, provided the original author(s) and the copyright owner(s) are credited and that the original publication in this journal is cited, in accordance with accepted academic practice. No use, distribution or reproduction is permitted which does not comply with these terms. 